Portland State University

PDXScholar

\title{
The Relationship Between Undergraduate Research Training Programs and Motivational Resources for Underrepresented Minority Students in STEM: Program Participation, Self-efficacy, a Sense of Belonging, and Academic Performance
}

Jennifer Lindwall

Portland State University

Follow this and additional works at: https://pdxscholar.library.pdx.edu/open_access_etds

Part of the Higher Education Commons, and the Psychology Commons

Let us know how access to this document benefits you.

Recommended Citation

Lindwall, Jennifer, "The Relationship Between Undergraduate Research Training Programs and Motivational Resources for Underrepresented Minority Students in STEM: Program Participation, Selfefficacy, a Sense of Belonging, and Academic Performance" (2019). Dissertations and Theses. Paper 5270.

https://doi.org/10.15760/etd.7143

This Thesis is brought to you for free and open access. It has been accepted for inclusion in Dissertations and Theses by an authorized administrator of PDXScholar. Please contact us if we can make this document more accessible: pdxscholar@pdx.edu. 
The Relationship Between Undergraduate Research Training Programs and Motivational Resources for Underrepresented Minority Students in STEM:

Program Participation, Self-efficacy, a Sense of Belonging, and Academic Performance

by

Jennifer Lindwall

A thesis submitted in partial fulfillment of the requirements for the degree of

\author{
Master of Science \\ in \\ Psychology
}

\begin{abstract}
Thesis Committee:
Ellen Skinner, Chair

Karlyn Adams-Wiggins

Thomas Keller
\end{abstract}

Portland State University

2019 


\begin{abstract}
Although calls for a more diverse workforce in biomedical fields have been widespread, racial and ethnic gaps in biomedical degree attainment persist. In order to succeed, URM STEM students must persevere despite numerous challenges and stay continuously motivated on the long road to degree attainment in biomedical disciplines. Past higher education research has identified two key self-appraisals, a sense of belonging and self-efficacy, as crucial for student success. These beliefs, which can serve as motivational resources for students, include students' convictions about whether they are a valued member of their academic community and whether they have what it takes to succeed in their discipline. This study explored how participation in an undergraduate research training program and students' motivational resources may be shaping their academic performance and thus contributing to their successful completion of undergraduate biomedical degrees. The study also dissected program participation into five components and explored whether a sense of belonging or self-efficacy played a mediational role in the relationship between program participation and academic performance for URM STEM students. Single and multiple linear regression analyses were used and results indicated significant links between overall program participation and both motivational resources as well as significant connections between various program components and these self-perceptions. No significant relationship surfaced between overall program participation and academic performance but in a multiple regression analysis, research dosage was linked to performance for students in the study.
\end{abstract}


Additionally, no significant connection was found between the motivational resources and academic performance and thus, the mediational role of a sense of belonging and self-efficacy in the relationship between program participation and performance could not be tested. 


\section{ACKNOWLEDGMENTS}

I have many people to thank for their support during this process. I am beyond grateful to my committee chair, Dr. Ellen Skinner, for her willingness to take on something new, commit to this process, and see it all the way through. To my committee member, Dr. Tom Keller, for bringing me to PSU and continually providing new opportunities for me to learn and grow. To Dr. Karlyn Adams-Wiggins for fully engaging in this process and asking me essential and important questions about my own understanding of this research. To my graduate school colleagues for their kindness and feedback. And to Jason and Miranda, two people who supported me at every step. Finally, to my family. To Esme and Kellan for believing in me and understanding, even as children, the importance of every human having space to work towards their own goals. And to Ben Lindwall, my partner and best friend, for an unwavering support and love that I never dreamed were possible. 
Table of Contents

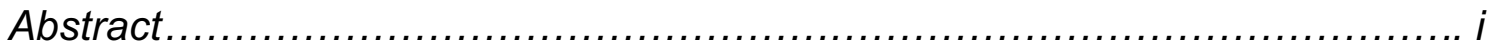

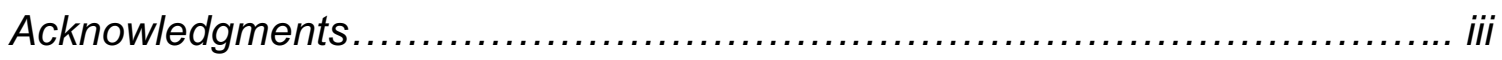

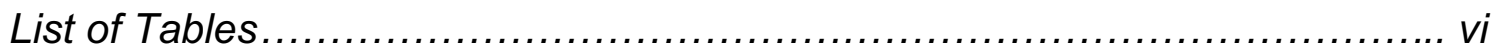

List of Figures.............................................................. vii

Chapter 1 : PROBLEM STATEMENT ......................................................

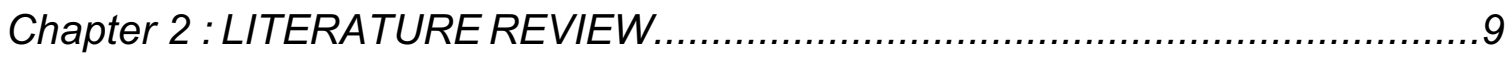

Challenges to URM Students in STEM .................................................. 11

Programs to Promote URM Success in STEM .......................................20

The Motivational Resources of URM Students in Biomedical Disciplines...............34

Chapter 3 : THE CURRENT STUDY ....................................................... 73

Benefits of Undergraduate Participation in Research Training Programs ............73

Research Training Program Components ............................................. 85

Motivational Resources as Mediators ................................................... 97

BUILD EXITO: A Multi-level Model to Support URM STEM Students .................. 104

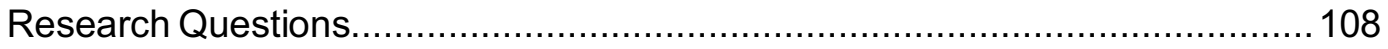

Research Questions and Hypotheses.................................................... 112

Chapter 4 : RESEARCH DESIGN AND METHODS......................................115

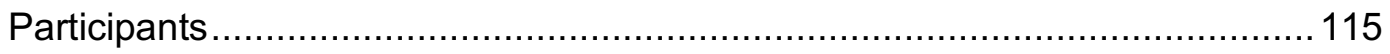

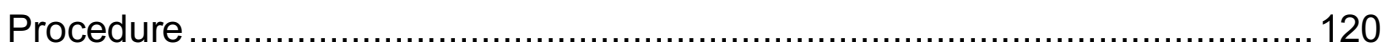

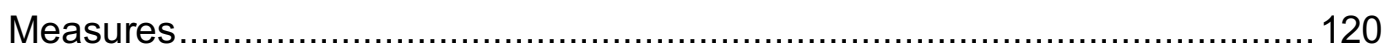

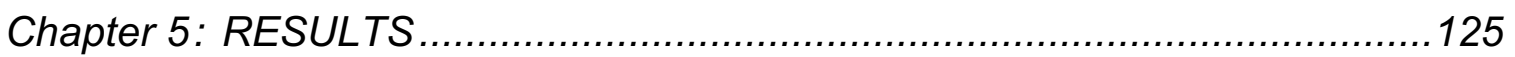

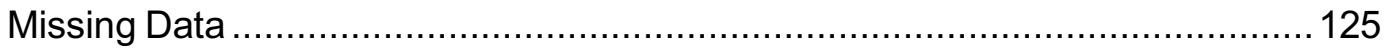

Measurement Properties and Descriptive Statistics.................................. 127

Univariate Outliers and Non-Normality .............................................. 129

Intra-Construct Correlations ........................................................... 131

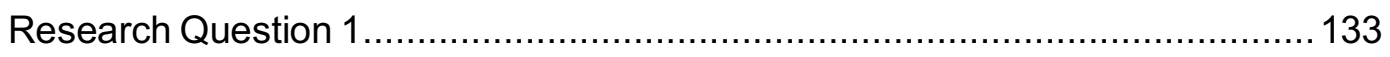

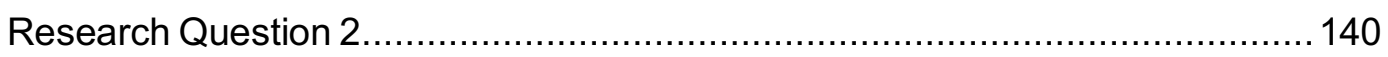




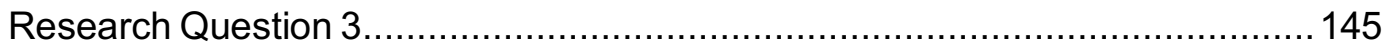

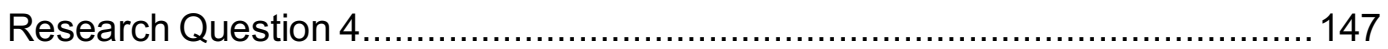

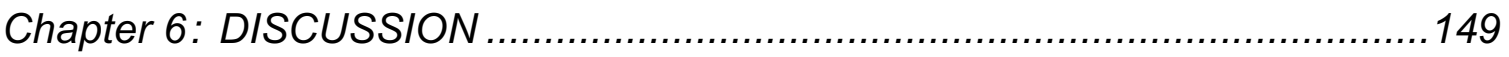

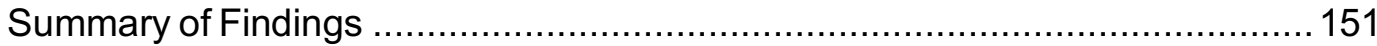

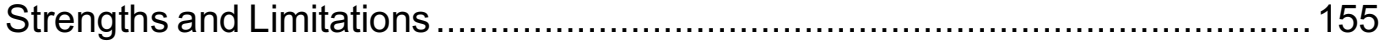

Implications for Research .......................................................... 162

Implications for Program Development and Implementation ........................... 186

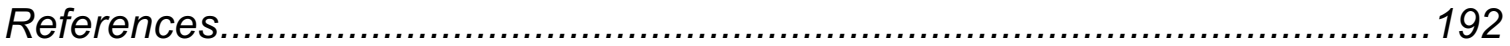

Appendix A: Description of NIH Racial Categories ...................................... 215 


\section{List of Tables}

Table 2.1 Summary of Studies Considering Sense of Belonging and Academic

Functioning

Table 2.2 Summary of Studies Considering Self-efficacy and Academic Functioning...67

Table 4.1 Demographic Characteristics of Participants .......................................... 117

Table 4.2 Demographic Characteristics of Participants by Race................................ 118

Table 5.1 Summary of Descriptive and Psychometric Statistics for Each Construct ..... 127

Table 5.2 Skew and Kurtosis Statistics for Each Construct ..................................... 131

Table 5.3 Intra-Correlations among Program Participation Components ..................... 132

Table 5.4 Intra-Correlations among Motivational Resource Components ................... 133

Table 5.5 Inter-Correlations Among Overall Program Participation and Motivational

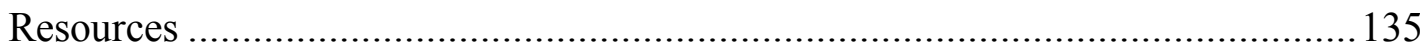

Table 5.6 Effects of Overall Program Participation on Sense of Belonging and Self-

efficacy.

Table 5.7 Inter-Correlations among Program Participation Components and Motivational Resources 137

Table 5.8 Effects of Program Participation Components on Sense of Belonging and Selfefficacy. 138

Table 5.9 Inter-Correlations between Program Participation, Participation Components and Academic Performance 141

Table 5.10 Effects of Overall Program Participation on Academic Performance 142 
Table 5.11 Effects of Program Participation Components on Academic Performance.. 143

Table 5.12. Inter-Correlations Between Motivational Resources and Academic

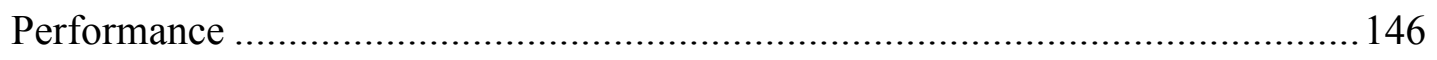

Table 5.13 Effects of Sense of Belonging on Academic Performance .........................146

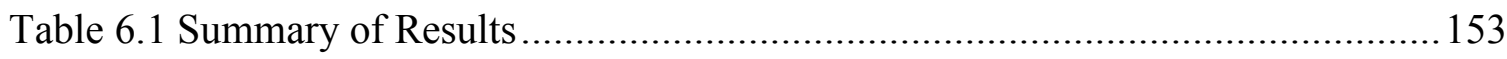




\section{List of Figures}

Figure 3.1. The BUILD EXITO Scholar Pathway................................................. 108

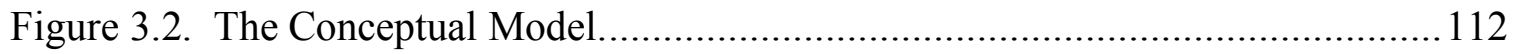

Figure 4.1. BUILD EXITO Student Pathway and Data Collection Timeline. .............. 119

Figure 5.1. Effects of Program Participation Components on Sense of Belonging........ 139

Figure 5.2. Effects of Program Participation Components on Self-efficacy................. 140

Figure 5.3. Effects of Program Participation Components on Academic Performance.. 144 


\section{Chapter 1 : PROBLEM STATEMENT}

Although calls for a more diverse workforce in biomedical fields have been widespread, racial and ethnic gaps in biomedical degree attainment persist. Students from minority racial and ethnic groups obtain college degrees at a much lower rate than their white counterparts with graduation rates fluctuating by up to $25 \%$ based on race and/or ethnicity (Shapiro et al., 2017). In biomedical disciplines this gap is even more pronounced. Underrepresented minority (URM) students make up $31 \%$ of the college population but attain only 13\% of STEM degrees (National Science Foundation, 2017). Achieving success in STEM majors presents significant challenges for all, not just those from URM groups. Students in STEM disciplines must navigate numerous cognitive demands including understanding large amounts of complex material in short periods of time, succeeding in extremely difficult coursework, solving complex problems, and staying current in a fast-paced environment. Additionally, most students in STEM fields experience personal failures and setbacks such as poor academic performance or making mistakes when participating in hands-on research activities. In order to succeed in these disciplines, students must persist despite these challenges and stay continuously motivated on the long road to biomedical degree attainment.

\section{Challenges to URM Students in STEM}

Beyond these anticipated challenges in STEM disciplines, URM students face several additional barriers to success. To start, many underrepresented students enter college with doubts about their ability to do college-level work and persist to degree 
attainment (Kuh, Kinzie, Buckley, Bridges, \& Hayek, 2006). This may be the result of experiences in previous academic environments, where many of these students encountered low teacher expectations and were told they likely would not succeed in college. Additionally, these students receive general messages from the broader society questioning their intelligence and capacity to succeed in difficult coursework and suggesting they are not an appropriate fit for a career in science. These experiences can contribute to negative self-appraisals regarding abilities and fit within science-related majors at universities and can have a negative impact on a student's transition to college. Although these pre-college experiences can make success in STEM majors difficult, once on college campuses these students face even greater challenges. Doubts about competence and belonging within STEM disciplines become particularly devastating when students, shortly after beginning in a STEM major, must take foundational courses designed to "weed out" students whom programs fear may not be successful. Additionally, experiences of discrimination lead to hostile academic environments in classrooms and lab settings (Hurtado \& Ruiz Alvarado, 2015). In fact, many minority college students report frequent and ongoing experiences of stereotype threat, implicit bias, and microaggressions with classmates and professors (McGee \& Martin, 2011; Solorzano, n.d.). Research has also shown that faculty often have lower expectations for the academic performance of minority students (Hurtado et al., 2011). Hence, the significant challenges of being a student in a biomedical major combined with 
the challenges of being a URM college student may provide insight into the reasons racial and ethnic gaps in STEM degree attainment persist.

\section{Programs to Promote URM Success in STEM}

In response to this disparity, university efforts to promote academic success in STEM courses and majors for URM students have increased dramatically over the past several decades. This has resulted in the implementation of numerous programs seeking to provide URM students with more supportive environments in which to pursue biomedical degrees (Dyer-Barr, 2014). Students who participate in these structured research training programs are often matched with mentors, engage in hands-on research, receive financial support, and participate in personal and professional development activities with other URM STEM students. Research suggests that participation in these programs contributes to positive outcomes for URM students and provides crucial support as they navigate the well-documented challenges in higher education (Hurtado, Cabrera, Lin, Arellano, \& Espinosa, 2009). However, the precise program components that help these students to succeed despite these challenges are not well understood (Leggon \& Pearson, 2006). The complex and evolving nature of undergraduate research training programs makes it difficult for researchers to understand the program elements necessary to increase URM STEM student persistence and performance. However, efforts to identify individual-level factors that may be important for URM students pursuing these pathways have yielded more results. In particular, research has shown that student motivation at the undergraduate level is a robust predictor of academic 
achievement and persistence across groups, institutions, and disciplines (Kappe \& van der Flier, 2012).

\section{Motivational Resources}

At the most basic level, student motivation can be thought of as a student's desire to actively participate in the learning process. Motivation is the process by which social, biological, emotional, and cognitive forces activate, direct, and maintain goal-oriented behaviors. Academic motivation involves the collection of a student's values, interests, beliefs, and perceptions that underlie their engagement and coping with challenges in their academic work. In research on undergraduate students in STEM, motivation is often combined with other "non-cognitive" or "affective" factors such as academic selfconcept or self-confidence but theory and research suggest that motivation may be a particularly important predictor of academic success and persistence for these students.

For URM students in STEM disciplines, staying motivated in the midst of challenges such as discrimination and self-doubt requires the development and growth of particular perceptions and beliefs about one's abilities and fit within their disciplines.

Past higher education research has identified two key self-appraisals, a sense of belonging and self-efficacy, as crucial for student success. These beliefs, which can serve as motivational resources for students, include students' convictions about whether they are a valued member of their academic community and whether they have what it takes to succeed in their discipline. These motivational resources, which are formed and 
cultivated within a student's affective domain, help students to stay motivated and to persist in the midst of academic and personal challenges.

The first key motivational resource for these students is a sense of belonging, defined by Goodenow as "the extent to which students feel personally accepted, respected, included, and supported by others in the school social environment" (1993, p. 80). Research in K-12 educational settings has shown a sense of belonging positively influences important educational outcomes like persistence and academic success (Hausmann, Schofield, \& Woods, 2007) and when examining these relationships in college settings, similar links have been found (Strayhorn, 2012). Additionally, a sense of belonging has been shown to predict higher academic performance in scientific disciplines and also greater persistence in biomedical careers (Johnson et al., 2007). URM students in STEM majors are frequently the lone member of their racial or ethnic minority group in courses or lab environments. As a result, feelings of isolation and alienation can be common (Strayhorn, 2009). Experiencing a sense of belonging in these settings can be particularly difficult for URM students, yet research has suggested that a sense of belonging may be even more important for these students because of the unique challenges they face in their course of study (Hurtado \& Carter, 1997).

The second crucial motivational resource, self-efficacy, has been defined as a judgment about one's ability to organize and complete necessary actions in order to attain a goal (Bandura \& Wessels, 1994; Zimmerman, 2000) and is essential for overcoming the academic challenges URM students may face in STEM. In fact, research has shown that 
self-efficacy is needed for students to succeed in difficult coursework and to stay engaged in their course of study (Rittmayer \& Beier, 2008). Furthermore, self-efficacy has proven especially important for underrepresented students in biomedical disciplines given the ongoing scrutiny they face from faculty and other students (Strayhorn, 2012). For these students, the self-perception that they possess the skills needed to be successful in academic settings allows them to counteract past self-doubts and persist in the face of ongoing stereotypes and microaggressions.

\section{Undergraduate Training Programs and Motivational Resources}

Given that research has demonstrated that these motivational resources, as well as participating in undergraduate research training programs, are important for URM students in STEM, understanding how these programs support the development of these motivational resources is crucial for enhancing the educational experiences of these students. At present, the relationships between program participation, a sense of belonging, and self-efficacy are not well understood. In fact, it is not entirely clear if or how participation in these programs is related to an increased sense of belonging or selfefficacy. Furthermore, little is known about the mechanisms that could be responsible for the development of these motivational resources for URM STEM students.

It remains the institution's responsibility to create environments that support the learning processes of students from all backgrounds as they pursue college degrees. A more nuanced understanding of how to best support the development of motivational resources for URM students interested in biomedical research careers could provide 
crucial insight for institutions seeking to promote student success through undergraduate research training programs. As a result, institutions could be better equipped to design and implement programs that more effectively support URM STEM students' development of a sense of belonging and self-efficacy within these disciplines or adapt current programming to assist students as they navigate their academic pathways. Given the large number of universities with existing research training programs, this is an important opportunity to deepen our understanding of motivational resources in the program context by considering the experiences and perspectives of URM STEM students. Consideration of how these motivational resources relate to both academic achievement and participation in undergraduate research training programs will give a fuller picture of how these factors can contribute to success for these students.

\section{Overview of Thesis}

The following chapters describe the larger context of the thesis study as well as the specifics of the study plan, analyses, and results. Chapter 2 provides a review of the literature on URM STEM student experiences in college and the effectiveness of undergraduate research training programs to support these students, giving specific attention to the role that the two key motivational resources, a sense of belonging and self-efficacy, may play in the success and persistence of URM students in STEM majors.

Chapter 3 provides more detail about the purpose of the current study including an overview of the specific components of program participation that will be considered. Chapters 4 and 5 provide details of the methods and analyses designed to examine each 
research question and the corresponding results for each research question. Finally, Chapter 6 concludes this thesis with a discussion outlining the strengths, limitations, and potential implications of this study. 


\section{Chapter 2 : LITERATURE REVIEW}

To provide a context for studying how research training programs in STEM can bolster the motivational resources underrepresented STEM students need to succeed in these challenging majors, this literature review first considers the breadth and depth of undergraduate research training programs for URM students in STEM. Next, the review summarizes what is known about how these students develop and sustain a sense of belonging and self-efficacy while pursuing their undergraduate degrees. Before doing so, however, it is important to delve into the larger social, cultural, structural, and historical contexts in which these student experiences are situated. Ultimately, student success in STEM cannot be isolated to the college campus but must be examined in a much larger context to consider how societal and cultural factors may be shaping students' adjustment to college, on-campus integration, academic performance, and persistence. Decisions about college and the transition to college for URM students are often influenced by additional factors such as family characteristics, peer relationships, previous schooling experiences, and other unique characteristics of students' communities of origin.

Looking more broadly at the background factors and pre-college experiences that shape students' perceptions and appraisals as they pursue a STEM degree in college, provides a broader understanding of how and why the challenges URM students face may influence their success in these disciplines so profoundly.

Researchers have long posited that antecedents to academic success at the college level include a variety of personal characteristics, background factors, psychological selfappraisals, motivational orientations, and social and academic integration experiences on 
campus (Demetriou \& Schmitz-Sciborski, 2011; Kuh et al., 2006). The most well-known framework for understanding student retention is Tinto's model of student retention (1975) which explains student persistence as an outcome of academic and social integration on campus. In this view, the level and quality of this integration at college are influenced by a student's personal characteristics and background factors. Tinto's model has been widely criticized because of what some see as an underlying assumption that succeeding in college rests solely on a student's ability to adapt and integrate rather social and contextual factors that may inhibit the achievement of students (Vaccaro \& Newman, 2016). Still, much of Tinto's theoretical foundation has been retained and tested over the last several decades and higher education researchers continue to adapt the model as research provides new insights and a deeper understanding of how students succeed at college.

Several other models of student success and persistence have emerged to provide additional explanations as to how and why students are successful in higher education. Astin's model of student involvement (1984), for instance, posits that the more students are involved in on-campus social and academic experiences, the more they will learn and thus the more successful they will be. In this view, the quality and quantity of a college student's involvement are what shapes and drives their learning in an academic setting and this, in turn, determines their success. A third prominent model, developed by Kuh (1996), focuses solely on student engagement and views student 
retention as a result of the time and effort students spend actively engaged in activities that are linked to student success.

The need to understand how and why students succeed becomes especially important in STEM disciplines where aptly named "weeder courses" are taught by professors who see themselves as gatekeepers for their disciplines, contributing to challenges for students attempting to attain degrees in these fields (Gasiewski, Tran, Herrera, Garcia, \& Newman, 2010). For underrepresented groups in these disciplines, the challenges are even greater as they face ongoing discrimination and hostile academic environments in addition to navigating the difficulties all STEM students encounter. For these students, the need for motivational resources, which are positive self-appraisals about ability and belongingness, are crucial ingredients to stay motivated and persist in college. Institutions have the responsibility to go beyond academic instruction to provide these students with experiences that will nurture their feelings of belongingness and selfefficacy on campus and in STEM majors.

\section{Challenges to URM Students in STEM}

Although overall degree attainment varies significantly based on racial and ethnic group membership, research has shown these gaps are even more prevalent in STEM fields (Shapiro et al., 2017). Due to the growing national demand for a diverse biomedical workforce to address mounting health disparities, research over the last two decades has sought to better understand URM success in higher education, focusing particularly on how to support URM students in STEM disciplines. This research has 
identified a large number of individual and contextual factors that contribute to the challenges and barriers of URM students in STEM.

\section{Background Factors}

Research has identified several background factors unique to URM students in STEM that may shape their student experience. These factors include socioeconomic status, being a first-generation college student, and attending under-resourced primary and secondary schools and may relate to students' choices to pursue STEM degrees, their ability to succeed in STEM disciplines, and the likelihood they will persist to degree attainment in STEM fields. In a comprehensive review of the literature on college success and retention, Kuh and colleagues (2006) concluded that URM students are significantly more likely to come from lower-income households, be first-generation college students, and experience financial strain while attending college suggesting that these background factors, which have documented negative relationships with college success, disproportionately impact URM students and may impact their ability to persist in college.

In a large longitudinal study with a national sample of 12,000 first time college students, Chen and Weko (2009) examined background factors that might influence whether a student would choose a STEM major in college. The study concluded that students from lower SES communities, a majority of whom were students of color, were less likely to enter STEM fields suggesting that being from a family with limited financial resources, a reality for many students from underrepresented groups, may be a 
factor in whether students choose to major in a STEM discipline. In another study, researchers found that the financial and family concerns of URM students had a negative relationship with students' social self-concept and their academic and social adjustment on campus (Hurtado et al., 2007). Given that in many prominent models of college student retention positive social integration and college adjustment are critical components of student success, these results suggest that the ongoing stressors that many individuals from minority groups face may be hindering their ability to be successful in higher education.

Other studies have looked at the relationship between K-12 STEM education and success in STEM disciplines at college. In a study by the National Commission on Teaching and America's Future (1996), students from lower SES schools, who are disproportionately from racial and ethnic minority groups, were significantly more likely to be taught STEM classes by teachers who had little or no training in science disciplines. Pre-college STEM experiences were also the focus of a study conducted by Chang and colleagues (2014). The results of this study suggested that being from a minority group may not only be negatively related to persistence in a STEM major but that this negative link may be the result of inferior preparation in high school science courses and a lack of access to high-quality educational opportunities. These results suggest that the gap in STEM college degree attainment for URM students may, in part, be the result of the inequities in secondary schooling options for these students.

\section{Previous Academic Environments}


Students enter college after over a decade of academic experiences in educational settings. Thousands of interactions with teachers and peers, along with years of academic coursework, contribute to the identity development of students and impact how they appraise their academic capabilities when entering college. Research has shown that college success in STEM relies, at least in part, on positive self-appraisals about one's abilities in these disciplines (Britner \& Pajares, 2006). Because of this, understanding how these previous academic environments and experiences shape students' academic self-concept has been of great interest to those studying URM students in STEM.

Across primary and secondary educational contexts, research has demonstrated that students of color are disproportionately placed into less academically challenging classes even when controlling for students' academic abilities (Oakes, 1990). In a mixed methods study that looked at factors contributing to college enrollment for students of color, Allen and colleagues (2003) found that the placement of students in courses based on teacher's perceptions of their academic abilities, which many refer to as a "tracking" system, results in school staff and administrators designating students in more academically challenging courses as a more appropriate fit for college. These students are subsequently prepared for college entrance with mentors and college tours while students outside this group often receive very little assistance planning for postsecondary education. What is more, research has suggested when students from URM groups receive instruction in science and math topics in K-12 settings, the curriculum is often not congruent with students' cultural identity and this lack of culturally responsive pedagogy 
can undermine the benefits of exposure to STEM topics in primary and secondary educational environments (Wang, 2013).

For URM students in biomedical disciplines, evidence is mounting that these precollege academic experiences predict students' self-appraisals of their scientific abilities as they pursue STEM degrees. It is crucial, then, to consider the frequent negative and damaging experiences of URM students in pre-college science-related classes. In a longitudinal study, Cherng (2017) found that math teachers were more likely to perceive their classes as too difficult for students of color compared to White students, even after controlling for homework completion rates and test scores suggesting that race may play a role in how teachers perceive students' abilities. Given the known link between precollege academic experiences and success in college, the experiences of URM students in primary and secondary academic environments may be contributing to the challenges they face in degree attainment at the higher education level.

\section{Discrimination, Bias, and Stereotype Threat}

Despite inequitable pre-college educational experiences and other challenging background factors, many URM students still choose to enter biomedical majors in college. Unfortunately, once on campus, these students regularly experience racial bias, discrimination, and stereotype threat. These experiences have well documented negative effects on academic experiences (Nora \& Cabrera, 1996) and academic performance for minority students (Smedley, Myers, \& Harrell, 1993). 
For students of color on college campuses, experiences of discrimination and student perceptions of a negative campus climate are widespread. For instance, research has demonstrated that African American students experience exclusion, racial discrimination, and alienation (Allen, 1992), ongoing harassment (Rankin \& Reason, 2005), and regular incidents of discrimination such as verbal expressions of prejudice (Swim, Hyers, Cohen, Fitzgerald, \& Bylsma, 2003). In scientific disciplines, this discrimination may be even more pronounced. In a qualitative study using structured interviews with 38 undergraduate URM STEM students, Strayhorn (2010b) found that nearly all participants had experienced conflict with faculty and/or peers as a result of what they perceived as a negative perception or stereotype that people of color lack the academic abilities and appropriate preparation to major in a STEM field.

Faculty and student interactions have been identified as a key ingredient for college student success for all students (Lundberg \& Schreiner, 2004) and for minority students specifically (Cole \& Espinoza, 2008; Pascarella \& Terenzini, 1991). However, for many URM students in STEM, negative experiences when interacting with faculty are common. The results from a study by Nora and Cabrera (1996) indicated that students of color often have negative experiences interacting with faculty while in the classroom. Additionally, research has found that URM students face higher levels scrutiny in courses and that faculty members hold lower expectations for their performance (McGee \& Martin, 2011) suggesting that faculty have a role in the ongoing negative environments many URM college students encounter. 
Stereotype threat refers to the phenomenon that negative societal stereotypes can be internalized to such a degree that it impacts an individual's academic performance. Claude Steele (1997) first popularized the term after conducting studies that found that students from racial and ethnic minority groups often perform worse on academic tasks when their identity as belonging to a racial or ethnic minority group was made more salient, thus triggering doubts about their competence. A study by Chang and colleagues (2014) examined stereotype threat among URM STEM students and found that experiences of stereotype threat among first-year URM students in biomedical disciplines led to lower rates of persistence in their major and may have contributed to lower academic performance. Given that URM students are frequently reminded of their membership in racial and ethnic minority groups in STEM disciplines, previous work on stereotype threat highlights the possible negative effect this may have on academic success for these students.

\section{Cultural Context of STEM in Higher Education}

A majority of URM students in STEM are the first in their families to attend college. As a result, students often have to navigate unfamiliar cultural values, expectations, and norms on college campuses. Previous research has suggested that the academic environment, and biomedical disciplines in particular, operate using norms and values from the dominant culture which often creates tension when paired with the lived experiences of URM students. Majority students often find "cultural continuity" between their communities of origin and the campus contexts (Padilla, Trevino, Trevino, \& 
Gonzalez, 1997). In a study by Hurtado and colleagues (2011), URM students in scientific disciplines viewed the science classroom environment as impersonal and competitive. In the same study, college administrative staff were interviewed about the reasons these negative classroom environments persist despite advances in educational pedagogy. Administrators reported that they believe faculty members are reluctant to introduce new supportive mechanisms in the classroom even if they might enhance classroom learning for diverse students. This highlights, again, the potential role of faculty in persistent negative experiences in these learning environments for URM college students.

Cooper and colleagues (1999), building on previous work by Phalen, developed the bridging multiple worlds model to describe and explain how youth form identities that coordinate their cultural and family traditions with other contexts including peer relationships and academic environments. This model was prompted by research that revealed how frequently minority students must cross between different "worlds" in order to succeed in the various domains in their lives. In higher education, and in STEM, students often enter an unfamiliar, intimidating, and even unwelcoming "world" into which they are expected to quickly and successfully integrate with little or no support in this process.

The clashes between faculty and students who come from different racial and ethnic backgrounds can leave URM students feeling alone, confused, and isolated (Johnson et al., 2007). Additionally, students of color report having little access to 
faculty of color in the sciences highlighting the reality that many URM STEM students do not have role models from similar backgrounds while pursuing their biomedical degrees (Hurtado et al., 2011). In a study conducted by Strayhorn and colleagues (2015), researchers used both quantitative and qualitative data to examine the experiences of 38 URM students in STEM. Results indicated that half of the participants expressed a lack of same race peers in their classes or hands-on research settings. In particular, these students shared that in these environments, they felt socially isolated and alienated and also described traveling long "cultural distances" in order to succeed and stay in school.

\section{Conclusion}

There is robust evidence that URM students in STEM face a host of daunting challenges. Some of these challenges stem from students' negative pre-college experiences in academic environments which disproportionately impact individuals in underrepresented minority groups. As students traverse their K-12 educational pathways, many are not provided sufficient opportunities to explore their science related interests or to form the kind of academic identity that facilitates college success.

For students who are able to overcome these pre-college challenges and enter into a biomedical major, ongoing discrimination and bias make persistence in academic work at college extremely difficult socially, emotionally, and psychologically. What is more, many of the cultural norms and values within disciplines espouse narrow, exclusive, and competitive norms and values that are often unfamiliar or off-putting to individuals from minority groups. The impact of these background and interpersonal factors on URM 
persistence in STEM points to larger social-contextual inequities in education and highlights the reality that student success in STEM cannot be isolated to the college campus but must be examined in a larger context. These challenging experiences and barriers, when taken together, provide a fuller picture of the differential struggles faced by URM students in STEM as they make progress towards degree attainment. They also help explain the foundational issues and inequities that undergraduate research training programs are seeking to address.

\section{Programs to Promote URM Success in STEM}

Recognition of the many barriers that URM students must overcome to succeed in higher education has prompted widespread efforts to support these students with campus programming designed specifically for URM students seeking to attain college degrees. Due to the gaps in science-related degree attainment previously discussed, these programmatic efforts have largely concentrated on URM students pursuing degrees in biomedical disciplines. Although program components and implementation strategies vary, these programs have a shared long-term goal to enhance the URM student experience and increase retention for these students by providing additional supportive components throughout their college experience.

Undergraduate research training programs are present on a majority of campuses in the United States and although they are generally thought to be effective, there are still large gaps in researchers' understanding of their precise benefits for URM students in STEM as well as the specific mechanisms that are responsible for positive student 
outcomes (Leggon \& Pearson, 2006; Seymour, Hunter, Laursen, \& DeAntoni, 2004; Tsui, 2007). To provide a broader picture of the efficacy of undergraduate research training program efforts to support URM students in STEM, the next section summarizes research on the prevalence of these programs, factors related to program design and implementation, what is known about the effectiveness of these programs in promoting URM student success and retention, and research training program evaluation.

\section{Undergraduate Research Training Programs Efforts to Support URM Students in STEM}

When initial efforts to decrease gaps in biomedical workforce diversity failed several decades ago, researchers began positing that there was a "leak in the pipeline," with unknown causes preventing particular groups from progressing through their education to advanced degrees in biomedical fields. Although this metaphor has been criticized for implying students are simply objects being funneled through a pipeline to a predetermined destination, the metaphor aptly captures the reality of pervasive issues that are preventing students from successful degree attainment and continue to puzzle higher education researchers and college administrators (Allen-Ramdial \& Campbell, 2014).

Higher education institutions of various sizes, located in different regions of the United States, and serving diverse student populations have sought to address these issues by identifying students from underrepresented backgrounds and building programs to support them as they pursue undergraduate degrees in STEM fields. As a result, programs designed to promote URM student success and retention in STEM have 
emerged at virtually every four-year institution of higher education in the United States (Tsui, 2007). Funding from government agencies and other education-based organizations has provided much of the financial support needed for these programs. Both the National Institutes of Health (NIH) and the National Science Foundation (NSF), as well as other non-profit foundations, have invested significantly in initiatives that seek to address what many call the "science crisis" facing our nation (Leggon \& Pearson, 2006; National Academy of Sciences, National Academy of Engineering, Institute of Medicine, 2007).

A primary driving force behind national efforts to train a more diverse group of scientists has been research linking diversity in the research workforce leads to gains in research productivity and enhanced effectiveness across disciplines (McGee Jr, Saran, \& Krulwich, 2012; Mitchell \& Lassiter, 2006; Valantine \& Collins, 2015). Notably, a study revealed that the biomedical research workforce in the United States is significantly less racially and ethnically diverse than in other developed countries (Mitchell \& Lassiter, 2006).

Although succinctly capturing the breadth and depth of these programs is nearly impossible, a common denominator across campuses is the overarching and long-term goal to increase diversity in the research workforce through deliberative programmatic efforts. These programs, sometimes referred to as STEM Intervention Programs (SIPs) or undergraduate research training programs, not only focus on support at the individual level by working to increase student engagement and success in STEM coursework, but 
also seek to address the larger historical and structural issues that have led to ongoing underrepresentation of certain minority groups in biomedical majors and professions (Tsui, 2007).

\section{Research Training Program Design and Implementation}

At present, the functional program components and implementation of undergraduate research training programs vary widely and are impacted by institutional context, funding sources, and a myriad of other factors. As a result, there is significant diversity in design and implementation of these programs on campuses across the United States (Hunter, Laursen, \& Seymour, 2007; Linn, Palmer, Baranger, Gerard, \& Stone, 2015; Seymour et al., 2004).

Tsui (2007) comprehensively reviewed the literature to examine the empirical evidence regarding the effectiveness of strategies that undergraduate research training programs employ in efforts to increase minority participation in STEM fields. After reviewing articles related to the operationalization of these programs on campuses, Tsui identified ten strategies that are commonly used across different programs and have welldocumented evidence supporting their effectiveness to support URM STEM student success. These strategies included summer bridge programming, mentoring, research experience, tutoring and learning opportunities, career counseling, academic advising, curriculum reform, and financial support. According to this review, research to date 
suggests that these strategies may be at the core of creating successful program-based interventions that will provide tangible benefits to URM STEM students.

Although these strategies are utilized by many programs, their translation into specific programmatic activities and components varies significantly across programs. For example, some programs last only a few weeks and focus heavily on training students in the practical skills needed for bench science while others span a student's entire undergraduate career and focus on promoting growth in students' scientific identity. Despite differing perspectives on the precise activities necessary for research training programs to be successful, higher education researchers seem to have converged on a few core components. Gándara and Maxwell-Jolly (1999) argued that there are five shared essential program elements that must be present in these programs for them to be successful. In this view, regardless of a program's duration or activity structure, programs must include mentoring, financial support, academic support, psychosocial support, and professional development opportunities. By including these five elements, researchers argue, programs provide holistic support and assist students across multiple domains increasing the likelihood that URM STEM students can benefit from programmatic efforts and persist to degree completion.

Other researchers have suggested that student engagement in particular experiences is the cornerstone of research training programs and that students must have the opportunity to interact with faculty mentors, engage in hands-on research, and receive high-quality academic advising (Fuchs, Kouyate, Kroboth, \& McFarland, 2016; McGee 
Jr et al., 2012; Tsui, 2007). This perspective emphasizes key experiences as the most crucial aspect of program participation and suggests that student exposure to various people and hands-on research opportunities plays a critical role in a student's ability to persist to degree completion in STEM majors.

These varying perspectives, when viewed together, highlight the complexity of current programming designed to support URM STEM students and the diversity of opinions regarding what essential active ingredients, or program components, must be in place to ensure that programs can successfully support students to increase URM STEM student persistence.

\section{Research Training Program Impact and Effectiveness}

Research examining the effectiveness of undergraduate research training programs has demonstrated links between program participation and positive student outcomes and also provided some insight into design and implementation elements that may increase the likelihood of program success. At present, there are numerous studies that support the efficacy of these programs by examining how URM STEM student participation in undergraduate research training programs may positively influence student outcomes and the conditions that must be met in programs for them to be successful. The findings from these studies can be grouped into three distinct categories.

The first six studies examine the potential relationship between undergraduate research training program participation and graduate school aspirations and/or entrance. In a study by Chang and colleagues (2014), researchers found that URM students who 
participated in an undergraduate research program increased their chances of progressing towards or obtaining a biomedical degree by 17.4 percentage points. In a longitudinal study with a sample of 4,152 undergraduates pursuing science-related degrees, students who participated in hands-on research experiences had greater intentions to pursue graduate school than those in a matched control group. This was particularly pronounced for Latino and Black students (Eagan et al., 2013). Two other studies found that by participating in programs that provide opportunities for undergraduate research, students significantly increased their chances of completing their undergraduate STEM education and pursuing an advanced science degree (Barlow \& Villarejo, 2004; D. Lopatto, 2004). For African American STEM students, in particular, two studies demonstrated that participation in undergraduate research activities increased retention and graduate school attendance as compared with African American STEM majors who did not engage in these programs (D. Lopatto, 2004; Nagda, Gregerman, Jonides, Hippel, \& Lerner, 1998). These six studies showcase a potentially strong link between student participation in undergraduate research training programs and graduate school aspirations and/or participation suggesting that students may gain essential skills and perspectives from these programs that enhance their ability to pursue advanced STEM degrees.

The second set of two studies examined how program participation may be linked to successful academic functioning for URM students in STEM. In a study by Hurtado and colleagues (2009), results showed that a majority of students in research programs are mentored by faculty who encourage them to take on increasingly challenging research 
tasks they would not otherwise have been afforded which, in turn, leads to increased identification as scientists. In yet another study, Fechheimer and colleagues (2011) demonstrated that extended participation in hands-on research within an undergraduate research training program was correlated with an increase in GPA. These results provide some evidence that programs may be providing students with experiences that increase positive academic functioning which in turn, may increase their likelihood of higher levels of academic achievement in STEM courses.

A third category, which includes one prominent review, considers the factors that may serve as necessary ingredients for programs to be successful. In Tsui's (2007) previously discussed review of research training programs, results examining program effectiveness indicated that the most effective programs used an integrated approach with multiple strategies woven into numerous program components. This illustrates the importance of multi-faceted programs that seek to holistically support URM students as they overcome barriers to their success in STEM majors and suggests that URM STEM students need an array of supports as they face challenges across many contexts and domains throughout their higher education experience.

These study results, when considered together, provide some evidence that there may be positive benefits for URM STEM students who engage in undergraduate research training programs and that particular factors may be more salient in program design and implementation to ensure the success of these programs.

\section{Undergraduate Research Training Program Evaluation}


Although research to date suggests that URM STEM students may benefit from programmatic efforts to support them in college, the evaluation of research training programs has been identified as insufficient and lacking rigor in the literature. The results from prior studies examining the benefits of undergraduate research programs, which suggest for instance that these programs increase students' likelihood of pursuing advanced biomedical degrees, may have significant shortcomings. For example, Eagen and colleagues (2013) pointed out that although previous studies have documented the benefits of undergraduate research programs, the vast majority of the literature regarding the benefits from undergraduate research participation utilized analyzed data from single institutions and researchers use simple descriptive statistics to analyze effects which could lead to an over-estimation of the positive benefits of undergraduate research programs (Eagan et al., 2013). This greatly limits the generalizability of the findings to other institutions or similar initiatives.

Another common critique of these programs is that their structure and implementation have not been guided by past research, but rather have been implemented in a "piecemeal style that has relied heavily on anecdotal information" (Dyer-Barr, 2014, p. 20). This lack of systematic evaluation begins in the program design phase when the staff and resources needed to conduct ongoing research on the program are often overlooked. In fact, the evaluation of undergraduate research training programs is often not included as a core component of pre-implementation planning. Researchers have suggested that, as a result, universities do not build program models on theoretical 
foundations and lack the intentionally designed evaluation plans needed to provide valuable insight for the field about how to increase student retention (Dyer-Barr, 2014; Seymour et al., 2004; Tsui, 2007). Because programs are not built with a thorough program evaluation plan in place, there are significant challenges for researchers looking for empirical evidence of program effectiveness.

In a review of articles that claimed there were positive student outcomes of participation in undergraduate research training programs, Seymour and colleagues (2004) identified 40 articles claiming that participation in undergraduate research training programs contributed to success for URM students in STEM. However, only 9 of the 40 articles were connected with research that was sufficiently thorough to support these claims. On the contrary, a majority of the articles describing benefits from participation in these programs related to student or faculty outcomes used evaluation methods that were “missing, incomplete, or problematic.” (2004, p. 495). This review further highlights that although there may be many benefits from participating in these programs for URM STEM students, there are large gaps in understanding regarding the role of undergraduate research training programs in URM STEM student success. Given that many research training programs were implemented without careful consideration of previous research or a comprehensive evaluation plan, much still needs to be understood to increase our understanding of how to improve or replicate these programs across campuses (Seymour et al., 2004).

\section{Conclusion}


University efforts to address barriers that URM STEM students face with programs tailored to assist these students are widespread and undergraduate research training programs have been implemented at nearly all four-year institutions in the U.S. Despite these efforts, overall gaps in biomedical degree attainment do not appear to be decreasing at a significant rate (James \& Carlson, 2012; National Science Board, 2012). This suggests that the widespread prevalence of undergraduate research training programming alone is not sufficient to achieve the goals of increasing URM student persistence in STEM disciplines. The research to date provides a complex picture of the effectiveness of programs designed to address minority participation in biomedical fields and how these programs are being designed, implemented, and evaluated across institutions.

Undergraduate research training programs employ a variety of strategies when implementing on-campus programming and each program includes unique activities and student experiences. These programs share the long-term objective to increase diversity in the scientific workforce and while they often have some overlapping core program components, they employ a wide variety of program structures and models. Researchers have attempted to identify the key ingredients necessary for these programs to be successful. From this, varying perspectives have emerged on the potential active ingredients these programs need to support URM STEM students including an emphasis on the holistic support programs must provide and the importance of student engagement in key experiences. 
Research that has considered student outcomes from undergraduate research training program participation provides some evidence that these programs may have a positive influence for URM STEM college students. Among the key hypothesized benefits is an increased interest in pursuing a graduate degree in a STEM field. Studies also suggest that programs may positively influence URM STEM students' persistence and academic achievement. However, the literature to date lacks information about the precise mechanisms that may be responsible for these positive program outcomes. In fact, thorough evaluation of undergraduate research training programs is often overshadowed by a lack of intentional planning when designing programs for implementation. Furthermore, studies that suggest there are benefits from participation in these programs often lack sufficient data or adequate analyses to support these claims. These gaps have resulted in a call for program evaluation that is conducted across multiple campuses using methods that can sufficiently measure program effectiveness and be generalized to a broader population of URM STEM undergraduates.

\section{Critique}

The dedication of institutions and organizations to developing and sustaining undergraduate research training programs is an indication of the commitment of many faculty and administrators to support URM STEM students. However, the lack of evidence-based interventions and systematic evaluation of program processes and outcomes requires attention. The following are critiques of the reviewed literature that future research on undergraduate research training programs could address. 
First, when programs are implemented in a "piecemeal style" using unsystematic approaches by faculty and anecdotal information shared across campuses, understanding the relationship between program participation and possible student, faculty, or institutional outcomes becomes difficult for interested researchers. Given that many researchers have suggested that universities do not build program models on a theoretical foundation and lack the intentionally designed evaluation plans needed to provide valuable insight for the field about how to increase student retention (Dyer-Barr, 2014; Seymour et al., 2004; Tsui, 2007), there is a clear need for evaluative efforts that provide specific links between program participation and positive student outcomes so that new and existing programs may be created or adapted using empirical evidence about program effectiveness.

Second, research appears to suggest that even when programs have evaluation plans in place, the research designs often lack rigor or employ statistical analyses that are not an appropriate fit for the data or research questions. For example, a review of studies claiming positive benefits from research training programs, revealed correlational techniques are frequently used to demonstrate the impact of undergraduate research training programs (Eagan et al., 2013). This, and the use of descriptive statistics in these studies, provide little insight into the relationships of interest and are not sufficient to build a robust case for positive outcomes from participation in these programs.

Third, program design and implementation vary significantly across institutions and there are numerous perspectives on the active ingredients needed for programs to be 
successful. Yet, little is known about the specific strategies that programs can utilize to support URM students in STEM. Despite positive documented gains from program participation, it appears that researchers still don't know exactly how and why programs are successful. Furthermore, most program-related findings lack the in-depth understanding needed for replication and optimization in other settings. Future research must seek to empirically demonstrate links between the active ingredients within the program context and URM STEM student achievement so that the mechanisms by which program participation shapes academic success can be better understood.

These three limitations are significant when considering the time, money, and resources being invested into these programs. The prevalence of these programs alone does not constitute success. In order to ensure that the ongoing investment of money and other resources is worthwhile, a deeper understanding of the student experience within these programs and a more thorough examination of the relationships between the various program components and outcomes within these programs is needed. Ultimately, the goal of future efficacy research on programs should be to identify the best practices used and determine the effectiveness of the specific interventions (Dyer-Barr, 2014). This research could provide the opportunity to discover how program benefits can be replicated and ultimately help close the persistent gap in STEM degree attainment between URM and non-URM students.

Next, the experience and perspective of URM STEM students will be considered with a review of the literature on how the two key motivational resources, a sense of 
belonging and self-efficacy, relate to academic achievement and success in college for URM students in biomedical disciplines.

\section{The Motivational Resources of URM Students in Biomedical Disciplines}

Thus far, this literature review has focused on barriers that may impede the success of URM students in STEM as well as the effectiveness of campus-based programming designed to support these students. Although the widely recognized challenges that URM students face can have lasting impacts on their educational experiences, the individual students who succeed despite these setbacks demonstrate admirable resilience, creativity, and perseverance. The work to create campus environments that support all students pursuing a college degree must begin with an acknowledgment of the individual strengths and assets of diverse students pursuing undergraduate degrees. Many of these students persist despite hostile and unwelcoming environments and take personal and professional risks to share their experiences and perspectives. In doing so, these students provide crucial information for the institutional transformations that are needed in higher education.

As these students pursue college degrees, many develop motivational resources that enable them to engage and persist on their educational pathways. These resources include psychological appraisals about whether they belong in the college environment and their abilities to be successful in college. Understanding how students develop and sustain these positive self-appraisals is an important piece of increasing student support services aimed at URM STEM student achievement and retention. 


\section{Student Motivation in Higher Education}

Motivation has been shown to be crucial for both student success and persistence in higher education (D. Allen, 1999; Guiffrida, 2006; Noble, Flynn, Lee, \& Hilton, 2007). Ramist (1981) argued that student motivation is the most important predictor of persistence and should be the focus of all persistence research in educational settings. At the most basic level, motivation is defined as the process that initiates, guides, and maintains goal-oriented behaviors. It is the level of effort a person is willing to put towards the achievement of a particular goal and is the fuel that feeds a student's engagement with academic work (Brennen, 2006).

Given that motivation is particularly salient when students are required to complete challenging tasks, STEM students must stay motivated to succeed academically. Additionally, the non-academic challenges that URM students face within these disciplines elevate the importance of motivation to ensure their success.

Reasons for attending college have been linked to sustained motivation throughout students' undergraduate experience. For URM students, research has found their reasons for attending college may not only be different from the majority student population, but also that these reasons may have negative relationships with sustained motivation after the transition into college. In a study by Guiffrida and colleagues (2013), which examined how reasons for attending college may be linked to sustained motivation during college, researchers found that minority students are more likely to attend college for financial reasons such as getting a high paying job to support their 
families. In this same study, URM students' reasons for attending college were less impactful in sustaining motivation in college than those of the non-URM students suggesting that URM STEM students may need intentionally supportive environments to help them sustain their motivation after transitioning into college.

Another challenge URM STEM students face when working to stay motivated is the widespread perception of unwelcoming campuses and classrooms. In fact, a study by Walter and Cohen (2007) found that students who perceived a hostile or unwelcoming climate on campus were less likely to feel motivated to complete academic work. For URM students in STEM, these results suggest that motivation may be difficult to sustain in the midst of frequent negative interactions in STEM departments and courses with faculty and peers.

Given these challenging background and contextual factors, which are outside students' control, it is essential to understand how URM STEM students can develop and maintain their motivation at college. To maintain motivation, students must have a positive self-perception about their sense of belonging to the college environment and their ability to succeed in science. URM students in STEM can utilize these two core motivational resources, a sense of belonging and self-efficacy, to develop and maintain the motivation they need to persist despite the challenges and barriers they may encounter throughout their undergraduate education.

Although motivation is important for all college students, it is particularly salient for URM STEM students. The final section of this literature review focuses on the two 
motivational resources identified as essential for academic success and persistence for minority students in biomedical disciplines. Research that examines the development of these two key self-appraisals, a sense of belonging and self-efficacy, is reviewed and summarized.

\section{A Sense of Belonging as a Motivational Resource for URM Students in STEM}

A sense of belonging is widely recognized as a significant predictor of academic success and motivation across the educational careers of students (Connell \& Wellborn, 1991; Furrer \& Skinner, 2003; Osterman, 2000). In fact, numerous studies have shown that students in K-12 settings who feel like they belong at school are more engaged and motivated in academic activities and tasks (Osterman, 2000). Additionally, research to date suggests that students who experience higher levels of a sense of belonging also report higher levels of confidence, interest, and excitement in the classroom compared to those who have a lower sense of belonging (Furrer \& Skinner, 2003).

These findings also hold true in higher education where research has shown that a sense of belonging predicts multiple positive student outcomes including academic achievement and persistence (Hausmann et al., 2007; Strayhorn, 2012). Next, this review will consider the definition of a sense of belonging and research that has examined the link between a sense of belonging and college student success. Additionally, studies that have considered the salience of a sense of belonging for URM students in STEM and how it may shape academic achievement and functioning for these students will be reviewed and summarized. 
A sense of belonging defined. The concept of a sense of belonging has been characterized variously as belongingness, relatedness, school membership, fit, and a psychological sense of community (Vaccaro \& Newman, 2016). According to motivational researchers, belongingness is a basic psychological need supporting human growth and development (Deci, 1985; Ryan \& Deci, 2000). A sense of belonging has also been described as a "basic human need and motivation, sufficient to influence behavior" (Strayhorn, 2012, p. 3).

Although studied widely with student populations, researchers still use a variety of definitions to capture the meaning of a sense of belonging. Four conceptualizations of a sense of belonging can be used to illustrate these varied perspectives. Some researchers focus their definition of a sense of belonging on a specific context in which an individual may experience belonging and highlight the interpersonal dynamics within these contexts. This focus is seen in the work of Goodnow, where a sense of belonging is defined as a "students' sense of being accepted, valued, included, and encouraged by others (teachers and peers) in the academic classroom setting and of feeling oneself to be an important part of the life and activity of the class" (1993, p. 25). Other definitions focus on the aspect of "mattering" within a group or environment such as Osterman's definition which describes belonging as "a feeling that members matter to one another and to the group, and a shared faith that members' needs will be met through their commitment to be together" (2000, p. 324). The third category of conceptualizations of a sense of belonging focus on an individual's belief about their "place" within a 
community such as in Anant's focused definition of a sense of belonging as an individual's perception of their "indispensability within a system" (1966). A fourth and final understanding of a sense of belonging focuses largely on an individual's appraisal of their place within a group or community. This is seen in the work of Tovar and Simon, who characterize a sense of belonging as "an individual's sense of identification or positioning in relation to a group or to the college community, which may yield an affective response" (2010, p. 200).

A sense of belonging as a theoretical construct has been less consistently defined and not as widely studied in higher education settings (Hoffman, Richmond, Morrow, \& Salomone, 2002; Hurtado \& Carter, 1997; Hurtado \& Ponjuan, 2005). However, researchers who have looked at students' belongingness in college have captured the essence of this student experience by describing it as "the individual's view of whether he or she feels included in the college community" (Hurtado \& Carter, 1997, p. 327). Strayhorn offers a more nuanced definition of a sense of belonging in higher education defining it as a "students' perceived social support on campus, a feeling or sensation of connectedness, the experience of mattering or feeling cared about, accepted, respected, valued by, and important to the group (e.g., campus, community) or others on campus (e.g., faculty, peers)" (2012, p. 122). When taken together, these definitions offer a robust description of the various facets of belongingness that may be central to students' experience as they navigate college life. 
A sense of belonging in college. Researchers who study a sense of belonging in higher education have insisted that in the college context, a sense of belonging operates as a fundamental component of the motivation that fuels student behaviors and facilitates educational outcomes such as academic achievement and persistence (Strayhorn, 2012). In this view, students must feel that they belong in their college environment to maintain engagement in the learning process and succeed at academic work.

Numerous studies have looked at how college success, broadly defined, may be influenced by a self-perception of belonging on campus. Looking across disciplines and student groups, a study by Hausmann and colleagues (2007) showed that a sense of belonging may predict academic achievement and retention even after controlling for a variety of student background characteristics including race, gender, SAT score, and financial difficulty. Five additional studies have examined the influence of a sense of belonging on various facets of student success in the broader college context and have found that a sense of belonging was positively related to social and academic integration (Tinto, 1993), a smooth transition to college (Johnson et al., 2007), intent to persist to degree completion (Hausmann et al., 2007), academic self-efficacy, intrinsic motivation, and task value (Niehaus, Rudasill, \& Adelson, 2012), and retention (Thomas, 2012). Conversely, research has shown that feeling a sense of rejection on college campuses is a consistent predictor of student attrition (O'Keeffe, 2013).

For a more in-depth look at a sense of belonging in the college context, some researchers have considered how a sense of belonging may be operationalized differently 
for students in different campus contexts or when examining various aspects of their college experience. At least one study has found that a sense of belonging may play a unique role in STEM disciplines. In a study that examined the role of a sense of belonging in STEM majors, Wilson (2015) surveyed 1,498 students in STEM disciplines to measure the links between their sense of belonging at various levels (classroom, discipline, and institution) and academic engagement. Using multiple regression for data analyses, results indicated that a sense of belonging at all three levels was strongly linked to academic engagement suggesting it may be an active contributor to persistence in STEM fields across a variety of institutional contexts and student populations. These findings also suggest that a sense of belonging within their disciplines may equip students to navigate the demands placed on them in STEM majors and help them overcome challenges related to their coursework.

A sense of belonging for URM students at college. As previously discussed, URM students in college face many challenges and setbacks, many of which could impact their ability to experience a sense of belonging on campus. Research has shown that not only are discrimination, microaggressions, and low faculty expectations widespread occurrences on college campuses for URM students, but these experiences have well documented negative relationships with a sense of belonging for URM students (Chang, Eagan, Lin, \& Hurtado, 2011; Hurtado \& Ruiz Alvarado, 2015).

Although calls for more studies that focus on a sense of belonging in minority college student populations have been widespread (Strayhorn, 2012; Vaccaro \& 
Newman, 2016; Wilson et al., 2015), several studies have considered how a sense of belonging operates for URM students on college campuses. Studies looking at a sense of belonging for URM college students across disciplines (and not specifically in STEM) fall into three general categories and help provide a more refined picture of how a sense of belonging operates for URM students in the higher education context.

The first category, which includes three empirical studies, considers how campus climate may play a role in predicting a sense of belonging for URM students. In a study conducted by Hurtado and Carter (1997), researchers found that hostile racial climates were negatively associated with a sense of belonging and hindered the academic adjustment of URM students. In another study, Cramer and colleagues (2017) conducted in-depth focus groups with undergraduate Latino men and found that campus climate significantly affected the students' integration into the community. Furthermore, the study concluded that the socially constructed environments on college campuses produced unique challenges for Latino men related to their sense of belonging on campus. In a third study, Chang and colleagues (2011) found that regular experiences of discrimination on college campuses negatively affected a sense of belonging for Black and Latino students, even for the most high-achieving students in the sample. The results from these three studies provide insight into the possible negative link between students' perceptions of a negative campus climate and a sense of belonging at college.

A second category, which includes two empirical studies, compared URM perceptions of a sense of belonging on campus with the perceptions of those from 
majority student populations. In the first study, which was qualitative and conducted indepth interviews with black and white male undergraduates, results showed that black male students had a higher likelihood of experiencing isolation in their courses and also expressed a need to experience greater levels of belonging at college compared to white male students (Strayhorn, 2009). In a second study, Johnson and colleagues (2007) found that first-year students of color felt a weaker sense of belonging on their campuses than their majority counterparts suggesting that minority students may be at greater risk of a lower sense of belonging at college than White/Caucasian students.

A final study, by Vaccaro \& Newman (2016), focused on how a sense of belonging may function uniquely for URM students and be conceptualized differently for students from minority groups. In this qualitative study with 51 first-year college students, researchers used a grounded theory approach to examine how students from a variety of racial and ethnic backgrounds define and experience a sense of belonging. Results indicated that a sense of belonging was essential for all participants across racial and ethnic groups. However, individuals from URM student groups defined this construct uniquely and revealed a heightened need to feel a sense of belonging on campus to engage and succeed in their academic pursuits.

When taken together, these studies suggest that minority college students may experience a lower sense of belonging due to hostile climates on campus and feeling isolated or out of place within courses or departments. However, research to date also suggests that these students may have an even greater need for belongingness than 
majority students and this self-appraisal may play a central role in their successful journey to degree attainment.

A sense of belonging for URM students in STEM. As previously established, beyond its importance for college student success generally, a sense of belonging is particularly crucial for both STEM disciplines and URM students on college campuses. The combined experience of being from a minority population and majoring in a scientific discipline create an academically and psychologically challenging environment for students that requires a strong sense of belonging to persist. Unfortunately, this same environment may also inhibit these much-needed feelings of belonging in academic settings. Next, research that considers the unique experience of URM STEM students' sense of belonging will be reviewed with a particular focus on differences in mean levels of a sense of belonging for URM students in STEM, the elevated importance of a sense of belonging for URM STEM students, and the relationship between a sense of belonging and academic success for these students.

\section{Mean differences in a sense of belonging for URM STEM students. URM}

students in STEM face both the academic challenges that accompany being a STEM major along with the ongoing challenges of being from a college student from a minority group. Three studies have examined the differential student perceptions of belonging in STEM courses or disciplines in URM student populations. In one study, conducted with 1,722 women majoring in STEM disciplines, women of color reported a significantly lower overall sense of belonging than white women (Johnson, 2012). These results 
suggest that being a member of a minority racial/ethnic group may have a significant role in determining the extent to which students experience a sense of belonging. In a second study, researchers found that black male engineering students were more uncertain about the quality of their social bonds with other students and faculty in their discipline than those from the majority group. Additionally, these students had a lower sense of belonging than white students within the engineering department (Walton \& Cohen, 2007). In a final, very recent, study with 201 college seniors who were all STEM majors, researchers found that students of color who major in STEM were significantly less likely to report a high sense of belonging than white students in STEM majors (Rainey, Dancy, Mickelson, Stearns, \& Moller, 2018). When taken together, these studies provide a sobering picture of the lack of belongingness that many URM students pursuing STEM degrees are experiencing and suggest that URM students likely have lower overall levels of belonging than students from majority populations within these disciplines.

The salience of a sense of belonging for URM students in STEM. Although helpful to students from all backgrounds, research has demonstrated that a sense of belonging may take on a more significant role for URM students in STEM. In fact, one study showed that a sense of belonging takes on heightened importance for students in environments where they feel unwelcome or where they see themselves as different than others (Freeman, Anderman, \& Jensen, 2007). Given that URM STEM majors often feel like they do not belong in their courses or disciplines, a sense of belonging may be an 
important motivational resource for URM STEM student persistence and success.

Two studies have documented the heightened importance of a sense of belonging for URM STEM students. In a study by Hurtado and Ruiz (2012), hostile racial climates on campus were negatively associated with a sense of belonging for students from all groups, but only negatively impacted the academic performance of URM students in the study suggesting that the need to belong was more central to academic success for minority students. In a second study with a sample of African American STEM students, a majority of students indicated feeling alone and isolated in their courses. More striking, these same students reported a significant need to feel like they belonged in their discipline in order to be successful (Strayhorn, 2015) suggesting that the combined experience of persisting through an academically challenging major and navigating ongoing experiences of discrimination and racism on campus may result in a greater need for a sense of belonging. This highlights the troubling reality that not only do URM STEM students have lower levels of belonging than students from non-minority groups, but this may have an even greater negative influence on their ability to succeed in college.

A sense of belonging and academic success for URM students in STEM. Given what is known about the particularly challenging experiences of URM students in STEM, their lower levels of a sense of belonging, and the salience of this self-appraisal for these students, researchers posit that a sense of belonging is an important motivational resource for URM students who successfully attain biomedical degrees. One study to date has 
examined the relationship between a sense of belonging for URM students in STEM and student achievement and two studies have examined the relationship between a sense of belonging and indicators of academic functioning including engagement in academic activities and persistence in a STEM major. Although academic functioning is qualitatively different from a student's academic performance, higher education researchers have empirically demonstrated that it is highly correlated with academic success and achievement at the college level (Kappe \& van der Flier, 2012; G. Kuh et al., 2006; Schneider \& Preckel, 2017). As a result, studies that consider how a URM students' self-perception of belonging relates to a variety of student outcomes are relevant to consider in this review.

The three studies that have isolated a sense of belonging for URM STEM students have considered its relationship with achievement, persistence, and academic engagement. Study details can be seen in Table 2.1. [1] Garcia and Hurtado (2011) conducted a quantitative study to explore the predictors of persistence for Latino undergraduate STEM students. A sense of belonging was measured using three items that tapped a students' sense of academic and social integration on their college campus. Items included "I feel I have a sense of belonging to this campus," "I feel I am a member of this college," and "I see myself as part of the campus community." Researchers predicted that a sense of belonging would be positively related to URM student persistence in STEM disciplines. Persistence was measured using a binary variable that indicated whether students persisted to STEM degree attainment. Participants included 
810 first-year Latino students, all STEM majors, who were surveyed at the start of their first year and again at the end of their fourth year. Logistic regression analyses revealed that a sense of belonging was significantly and positively related to persistence for Latina/o students in STEM majors suggesting that when a student feels a greater sense of belonging, they will be more likely to persist to degree completion in their STEM discipline.

[2] Strayhorn (2015) conducted a mixed methods study to examine how demographic factors, STEM interest, pre-college self-efficacy, and a sense of belonging might be shaping the adjustment to college and academic success of black undergraduate males in STEM majors. Strayhorn predicted that a sense of belonging, defined as a perceived membership or a feeling of belonging in the academic community, would correlate with academic achievement for these students. Study participants included 140 black undergraduate men, a majority were first-generation college students and one-third were STEM majors. All participants were given a survey electronically at one time point during spring semester of their first year at college. Zero-order correlations revealed a significant and positive association between a sense of belonging and several student success measures for the STEM students in the sample including college GPA, satisfaction with college, overall satisfaction, and departure intentions. Qualitative data, from 38 in-depth one-on-one interviews with participants, corroborated these findings, further supporting the notion that belonging may take on heightened importance for black male students in STEM majors and departments, where they often feel alone and isolated. 
[3] A study by Wilson and colleagues (2015) examined the role of a sense of belonging in predicting academic engagement for STEM students. The sample was recruited through STEM courses and science-focused activity groups and included 1,507 sophomores, juniors, and seniors in STEM majors from five different types of higher education institutions. These five institutional types included a private institution, a women's college, a research-intensive university, a teaching university, and most relevant to the current study, a historically black college (HBCU). The students from the HBCU were all undergraduate minority STEM students. Researchers used multiple regression analyses to examine whether belongingness at any one of three levels (class, academic major, and university) accounted for the variance in the students' academic engagement in STEM coursework at any of the five institutions. Researchers measured students' sense of belonging to their courses and academic major using adapted items from the belonging scale (Anderson-Butcher \& Conroy, 2002). These items were designed to assess students' feelings of acceptance and support within their STEM disciplines and courses. At the class level, items included "I feel that I am accepted in this class" and "I feel that I am a part of this class." With regards to students' sense of belonging to their major, items included "I feel comfortable in this major" and "I feel that I am a part of this major." The third level of belonging, university belonging, was measured using items from the collegiate psychological sense of community scale (Lounsbury \& DeNeui, 1995) and assessed the students' sense of belonging to the college they were attending. Items in the university belonging subscale included statements such as "I feel like I really 
belong at this university/college." Researchers controlled for self-efficacy, year in college, and student demographic factors. The three measures of a sense of belonging were the only predictors in the model and the results from the multiple regression analysis showed that for the African American STEM students, there was a significant and positive relationship between students' belonging to their STEM courses and student engagement in academic activities required to complete their class. Although belonging at the major or institutional level was not a significant predictor of engagement for these students, these results suggest that students' sense of belonging in the classroom environment may be essential to their success in STEM fields.

Conclusions about the role of belongingness. Research on a sense of belonging in education has demonstrated an empirical link between students' sense of belonging and positive student outcomes such as academic engagement and performance. Researchers have conceptualized a sense of belonging in a variety of ways including dimensions such as relatedness, school membership, mattering within a group, and fit.

In higher education, a sense of belonging is not as clearly defined or as widely studied as in other student populations. At the core, this self-appraisal in college settings speaks to a student's belief about whether or not they are welcome and included across various college contexts. Research to date has shown that for college students across groups and majors, a sense of belonging is a significant predictor of success and belonging has shown particular salience which may be a result of the challenging academic environments that students encounter in STEM majors. The combined 
experience of facing ongoing challenges in higher education as a minority student while pursuing a degree in a particularly difficult major, suggests that a sense of belonging may be a critical factor for URM STEM student success.

Table 2.1

Summary of Studies Considering Sense of Belonging and Academic Functioning

\begin{tabular}{|c|c|c|c|c|c|}
\hline $\begin{array}{l}\text { Author } \\
\text { (year) }\end{array}$ & $\begin{array}{l}\text { Terminolo } \\
\text { gy and } \\
\text { Definition }\end{array}$ & Design & Participants & Methods and Scale & Results \\
\hline $\begin{array}{l}\text { Garcia } \\
\text { and } \\
\text { Hurtado } \\
(2011)\end{array}$ & $\begin{array}{l}\text { Sense of } \\
\text { belonging: } \\
\text { academic } \\
\text { and social } \\
\text { integration } \\
\text { on campus }\end{array}$ & $\begin{array}{l}\text { Longitudinal, } \\
\text { two time } \\
\text { points }\end{array}$ & $\begin{array}{l}810 \text { Latino } \\
\text { undergraduate } \\
\text { s, all STEM } \\
\text { majors }\end{array}$ & $\begin{array}{l}\text { Logistic regression, } \\
\text { student report, } \\
\text { Sharkness et al. } \\
\text { (2010) Construct } \\
\text { Technical Report }\end{array}$ & $\begin{array}{l}\text { significant } \\
\text { and positive } \\
\text { relationship } \\
\text { between a } \\
\text { sense of } \\
\text { belonging } \\
\text { and } \\
\text { persisting }\end{array}$ \\
\hline $\begin{array}{l}\text { Strayhor } \\
\mathrm{n}(2015)\end{array}$ & $\begin{array}{l}\text { Sense of } \\
\text { belonging: } \\
\text { Strayhorn's } \\
\text { definition } \\
\text { of } \\
\text { belonging } \\
\text { in college }\end{array}$ & $\begin{array}{l}\text { Two phase } \\
\text { exploratory, } \\
\text { sequential, } \\
\text { mixed } \\
\text { methods } \\
\text { design }\end{array}$ & $\begin{array}{l}140 \text { black } \\
\text { male } \\
\text { undergraduate } \\
\text { s, one-third } \\
\text { STEM majors }\end{array}$ & $\begin{array}{l}\text { Correlational } \\
\text { analyses, student } \\
\text { report } \\
\text { Strayhorn's (2015) } \\
\text { Student Success } \\
\text { Questionnaire } \\
\text { (SSQ) }\end{array}$ & $\begin{array}{l}\text { A significant } \\
\text { and positive } \\
\text { relationship } \\
\text { between } \\
\text { sense of } \\
\text { belonging } \\
\text { and GPA }\end{array}$ \\
\hline $\begin{array}{l}\text { Wilson } \\
\text { et al. } \\
(2015)\end{array}$ & $\begin{array}{l}\text { Sense of } \\
\text { belonging: } \\
\text { considered } \\
\text { at three } \\
\text { levels of } \\
\text { class, } \\
\text { academic } \\
\text { major, and } \\
\text { institution }\end{array}$ & $\begin{array}{l}\text { Surveyed at } \\
\text { one time } \\
\text { point }\end{array}$ & $\begin{array}{l}1,507 \text { students } \\
\text { total, } 157 \\
\text { URM STEM } \\
\text { majors }\end{array}$ & $\begin{array}{l}\text { Multiple regression, } \\
\text { class and university } \\
\text { level adapted from } \\
\text { Anderson-Butcher } \\
\text { and Conroy's scale } \\
\text { (2002), university } \\
\text { belonging with } \\
\text { Lounsbury and De } \\
\text { Neui's PSC scale } \\
\text { (1995) }\end{array}$ & $\begin{array}{l}\text { A significant } \\
\text { and positive } \\
\text { relationship } \\
\text { between } \\
\text { STEM } \\
\text { course } \\
\text { belonging } \\
\text { and } \\
\text { academic } \\
\text { engagement }\end{array}$ \\
\hline
\end{tabular}


Researchers have explored the importance of a sense of belonging for URM students in STEM and the differential college experiences of these students to better understand how these self-appraisals contribute to their success as undergraduate students. The research to date suggests that URM STEM students experience lower levels of belonging within their disciplines and at their institutions. This may be the result of hostile campus climates and ongoing experiences of bias and discrimination for minority students. Additionally, research has demonstrated that URM STEM students may have a greater desire and need for belongingness in order to persist through the challenges they encounter. When considered together, these findings suggest that although many URM STEM students have lower levels of a sense of belonging at college, they may have a heightened need for this self-appraisal to succeed.

Studies looking at how a sense of belonging may shape various aspects of academic outcomes for URM STEM students have found that a sense of belonging may be positively related to various facets of academic success for URM STEM students. Research to date has demonstrated empirical links between a sense of belonging for URM college student academic performance, engagement, and retention. These results provide important insight into how a sense of belonging may be influencing the longterm success of URM STEM students through positively impacting academic functioning for these students in their courses and disciplines.

\section{Self-efficacy as a Motivational Resource for URM Students in STEM}


Self-efficacy has a well-documented and robust relationship with student success across the educational pathway for students (Wigfield, Eccles, Schiefele, Roeser, \& Davis-Kean, 2006). In higher education, self-efficacy has shown to be a significant predictor of academic success and persistence (Bong, 2004; Pajares, 1996; Zimmerman, 2000). In fact, self-efficacy beliefs play a central role in Bean and Eaton's (2001) psychological model of college student retention. This model posits that when students believe they can complete particular tasks, not only are they more likely to persist on those tasks and progress through their undergraduate pathway to degree completion, but they also develop more difficult goals related to task completion and increase their academic opportunities for achievement in the process. This model, and other theories that consider the role of self-efficacy in college student success, see this positive selfappraisal about abilities as essential for academic functioning and persistence to degree completion for students from all backgrounds pursuing any type of undergraduate degree.

Self-efficacy defined. Self-efficacy was introduced by Bandura (1997) who argued that it was the self-appraisal that most shaped individual's motivation. Bandura defined self-efficacy as an individual's belief in his or her capacity to execute the actions necessary to produce specific performance outcomes. Since then, researchers have studied this self-appraisal using a range of perspectives such as Zimmerman (2000) who defined self-efficacy as the judgment about one's capacity to organize the activities required to exhibit a specific performance; or Lent and colleagues (1994) who described self-efficacy as an individual's beliefs about their capabilities. At its core, self-efficacy is 
an individual's self-perception about their capacity to succeed at a particular task. These cognitive self-evaluations about abilities influence all behaviors of individuals including the goals they set for themselves, the amount of effort they put towards those goals, and the likelihood of goal achievement.

Bandura posited that there are four primary sources of self-efficacy: mastery experiences, social persuasion, vicarious experiences, and physiological states. Mastery experiences refer to episodes in which an individual completes a task or reaches a goal successfully. In an academic setting, this means having previous, positive experiences that directly connect with the target task such as completing a course with similar content or performing well on a test in a related subject. The second source of self-efficacy, social persuasion, refers to the overt or covert influence of others on a person's selfperception about their abilities. The third source, vicarious experiences, occurs when a person observes someone they perceive as similar to them succeed at the task. This person serves as a model and this experience can influence the observer's self-efficacy as it relates to that task. Fourth and finally, physiological state considers taxing or stressful situations that may elicit emotional arousal from an individual and, depending on the circumstances, might influence a person's view of their competency or ability to complete a particular task.

Self-efficacy is domain and task-specific and research has shown that these selfperceptions can vary between contexts and from one task to the next (Pajares, 1996). In the academic domain, self-efficacy influences one's choice of academic activities and the 
efforts put towards task completion in coursework. This influence remains salient in college, where students have particular beliefs about their academic abilities as it relates to the tasks they are asked to complete during their courses. According to Solberg and colleagues (1993), college self-efficacy is defined as a student's degree of confidence in performing various academic tasks at college to produce a particular and desired outcome, such as a high grade on a test. Looking even more specifically at students engaged in science-related work in higher education, Ballen and colleagues (2017) called these self-appraisals related to STEM work "science self-efficacy" which is operationally defined as a students' self-appraisal about abilities to complete tasks related to STEM discipline demands or even more simply, a student's self-reported confidence in their ability to do science. This focused definition, taken in context with the others, effectively captures the essence of how self-efficacy among STEM undergraduate students is traditionally operationalized and the crucial role it plays in determining students' likelihood of success in academic activities within these disciplines.

Self-efficacy in college and STEM disciplines. As previously discussed, selfefficacy in college students has consistently predicted desirable student outcomes such as academic success and persistence across groups and majors (Bandura, 1997; Lane, 2001; Pajares \& Miller, 1994; Pajares, 1996; Schunk, 1982). Bandura (1993) posited that these self-efficacy beliefs influence grades and persistence in college by increasing students' motivation to master challenging academic tasks. 
The influence of self-efficacy is evident from the very beginning of the college experience for students. Chemers, Hu, and Garcia (2001) examined the academic success and personal adjustment of first-year university students. They found that above and beyond any effects of previous ability or experience, academic self-efficacy was the most influential and significant predictor of academic success, adjustment to college, and goal setting for students at these early stages of their college career providing some evidence that self-efficacy may be a critical component of a successful transition to college.

The importance of self-efficacy extends beyond this initial transition and continues to be a key predictor of success in college as students advance towards degree completion. Self-efficacy plays a critical role in determining the academic activities that students choose and their willingness to set challenging goals in their coursework. Unsurprisingly, a large body of literature confirms a positive relationship between college students' self-efficacy and academic achievement as measured by course grades (Bong, 2004; Hackett, Betz, Casas, \& Rocha-Singh, 1992; Multon, Brown, \& Lent, 1991; Brown, Lent, \& Larkin, 1989). This significant and positive relationship has also been found between self-efficacy and persistence to degree completion (Lent et al., 1994; R. W. Lent, Brown, \& Larkin, 1986; Zhang \& RiCharde, 1998).

Given the importance of self-efficacy for tackling challenging tasks, this selfappraisal may be even more salient for students in STEM disciplines due to their academically rigorous and demanding coursework. Students with high self-efficacy are more likely to overcome the academic challenges they encounter in STEM courses, to 
succeed in challenging coursework, and to stay engaged in their course of study. For example, a study that looked at the self-efficacy of 113 undergraduate biology students showed that higher levels of self-efficacy in science courses led to better academic performance for students (DiBenedetto \& Bembenutty, 2013). The body of research that has considered the importance of self-efficacy at college provides clear and consistent evidence that students' beliefs about their abilities to perform required academic tasks play a crucial role in their ability to persist and succeed academically which may be particularly true in STEM disciplines where students must regularly put effort towards challenging tasks to progress toward degree attainment.

Self-efficacy and URM students at college. Although studies considering the self-efficacy of URM college students are limited, results from these studies are consistent with broader trends that posit that self-efficacy plays a crucial role in success and achievement at college. In a study investigating the effect of academic self-efficacy on the academic performance of 107 , mostly minority, undergraduate students, results showed that self-efficacy was a significant predictor of three academic performance outcomes including first-year college GPA, retention after the first year, and number of accumulated credits (Zajacova, Lynch, \& Espenshade, 2005). These results suggest that academic self-efficacy may be an important antecedent to academic success for URM students across disciplines.

Although regular experiences of low faculty expectations, discrimination, and racial bias might suggest that URM college students would have more negative self- 
perceptions about their academic abilities, research to date examining differences in selfefficacy between racial groups has been inconclusive or had mixed results. For example, in a study that looked at a cross-section of undergraduate students, black students demonstrated higher levels of self-efficacy than white students for academic and social tasks even when researchers used two separate assessment instruments to measure students' self-efficacy (Betz \& Gwilliam, 2002). Another study, which compared Mexican-American and white students' self-efficacy showed that Mexican-American students had lower levels of self-efficacy than white students concerning academic program requirements within their disciplines (Hackett et al., 1992). In yet another study, researchers compared the self-efficacy in white and black college students and found no differences between students from the two racial groups on self-efficacy ratings regarding academic abilities (Gwilliam \& Betz, 2001). These study results highlight that although self-efficacy levels may not differ between racial or ethnic groups, a variety of contextual and other factors may be shaping the self-efficacy of particular groups at college.

Limited research that has considered self-efficacy sources for URM college students has examined how Bandura's four source variables may shape self-efficacy levels for URM students and found some evidence that there may be differences between racial groups. In one study, Ali and colleagues (2005) compared sources of self-efficacy for URM and non-URM college students and found that for URM students, verbal persuasion, which for non-URM students most often comes from parents and guardians, more frequently comes from siblings and peers which may be because URM students are 
often first generation college students. In another study that considered possible differences in self-efficacy sources among college students, results showed that persuasion was just as predictive of self-efficacy for black undergraduates as their mastery experiences which was different than the majority population (Gainor \& Lent, 1998). These results suggest that although self-efficacy is important for all students, the precise sources that support the development of this self-appraisal may differ for students from URM groups and tailored efforts to help them develop self-efficacy at college may be warranted.

Self-efficacy is frequently seen as an important predictor of successful career attainment after college. In a study that examined the coping self-efficacy of URM and white students, white students were found to have a higher level of self-efficacy for coping with perceived career related barriers while URM students anticipated more barriers and demonstrated lower coping self-efficacy to deal with anticipated challenges related to future careers (Luzzo \& McWhirter, 2001). These results suggest that minority students may not believe in their ability to cope with the struggles that await them in the workforce and may have an even greater need for sustained support and experiences that enhance their self-efficacy in college so they are prepared to tackle challenges after degree attainment.

Self-efficacy for URM students in STEM. As previously discussed, selfefficacy is centrally important for student success in higher education for all students in all disciplines. However, when combining the challenging environment that STEM 
disciplines create for students, as well as the ongoing barriers that URM students encounter in college, the need for self-efficacy is likely central. Next, research that considers the role self-efficacy plays in the college experiences of URM STEM students will be reviewed with a particular focus on the salience of self-efficacy for URM STEM students and the relationship between self-efficacy and multiple facets of student achievement.

Importance of self-efficacy for URM students in STEM. In STEM environments on college campuses, URM students often face scrutiny by faculty and peers regarding their academic abilities and thus, the continued development of self-efficacy is crucial for persistence. For these students, the self-perception that they have the skills required to be successful in their academic work allows them to counteract past self-doubts and persist in the face of ongoing microaggressions and stereotypes. The salience of self-efficacy for URM STEM students was highlighted in a longitudinal study with 806 URM students in biomedical majors where self-efficacy was shown to increase the scientific identity of URM STEM students suggesting that it may play a key role in how these students see themselves within STEM majors (Robnett et al., 2015).

Research suggests that given the positive relationship between academic performance and academic self-efficacy, and the higher number of obstacles URM STEM students face in navigating academic milestones needed for degree attainment, lower levels of self-efficacy may have even more significant negative consequences for these students (Lent et al., 2005). However, self-efficacy at the college level is influenced by a 
variety of previous experiences, personal characteristics, and contextual factors.

Regarding possible pre-college antecedents to self-efficacy, past research has shown that academic preparation before college can positively influence academic self-efficacy at the higher education level and that the reverse may also be true. Furthermore, researchers posit that lack of preparation in secondary education may also account for fewer URM students persisting to degree completion and going on to graduate school (for review, see Betz \& Hackett, 1997). For URM students in STEM, who tend to enter college with less rigorous scientific training, self-efficacy may be at risk. Furthermore, high levels of selfefficacy could play a crucial role for URM students as they work to succeed despite differential levels of preparation, persist through ongoing challenges to their academic self-concept, and sustain interest in long-term STEM career pathways.

\section{Self-efficacy and academic success for URM students in STEM. Multiple} studies provide evidence that scientific self-efficacy relates to academic success and persistence for URM students in STEM. To date, five studies have examined the relationship between self-efficacy and positive student academic functions including academic achievement, persistence, commitment to science careers, and retention. In these studies, which are detailed in Table 2.2 , findings have consistently shown that selfefficacy is a significant predictor of academic success for URM minority students in STEM disciplines. Next, these studies will be reviewed and summarized individually.

[1] Hackett and colleagues (1992) conducted a quantitative study involving 218 engineering majors to examine whether gender, ethnicity, and various social cognitive 
factors, including self-efficacy, predicted academic achievement. Although the sample came from a variety of racial and ethnic backgrounds, researchers examined the potentially unique experience of Mexican American students who made up $20 \%$ of the total sample. Self-efficacy with regards to students' self-perception about abilities in their engineering disciplines was operationalized by adapting two subscales from Lent and colleagues (1992). The chosen subscales looked at overall occupational self-efficacy and self-efficacy for academic milestones. The items for overall occupational selfefficacy assessed students' confidence in their ability to complete the tasks required for a variety of occupations in science and engineering fields. To assess students' self-efficacy with regards to academic milestones, students were asked to rate their ability to complete twelve foundational requirements in their engineering program including tasks such as "completing the math requirements for your engineering major." Academic achievement was measured using cumulative GPA taken at the time of the survey. Researchers conducted a forward selection stepwise multiple regression analyses, where self-efficacy was entered first followed by their SAT mathematics score, faculty encouragement, and high school GPA. These variables accounted for $51 \%$ of the outcome variance and results showed a significant relationship between self-efficacy and academic achievement for the Mexican American engineering students, such that higher levels of both occupational self-efficacy and discipline-specific self-efficacy predicted higher GPA for these students. 
[2] Chemers and colleagues (2011) conducted a study to test a model they posited might explain the relationship between scientific self-efficacy and commitment to a career in science. They used web-based surveys with a sample of students members of the Society for the Advancement of Chicanos and Native Americans in Science (SACNAS). The study included 327 undergraduate students from diverse backgrounds including $11 \%$ white students, $49 \%$ of Latino/Hispanic heritage, and the remaining $40 \%$ reporting to be Black/African-American, Native American, mixed race, Asian American, or Pacific Islander. The science self-efficacy scale, developed for a previous study by the first author, was used to assess students' confidence in their abilities to complete science-related tasks. The scale included ten items and students rated on a 5-point Likert scale the "extent to which you are confident you can complete the following tasks" for activities such as "create explanations for the results of a study." The outcome variable of interest, commitment to a science career, was measured using a scale developed for this study to measure students' intentions to work in the field of science. The scale had seven items, also rated on a 5-point Likert scale, with items such as "I intend to work in a field of scientific research." In the final model, which also included engagement in scientific activities and science identity, science self-efficacy significantly predicted a commitment to a career in science, suggesting that it is a key psychological variable in success among URM students who are pursuing STEM-related degrees.

[3] Wang and colleagues (2013) conducted a study to enhance understanding of a critical part of success for URM students in STEM, their intent to choose a STEM-related 
major when entering college. To do so, they used structural equation modeling to test a conceptual framework that considered URM students' entrance into STEM majors at 4year institutions. Researchers surveyed students as they completed high school and again two years after high school. In the initial survey, students answered a variety of questions about their high school academic experiences, beliefs about their abilities, and plans for future education. At the second time point, students were asked to report on choices of college major and speak to aspects of their experience in college. Although the sample included 6,300 students from a variety of racial backgrounds, researchers grouped students into three racial categories (white, URM, and Asian) and conducted analyses separately. Self-efficacy was only considered in the domain of performing math tasks and measured with five items, each on a 4-point Likert scale, which represented students' beliefs about their abilities to perform well on a math test and complete math assignments. Researchers measured intent to pursue a degree in the STEM field by asking students for the most likely field of study they would pursue when going to college. For the underrepresented students in the sample, researchers used structural equation modeling to test the relationships between several motivational attributes, including math self-efficacy and intent to pursue STEM degrees. They found that intent to pursue STEM majors was positively and significantly predicted by math self-efficacy. Researchers suggested that self-efficacy had a positive effect on students' intent to pursue a STEM degree and in doing so, had an indirect effect on entrance into STEM disciplines at the higher education level. 
[4] In a mixed methods study with 140 African American college students, onethird of whom were declared STEM majors, Strayhorn (2015) examined the relationship between academic self-efficacy and GPA. This study was conducted in two phases starting with a survey using the Student Success Questionnaire, which was designed for this study by the author. Self-efficacy was measured using 3 items that related to students' beliefs about their academic abilities. In the second phase, in-depth interviews were conducted with a subset of the student participants. The quantitative analyses, which were conducted with Hierarchical Linear Modeling, added four variables including academic self-efficacy, sense of belonging, academic skills, and social skills to a regression equation seeking to predict GPA. Regression results indicated that academic self-efficacy was a statistically significant and positive predictor of the outcome of GPA for these URM STEM students. Furthermore, qualitative data corroborated this finding, highlighting that for many black males in STEM disciplines, self-efficacy was described in interviews as an important component of their academic success.

[5] Ballen and colleagues (2017) designed a study to examine the relationships between active learning, self-efficacy, and academic performance in the classroom. Participants included 254 students in a science course, which took place in fall 2014, and came from diverse backgrounds (35.9\% Caucasian, 34.9\% Asian American, and 21.4\% other racial backgrounds). Researchers grouped students into two categories; URM students as those who were African American, Latino, Pacific Islander, and Native American and non-URM students included those who are not underrepresented in STEM 
fields, mainly white and Asian American students. Researchers were particularly interested in whether positive gains in performance, which were expected to be associated with active learning strategies in the classroom, would be mediated by student's self-efficacy levels. Using Bandura's (1997) work on self-efficacy as a framework, researchers focused their conceptualization of self-efficacy on whether students felt confident comprehending, critically assessing, and communicating scientific concepts. The scale for measuring self-efficacy used was modified from an existing instrument (Robnett et al., 2015) in which students rated their confidence in their ability to complete course-relevant tasks in STEM. Student responses to these items were on a five-point Likert scale. Researchers used structural equation modeling and ran mediational path analyses to test the role of self-efficacy in the relationship between active learning and academic success, as measured by GPA, for URM and non-URM students separately. Results indicated that for URM students, an increase in self-efficacy mediated the positive effect of active-learning pedagogy on their academic performance. This significant effect was not present for non-URM students suggesting that selfefficacy may play a crucial role for URM students in STEM courses and they may need this positive self-appraisal to perform well in class. 
Table 2.2

Summary of Studies Considering Self-efficacy and Academic Functioning

\begin{tabular}{|c|c|c|c|c|c|}
\hline $\begin{array}{l}\text { Author } \\
\text { (year) }\end{array}$ & $\begin{array}{l}\text { Terminolo } \\
\text { gy and } \\
\text { Definition }\end{array}$ & Design & Participants & Methods and Scale & Results \\
\hline $\begin{array}{l}\text { Hackett } \\
\text { et al. } \\
\text { (1992) }\end{array}$ & $\begin{array}{l}\text { Self- } \\
\text { efficacy: } \\
\text { Bandura } \\
(1977)\end{array}$ & $\begin{array}{l}\text { Students } \\
\text { surveyed at } \\
\text { one-time } \\
\text { point }\end{array}$ & $\begin{array}{l}218 \text { engineering } \\
\text { undergraduates, } \\
\text { diverse sample, } \\
\text { 20\% Mexican } \\
\text { American }\end{array}$ & $\begin{array}{l}\text { Regression. } \\
\text { Self-efficacy scale, } \\
\text { Lent (1986) }\end{array}$ & $\begin{array}{l}\text { A significant } \\
\text { relationship } \\
\text { between } \\
\text { self-efficacy } \\
\text { and GPA }\end{array}$ \\
\hline $\begin{array}{l}\text { Chemers } \\
\text { et al. } \\
(2011)\end{array}$ & $\begin{array}{l}\text { Self- } \\
\text { efficacy: } \\
\text { Bandura } \\
(1977)\end{array}$ & $\begin{array}{l}\text { Students } \\
\text { surveyed at } \\
\text { one-time } \\
\text { point via the } \\
\text { web }\end{array}$ & $\begin{array}{l}327 \\
\text { undergraduates, } \\
89 \% \text { URM } \\
\text { students }\end{array}$ & $\begin{array}{l}\text { Science self- } \\
\text { efficacy scale } \\
\text { (Chemers et al., } \\
\text { 2011) }\end{array}$ & $\begin{array}{l}\text { Science self- } \\
\text { efficacy } \\
\text { significantly } \\
\text { predicted } \\
\text { commitment } \\
\text { to a career in } \\
\text { science }\end{array}$ \\
\hline $\begin{array}{l}\text { Wang } \\
\text { (2013) }\end{array}$ & $\begin{array}{l}\text { Math self- } \\
\text { efficacy: } \\
\text { Hackett \& } \\
\text { Betz, } \\
(1989)\end{array}$ & $\begin{array}{l}\text { Students } \\
\text { surveyed } \\
\text { during senior } \\
\text { year and two } \\
\text { years into } \\
\text { college }\end{array}$ & $\begin{array}{l}6,300 \\
\text { undergraduates } \\
\text { total, } 1,490 \\
\text { URM students }\end{array}$ & $\begin{array}{l}\text { Structural Equation } \\
\text { Modeling. Scale } \\
\text { included five items } \\
\text { related to math } \\
\text { performance using } \\
\text { a 4-point Likert } \\
\text { scale }\end{array}$ & $\begin{array}{l}\text { Intent to } \\
\text { pursue } \\
\text { STEM } \\
\text { majors was } \\
\text { positively } \\
\text { and } \\
\text { significantly } \\
\text { influenced } \\
\text { by math } \\
\text { self-efficacy }\end{array}$ \\
\hline $\begin{array}{l}\text { Strayhor } \\
\text { n (2015) }\end{array}$ & $\begin{array}{l}\text { Self- } \\
\text { efficacy: } \\
\text { Bandura } \\
(1977)\end{array}$ & $\begin{array}{l}\text { Students } \\
\text { surveyed at } \\
\text { one-time } \\
\text { point, } \\
\text { followed by } \\
\text { an interview }\end{array}$ & $\begin{array}{l}140 \text { black } \\
\text { undergraduates, } \\
\text { one-third } \\
\text { STEM majors }\end{array}$ & $\begin{array}{l}\text { Student Success } \\
\text { Questionnaire } \\
\text { (SSQ) (Strayhorn, } \\
\text { 2015) }\end{array}$ & $\begin{array}{l}\text { Self-efficacy } \\
\text { predicted } \\
\text { college } \\
\text { student GPA }\end{array}$ \\
\hline $\begin{array}{l}\text { Ballen et } \\
\text { al. } \\
(2017)\end{array}$ & $\begin{array}{l}\text { Self- } \\
\text { efficacy: } \\
\text { Bandura } \\
(1977)\end{array}$ & $\begin{array}{l}\text { Students } \\
\text { surveyed at } \\
\text { beginning } \\
\text { and end of a } \\
\text { one-semester } \\
\text { course }\end{array}$ & $\begin{array}{l}\text { URM students } \\
(\mathrm{N}=58) \text { and } \\
\text { non-URM } \\
\text { students } \\
(\mathrm{N}=196)\end{array}$ & $\begin{array}{l}\text { Structural Equation } \\
\text { Modeling, } \\
\text { Modified survey } \\
\text { questions from } \\
\text { Robnett et al's scale } \\
\text { (2015) }\end{array}$ & $\begin{array}{l}\text { A significant } \\
\text { relationship } \\
\text { between } \\
\text { sense of } \\
\text { self-efficacy } \\
\text { and course } \\
\text { grade only } \\
\text { for URM }\end{array}$ \\
\hline
\end{tabular}


Conclusions about the role of self-efficacy. Self-efficacy has a well-

documented relationship with academic success and persistence in higher education for all students seeking undergraduate degrees. Research to date has demonstrated that students' self-perceptions about abilities to complete necessary academic tasks in college shape their persistence and performance throughout their undergraduate career.

Research focused on scientific self-efficacy for URM students has shown that students' beliefs about their abilities matter a great deal in their chosen disciplines. Although levels of self-efficacy don't appear to differ drastically based on minority status, this self-appraisal may play a unique role for URM STEM students who often attend under-resourced secondary schools and face ongoing scrutiny regarding academic abilities on college campuses. Research has provided evidence that there is a positive relationship between self-efficacy and academic performance for URM students in STEM highlighting the importance of self-efficacy for students to succeed academically within courses for their major. For these students, self-efficacy also appears to predict a myriad of positive student outcomes such as intent to persist, commitment to a science-related career, and continuing to degree completion. When taken together, these results suggest that high levels of self-efficacy serve as an important motivational resource for URM students and support their academic success in STEM majors.

\section{Conclusions about Motivational Resources}

Consistent with a larger body of research showing that motivation is a salient predictor of academic success for students in K-12 settings, studies examining college 
students have found that motivation is important for students to succeed academically and persist to degree completion. At the college level, however, URM students face a variety of challenging background and contextual factors, such as being first-generation college students and experiencing racial discrimination on campus, which can negatively impact their motivation. Additionally, STEM disciplines are both cognitively demanding and academically rigorous, requiring sustained motivation for persistence. Hence, it is especially important for URM students in STEM to draw on resources that will help them stay motivated while pursuing their degrees.

Research has identified two vital motivational resources, a sense of belonging and self-efficacy, that may play crucial roles in helping URM students succeed in STEM disciplines. Research has shown that URM students in STEM experience a lower sense of belonging on campus than students from majority groups. Additionally, because of feelings of isolation and exclusion, their need for a sense of belonging on campus may be even more salient. Taken together, these two factors suggest that URM students in STEM may benefit from institutional efforts to nurture their feelings of connection on campus and within their disciplines. When considering self-efficacy among URM STEM students, research suggests that URM students, who have overcome a variety of negative experiences in previous academic environments and often face lower faculty expectations than non-URM students, may benefit from tailored, intentional, and sustained efforts by campus staff and faculty to increase their self-efficacy. 
The importance of both of these motivational resources is highlighted by research on college students showing that, consistent with broader research in K-12 students, a sense of belonging and self-efficacy have well-documented positive relationships with crucial aspects of academic functioning and success. For example, these motivational resources are key predictors of persistence and intent to remain in a STEM major. Although studies that explicitly examine these motivational resources for URM STEM students are limited, the robust research that has considered the importance of these motivational resources for the academic success of college students in general, coupled with what is known about the uniquely challenging experiences of URM STEM students, provide rationale for further consideration of the role of these motivational resources in the academic performance of this student population.

\section{Critiques of the Motivational Research on URM Students in STEM}

Although growing evidence suggests that a sense of belonging and self-efficacy may be important motivational resources for URM STEM students, several gaps remain that research can address. First, although broader educational research looking at URM college students has found evidence that these motivational resources shape the success of minority students, remarkably few studies have directly considered the relationship between self-efficacy or a sense of belonging and academic achievement for URM students in STEM disciplines. Understanding the link between motivational resources and academic performance for these students is critical because students' ability to perform well in STEM courses is a key ingredient to their long-term success in college. 
Given the importance of academic achievement for URM STEM student success, a deeper understanding of the extent to which these motivational resources contribute to academic achievement could help to identify an important lever through which more effective support can be provided for these students on their educational pathways.

Second, previous research suggests that both a sense of belonging and selfefficacy may serve as important motivational resources for URM students in STEM, yet most studies examine only one these self-appraisals individually. Both the feeling of belonging on campus and an individuals' beliefs about their ability to be successful in completing a task are at the core of student motivation. When looking holistically at the student experience, it is essential to consider both how they view their own abilities and how they perceive their fit within the college community. If both of these motivational resources play an important role in student success, then programmatic efforts to support these students need to focus on simultaneously cultivating a sense of belonging on campus and self-efficacy for students and be careful not to provide URM STEM students with programs that intentionally nurture one of these motivational resources but inadvertently neglect the other.

Third, the few studies on motivational resources to date focus primarily on selfefficacy and a sense of belonging as antecedents of academic success. Relatively few studies empirically examine how a sense of belonging and self-efficacy can be developed and sustained for URM students in STEM. As a result, little information exists to help institutions determine how to support students as they develop and build these 
motivational resources. If these motivational resources are the targets of current research training programs, a limited understanding of how a sense of belonging and self-efficacy can be developed and maintained could lead to the creation and implementation of programs that do not effectively support URM STEM students.

Fourth, although many studies considering the experiences of URM students in STEM use samples from undergraduate research training programs, very few of these studies consider the role that program participation plays in students' ability to develop and sustain a sense of belonging and self-efficacy as they proceed through college. As a result, there is limited understanding about the unique program components or experiences that may contribute to the development of motivational resources like a sense of belonging and self-efficacy. Because training programs often provide a myriad of services and supports for students, understanding the particular experiences that lead to positive outcomes is essential for future program implementation and success. 


\section{Chapter 3 : THE CURRENT STUDY}

The purpose this study is to broaden our understanding of two vital motivational resources, a sense of belonging and self-efficacy, and examine how they relate to participation in undergraduate research training programs and academic achievement for URM students in STEM. More specifically, this study sought first to examine the importance of participation in undergraduate research training programs in shaping a sense of belonging and self-efficacy for students. Second, this study aimed to consider the relationship between program participation and academic achievement, looking first at overall program participation and then testing whether the relationship differs for five specific program components. Third, this study examined the role self-efficacy and a sense of belonging may play in student success by considering how these two constructs relate to academic achievement for URM students in STEM. Finally, this study considered the potential role motivational resources play in explaining the relationship between program participation and academic achievement, paying particular attention to how mediational effects may differ between program components. The following sections summarize the empirical evidence that provides the rationale for each of these study aims. The chapter concludes with research questions.

\section{Benefits of Undergraduate Participation in Research Training Programs}

Undergraduate research training programs focus on initiating undergraduates into biomedical research careers with an emphasis on supporting students during their educational journey and exposing students to real-world scientific careers (Kinkead, 
2003). Results from studies examining the benefits of these programs suggest that participating in undergraduate research training programs may lead to several positive student outcomes including persistence, achievement, and intent to pursue a career in science. Although there have been widespread calls for more empirical evidence regarding the effectiveness of these programs for URM STEM students (Hausmann et al., 2007; Marra, Rodgers, Shen, \& Bogue, 2009; Seymour et al., 2004; Strayhorn, 2012), two recent systematic reviews of program benefits highlighted a range of positive outcomes for URM students in STEM (Hunter et al., 2007; Seymour et al., 2004). Among these outcomes are motivational resources and academic achievement, both essential components of success on the pathway to degree attainment for URM STEM students.

\section{Program Participation and a Sense of Belonging}

Although the importance of undergraduate research training programs in developing and maintaining a sense of belonging is widely hypothesized, relatively few studies have looked at the particular role of participation in shaping this self-perception for students (Judson et al., 2015). However, three studies considering this relationship have suggested that participating in research training programs may lead to a higher sense of belonging at college for URM STEM students.

The first study, by Seymour and colleagues (2004), was a qualitative inquiry study that considered the results of 76 interviews with URM STEM undergraduates who participated in a summer research training program. The study was a pilot, designed by 
researchers as "the first step in addressing some fundamental questions about the benefits (and costs) of undergraduate engagement in faculty-mentored, authentic research undertaken outside of class work, about which the existing literature offers few findings and many untested hypotheses" (2004, p. 500). With the long-term goal of helping develop measurement instruments for the evaluation of research training programs, researchers looked at a subset of the interview data in which participants described the benefits or costs of participating in their research training program. Researchers used a specific software tool, called "The Ethnography," designed to analyze interview transcripts to determine themes and frequency of themes from the interviews. Results indicated that $27 \%$ of URM STEM students described positive benefits from program participation related to an increased sense of belonging in science-related fields after engaging in these programs suggesting that participation may play a role in supporting URM STEM students' self-appraisals of belongingness within biomedical disciplines.

A review by Corwin and colleagues (2015) identified two additional studies that looked at URM STEM program participation and a sense of belonging. This review considered studies that provided evidence of the positive outcomes of course-based undergraduate research training experiences and research training internship experiences. Researchers identified 39 studies that met their criteria and considered the precise positive outcomes that programs claimed were a result of participation. Next, they considered whether there was adequate empirical evidence to support these claims. Researchers then categorized the level of sufficient evidence to support claims about the 
outcomes. In all, the review and analysis revealed eight "probable" outcomes, seven "possible" outcomes, and four "proposed" outcomes for URM STEM students resulting from program participation. One of the "possible outcomes" identified was a sense of belonging, which reviewers based on two empirical studies.

The first study was a qualitative study conducted by Jordan (2014) considering the efficacy of an intervention for URM students majoring in computer science. Researchers looked specifically at the experiences of 406 URM freshman across three universities and measured a sense of belonging by using a subscale of the previously created and tested Longitudinal Assessment of Engineering Self-Efficacy (LAESE) which was designed to measure students' sense of inclusion. A control group of URM computer science majors was used for comparison and data were gathered at two time points, before and after the intervention had been delivered to the treatment group. An independent groups t-test indicated first, that the intervention designed to increase underrepresented engineering students' sense of belonging had a positive and significant impact on students' sense of belonging when comparing pre and post-test scores. Second, results showed there was an increase in a sense of belonging over the semester after participating in the intervention which was significantly higher than the increase for underrepresented students in the control group suggesting that the intervention may be responsible for the higher levels of a sense of belonging for URM students in the treatment group. 
The second study looked at a specific program called OSTEP and was conducted by Tomasko and colleagues (2016). Students were provided programmatic opportunities designed to increase their sense of belonging in the university STEM community through a summer bridge program. Surveys were administered to five cohorts, with a total of 188 URM students, before and after their research training program participation. All items were on a 5-point Likert scale and asked students to respond to the prompt "Please indicate the degree to which you agree or disagree with each of the following." On the first survey, the questions included inquired about participant attitudes and feelings while the post-survey examined students' perceptions regarding the impact of the summer bridge program. In the post-survey, there were 14 items including "were part of a study group that would continue in the academic year" and "made friends." Additionally, participants responded to the open-ended question, "What impact do you think this program had on you?" Quantitative survey results were analyzed with descriptive statistics and significant mean differences were found in students' sense of belonging levels when comparing ratings before and after participating in the program. Qualitative analyses were analyzed with the assistance of content experts considering themes and frequency within student responses to the open-ended question on the survey. Results from this analysis suggested that a number of students may have gained a greater sense of belonging associated with their participation. Together, these results suggest that programmatic efforts designed to increase a sense of belonging for URM STEM students 
may be an important strategy to build and maintain this self-appraisal regarding fit in STEM for these students.

In addition to shaping a student's sense of belonging, undergraduate research training programs may also serve to buffer students' feelings of isolation on campus and participants in these programs may experience a higher level of connectedness to their campus and discipline. One study, by Walton and Cohen (2007) considered how program participation might shield against negative feelings of exclusion for URM STEM students. This study examined the possible outcomes of URM student participation in a small, theory-driven intervention designed to normalize doubts about social belonging. The intervention consisted of two experiments which tested what researchers called "belonging uncertainty" and the role a program might play in helping students overcome doubts about their belonging. Belonging uncertainty was conceptualized as a student's perception that people like them don't belong in a particular context and is considered to have a negative influence on the success and motivation of students. Researchers sought to examine whether there were differences in URM and non-URM students' belonging uncertainty in a STEM discipline in the college context. Researchers used two experiments and study participants included 77 undergraduate computer science majors, one-third of whom were URM students. Researchers used ANCOVA for analyses and performed planned contrasts between URM and non-URM students. The outcome of interest was a sense of academic fit which was measured with a scale including 17 items which assessed students' sense of social fit in the computer 
science department. Items were on a 5-point Likert Scale and included "People in [the] computer science department like me" and "I belong in [the] computer science department." In Experiment 1, students were led to believe that they had limited friends within their academic domain. They surveyed to students after this experiment to measure their sense of academic fit. Whereas White students were unaffected, Black students displayed a drop in their sense of belonging after this experiment. Experiment 2 was an intervention designed to mitigate doubts about social belonging in college raised the academic achievement (e.g., college grades) of Black students but not of White students. These results suggest that not only do URM students have a greater risk of feeling like they don't belong, campus interventions may be able to play a role in mitigating these negative self-perceptions and buffer them against the expected lower levels when considering their fit within their discipline.

Although these results suggest that undergraduate research training programs may be able to address URM STEM students' needs for a sense of belonging, the lack of systematic program evaluation across campuses has resulted in a limited understanding of the precise mechanisms by which sense of belonging may be developed within these programs. Given what is known about developing a sense of belonging for URMs in STEM, likely contributors to this increased sense of belonging are positive interactions with peers, structured mentoring relationships with faculty designed to promote instrumental and emotional support for students, and the opportunity to engage in research experiences with others. However, more information is needed to understand 
which elements of programs are essential for URM STEM students to feel a sense of belonging in their disciplines.

\section{Program Participation and Self-efficacy}

Undergraduate research training program participation has also been shown to increase minority students' self-efficacy. Researchers commonly explain this relationship using a theoretical framework by Lent (1994) called the Social Cognitive Career Theory (SCCT). SCCT is most interested in college students' career aspirations and posits that these are determined by students' self-efficacy which can be shaped by particular experiences while in college. Researchers believe that there are important social and psychological experiences in undergraduate research training programs that lead to increased self-efficacy. Ultimately, SCCT builds on Bandura's four source variables for self-efficacy development and provides a framework to consider the active ingredients in research training programs that may increase self-efficacy such as the chance to engage in hands-on research related tasks (which can serve as mastery experiences), an opportunity to connect with faculty and peers who are drawn to sciencerelated careers (which often leads to social persuasion), and structured mentoring relationships with senior students and researchers who provide support and guidance (a form of social modeling). Researchers posit that these experiences may increase students' self-efficacy as they continually build students' self-perceptions about their abilities to complete tasks within the scientific domain. 
Two specific studies showed an increase in URM STEM students' self-efficacy after they completed a research training program. The first was a qualitative case study with 47 undergraduate research training program participants from URM background by Carpi and colleagues (2017). In this study, researchers used the theoretical foundation of SCCT and used institutional record data, artifacts of student work such as student research proposals and publications, formal interviews with participants, and focus groups with students to understand the possible positive outcomes of participating in the program. Researchers transcribed interview and focus group recordings verbatim and then coded using an open emergent scheme to assist in the continual refinement of questions asked. The related codes that emerged were consolidated and put into categories that aligned with the Social Cognitive Career Theory framework. After analyses were completed, researchers suggested that participating in this multi-year undergraduate research training program positively impacted self-efficacy for students pursuing careers in science. Specifically, these students reported gains in self-efficacy during interviews and focus groups related to their skills as research scientists suggesting that program participation may help students gain confidence to complete the tasks needed to be successful in research settings.

In a second study with students who participated in a 5-week summer program, Strayhorn (2010a) examined whether a program designed to enhance the transition to college for students helped facilitate their adjustment to college, specifically looking at academic self-efficacy, a sense of belonging, academic abilities, and social skills. Data 
were collected longitudinally during the summer before students entered college, at the beginning of their first fall term, and at the end of their first semester in college.

Students were surveyed using the Summer Institute Survey (SIS), an 83-item instrument developed for this study by the principal investigator. The SIS has multiple dimensions, the subscale for academic self-efficacy included five items, asking students to rate their confidence in their ability to perform academic tasks such as "write a term paper." Responses were on a 7-point Likert Scale ranging from 1 (no confidence) to 7 (complete confidence). To measure whether students' academic self-efficacy increased after program participation, a paired-samples t-test was conducted to evaluate whether students' academic self-efficacy changed after participating in the program. Results indicated that students' mean academic self-efficacy at the end of the program was significantly higher than the mean academic self-efficacy prior to the program suggesting that participating in the program may have contributed to an increased self-efficacy for students.

Although these results demonstrate the role programs may play in improving selfefficacy for URM STEM students, more research is needed on how program participation can shape this motivational resource (Adedokun, Bessenbacher, Parker, Kirkham, \& Burgess, 2013). Future research could further examine the relationship between program participation and self-efficacy for URM STEM students, focusing on whether specific program experiences play a more significant role in shaping this self-appraisal for students. 


\section{Program Participation and Academic Performance}

At present, research considering how structured training programs in STEM disciplines relate to academic performance for URM students is limited. In past research, many studies have focused on psychological outcomes such as intent to persist in a science career or long-term outcomes such as entrance into a biomedical career. Although these outcomes are an essential piece of assessing program effectiveness, this focus leaves a gap in understanding regarding the immediate, positive outcomes of program participation for students. For instance, academic performance in particularly challenging science courses provides an important glimpse at how students are faring within their disciplines and serves as an important indicator of whether or not motivational resources are available to adequately support their learning and success. Additionally, poor academic performance can limit students' future graduate school and professional options.

Two studies have looked at the academic performance and achievement of URM STEM students participating in research training programs. The first was a study by Jones and colleagues (2010) which used a sample of 6,834 URM students who entered a large urban institution as biology majors. Researchers were seeking to examine whether academic performance could be associated with participation in an undergraduate research training program. Logistic regression was used to build a model predicting graduating with a degree in biology with a GPA of 3.0 or higher. Results indicated that participation in hands-on research was strongly associated with performance in biology 
courses (as measured by GPA) and that participating in research programming during the first two years of college was associated with a $240 \%$ increase in a student's odds of graduating with a degree in biology with a GPA competitive for admission to graduate or professional school. These results, which controlled for prior achievement and demographic characteristics, suggest that undergraduate research program participation may provide crucial experiences for students to achieve academically while navigating their undergraduate pathway.

A second study, conducted by Maton and colleagues (2000), included 93 URM STEM students who were participants in the Meyerhof Scholars Program and looked broadly at the benefits of program participation and the impact of factors such as SAT scores and high school GPA on student success. In particular, researchers considered the possible relationship between program participation and college GPA using 31 matched samples with students who were in the program and similar students who had declined the opportunity to participate. Each group contained 6 students, resulting in a total matched subsample of 186 URM undergraduate students. GPA was measured using institutional records taken at one time point in the middle of the treatment group's tenure in the program. A MANCOVA analysis indicated that the Meyerhof students achieved significantly higher GPAs in biomedical disciplines than students who had not participated in the program. These results, which show that students who participated in an undergraduate research training program consistently achieved higher grade point 
averages than similar students who did not participate, provide evidence that programmatic efforts to increase URM STEM student performance may be effective.

Research training program aims often focus on increasing psychological perceptions such as self-efficacy and sense of belonging, promoting positive interpersonal relationships through mentoring and peer interactions, and providing handson experiences which program staff posit will lead to higher academic achievement. For these students, however, academic success in challenging STEM courses is needed both for students to persist and for students to develop and sustain positive self-appraisals within these disciplines. To date, relatively few studies have considered the impact of research training programs on the short-term academic performance of students within STEM disciplines leaving a gap in understanding about the possible immediate academic benefits of program participation.

\section{Research Training Program Components}

As past reviews have indicated, although numerous studies have considered the success of research training programs holistically, few provide empirical evidence of the specific components that may lead to desired outcomes for students (Judson et al., 2015; Seymour et al., 2004). Research training programs vary drastically in design and often change structures or strategies throughout implementation, making it challenging to evaluate program components individually. However, a majority of these programs are built around several shared experiences for students that could serve as active ingredients in their success. Chief among these experiences are supportive mentoring relationships, 
hands-on research experiences, and professional development workshops. The current study seeks to examine if levels and quality of participation in any of these experiences are more important than others in the development of motivational resources and academic achievement. In the next section, information from past research about the relationship between these three elements of program participation and positive student outcomes will be summarized.

\section{Mentoring}

Nearly every program that seeks to support URM students in STEM has a mentoring component. According to Hurtado and colleagues (2009), undergraduate research initiatives that provide supportive mentoring relationships can assist to acquaint students with scientific norms and allow students to develop "science orientation" in their undergraduate experience. Broadly, mentoring in these research training programs has been defined as a collaborative learning relationship that proceeds through intentional stages over time with the central goal of supporting mentees as they gain crucial skills for success in their chosen career (Pfund, Byars-Winston, Branchaw, Hurtado, \& Eagan, 2016). Faculty serve as mentors and use their own experience and expertise to guide students on their pathways with a variety of strategies including active listening as students reflect on their college experiences, assistance with networking, and support in graduate school preparation.

The roles and responsibilities of mentors within programs vary widely. For instance, students are often paired with a faculty member in a supportive relationship 
outside of structured research settings or academic coursework to provide support for students navigating challenges in both their personal and academic lives on campus. Each of these mentoring dyads is unique, and mentors offer support and guidance on a range of topics including overcoming academic challenges, considering career options and trajectories, and balancing academic and personal demands. This type of mentoring has been shown to have positive effects on student retention and academic performance (Campbell \& Campbell, 1997). Additionally, students who report more support from their faculty mentors are also more likely to report plans to attend a graduate STEM program (Hurtado, Clayton-Pedersen, Allen, \& Milem, 1998).

Another key role that mentors play in these program settings is supporting students within hands-on research experiences. The role of this type of mentor usually includes onboarding and training students, providing ongoing supervision, and giving constructive feedback to students as they engage in research activities. For example, a research mentor may train students to use lab equipment properly and provide ongoing feedback about student performance on particular tasks.

In a review of 60 studies that were designed to examine the effectiveness of undergraduate research training programs, Linn and colleagues (2015) found that "the most convincing studies show benefits for mentoring" (p. 1). Throughout these studies, researchers found evidence that mentors play a significant role in helping undergraduates deepen their understanding of science and guiding them as they develop a scientific identity. To be most supportive, mentors can help students develop and integrate a fuller 
understanding of their research experience, participate in scientific activities such as conference presentations and poster sessions, and provide insights into the culture of the discipline or lab. However, notably, researchers also found that these 60 studies suggested a significant tension between mentor availability and mentor impact as students appear to need more time with mentors than mentors have available.

Additionally, mentors rarely receive training, guidance, or support regarding how best to mentor undergraduate students from URM backgrounds, suggesting that the quality of mentoring may vary wide between relationships.

Although research has shown that these mentoring relationships relate to positive student outcomes, there is only marginal evidence of the active ingredients necessary for these outcomes. Jacobi (1991) conducted the first review of the undergraduate mentoring literature which surfaced some critical issues around methods and interpretation with higher education mentoring research up to 1989. In particular, Jacobi identified that a common definition of mentoring in higher education was missing and that the methods employed to examine the effectiveness of mentoring were insufficient. Additionally, Jacobi surfaced several widespread limitations in studies examining the impact of mentoring on college student success including small sample sizes, lack of a control group for comparison, a lack of reliable measurement tools, and limited studies with more than one time point. Following that review, Crisp and Cruz (2009) reviewed the mentoring literature over the next period covering 17 years, from 1990 through 2007, and identified similar limitations and gaps in research. 
The third and most recent review, by Gershenfeld (2014), extended the literature by reviewing undergraduate mentoring studies from 2008 through 2012. Twenty studies met the inclusion criteria, which only included studies with empirical research on formal mentoring programs on college campuses with undergraduate students. Each study was assessed based on the key limitations identified in the two earlier reviews of the mentoring literature which included the presence of a definition of mentoring, the strength of the theory used in the program implementation, and the appropriateness of study methods. Gershenfeld carefully considered the methodological rigor of each study, the function or role of the mentor in each study, and the validity of the findings. Results from this review indicated that "minimal progress" has been made in these three areas over the past two decades and consistent with the first two reviews, there were still significant deficiencies in mentoring research. Gershenfeld attributed this to a lack of a consistent definition of mentoring, an absence of a guiding theoretical framework for mentoring programs, and the other numerous previously uncovered methodological limitations.

Although mentoring is often elevated as an effective strategy for supporting URM STEM students on their pathway to biomedical careers, the gaps in previous mentoring research and lack of in-depth understanding regarding which key characteristics of these relationships are most important to support students, leave programs without an empirical foundation to assist in mentoring program design and implementation. Furthermore, there remains limited understanding for institutions regarding how to structure mentoring 
relationships and train mentors to be successful working with URM STEM students within research training program settings.

Mentoring relationship dosage and duration. While some programs operate under the assumption that short-term contact with mentors is enough to provide the support needed for success, others believe that students must be matched with mentors for a minimum of one academic year. Although empirical evidence on this is limited, researchers hypothesize sustained mentoring matches may allow students to reap important benefits from their mentoring relationship. For instance, a study that looked at students who were in a yearlong relationship found that after one year of mentoring by faculty, students had higher GPAs and were more likely to stay in college compared to academically similar students without mentors (Campbell \& Campbell, 1997). In another study, researchers found that students who spent a sustained amount of time working with their mentors on research (more than a summer or semester) reported significant gains in confidence in their research skills, independence, and understanding of the research process (Haeger \& Fresquez, 2016).

In their review of the mentoring literature, Gershenfeld (2014) considered how the duration and frequency of meetings in the studies they reviewed may have contributed to student outcomes. However, they found that there was significant variation in how programs reported information regarding the amount and frequency of contact. For example, in $65 \%$ of the studies, no information was provided on the duration of the mentoring relationships. For 55\%, there was no information regarding the frequency of 
meetings. When duration and/or frequency information was provided, there was lack of consistency. For example, some studies looked at the frequency of meetings but were not specific about the amount of time dyads spent in each meeting and others did the opposite. Given the central role of mentoring in undergraduate research training programs, understanding how dosage may influence student outcomes is essential to building mentoring programs that best support URM STEM students.

Mentoring and motivational resources. In addition to persistence in STEM, mentoring has also been positively associated with students' sense of belonging and selfefficacy (Byars-Winston et al., 2016; Chemers et al., 2011; Eagan et al., 2013; David Lopatto, 2007; Thiry, Laursen, \& Hunter, 2011). Although empirical evidence is limited for the link between mentoring and a sense of belonging for URM STEM students, faculty and student interactions are important to a sense of belonging across groups and disciplines and researchers hypothesize that these interactions within programs may influence URM STEM student's perception of their fit at college and buffer against feelings of isolation. Furthermore, mentors may provide much needed support to students who are navigating challenging and inequitable environments and protect students against some of the adverse effects of these ongoing negative experiences. In a qualitative study that examined the influences of proximal exchanges within the mentoring relationship, researchers examined how these interactions may lead to an increased sense of belonging. Among the 174 undergraduate URM STEM participants, students who rated their mentors higher in culturally relevant mentoring skills also felt 
more connected to their fields of study and felt a greater "sense of belonging in the research world" (Haeger \& Fresquez, 2016). This study provides evidence that particular mentor characteristics may be more salient than others in supporting URM STEM students' sense of belonging.

Research has also shown that mentoring relationships with faculty can influence the self-efficacy of URM STEM students. Two studies have specifically examined how faculty mentoring in research training programs may shape self-efficacy for URM STEM students. In the first, Chemers and colleagues (2011) conducted a study with 327 undergraduates examining the relationship between students' science support experiences, including faculty mentoring relationships, and a variety of psychological variables including scientific self-efficacy. They found that for the undergraduate students, there was a strong relationship between instrumental mentoring and science self-efficacy, suggesting that students who had greater involvement in mentoring relationships were more confident that they could perform the functions of a scientist and had higher levels of science self-efficacy.

A second study, by Carpi and colleagues, (2017) which was previously discussed, examined a research training program that had mentoring as its core focus. Results indicated that program participants showed a significant increase in self-efficacy as a result of engaging in the program which led researchers to suggest that the supportive mentoring relationships between students and faculty may be of key importance in program's potential influence on student self-appraisals. When taken together, these 
results suggest that mentoring relationships may serve to build up students' self-efficacy by providing a supportive and nurturing relationship for students as they persist through challenging experiences on campus and within their disciplines.

\section{Hands-on Research Experience}

Similar to mentoring, nearly every research training program includes an opportunity for students to engage in hands-on research experiences. These research placements are most often large, grant-funded projects where students gain exposure and experience in real-life research settings. This opportunity has been linked to several positive outcomes for URM students including increased retention in biomedical fields and increased likelihood of attending graduate school (David Lopatto, 2007; Nagda et al., 1998). In Seymour's (2004) review of studies considering the positive benefits of undergraduate research program participation, $91 \%$ of students' evaluative statements across studies provided evidence for specific positive benefits gained from hands-on research experience including providing real-world work experience, providing the opportunity to network with faculty, peers, and other scientists, getting exposure to new opportunities/experiences, and enhancing graduate school and career preparation. According to reviewers, this finding "lends substantial support to the proposition that undergraduate research is an educational and personal-growth experience with many transferable benefits" (2004, p. 530).

Studies have found that longevity in research placements is an important consideration in program design. Researchers posit that extended periods of participation 
in undergraduate research experiences may be significant because students need time to gain confidence in their disciplines and more time on the project provides increased levels of peer and faculty contact (Pascarella \& Terenzini, 1991). Additionally, longevity in research placements may increase motivation because the extended amount of time and effort of investment increases students likelihood to persist to degree completion (Jones et al., 2010). In summary, research to date suggests giving students the opportunity to participate in meaningful research activities over a substantial amount of time may be an important contributor to their motivational resource development and ability to successfully transition into a biomedical career.

Research experience and motivational resources. Hands-on research experience is hypothesized to be central to URM student success because of the sustained exposure to real-world science environments, access to faculty and peers engaging in research, and opportunities to "do science" for students. Although no studies to date have explicitly examined the relationships between participating in these experiences and developing a greater sense of belonging for URM STEM students, what is known about the effectiveness of this program component more generally suggests that work in labs and with research teams may serve a variety of functions for URM STEM students including increasing their feelings of belonging in scientific environments.

Hands-on research experience has a well-documented relationship with selfefficacy for students. Given what is known about the development of self-efficacy, it is posited that the opportunity to complete scientific tasks and get feedback on those tasks, 
in addition to watching others in the lab complete research related work, increases students' self-perceptions about their abilities to complete the required tasks with STEM disciplines. Three studies have examined this relationship directly.

In the first study, Hurtado and colleagues (2009) conducted focus group sessions with 65 URM STEM student participants who formed a racially diverse group. Women constituted $62 \%$ of the sample, and the majority of students ( $72 \%)$ were biology, biochemistry, or chemistry majors. Researchers then thematically coded the transcripts and used NVivo software to organize the findings into common themes. Results indicated that students who participated in hands-on research experiences had a strong sense of self-efficacy which students attributed feeling like they were "doing science" in their research placements within programs. These findings provide insight into the importance of opportunities to engage in research related activities for students to develop beliefs about their ability to complete particular science related tasks.

In a second study, Chemers and colleagues (2011) conducted a study with 327 undergraduates URM STEM students who were part of the Society for Advancement of Chicanos/Hispanics and Native Americans in Science (SACNAS) to examine the relationship between students' research experience and self-efficacy. Students were given a survey measuring numerous constructs. Self-efficacy was conceptualized building on the work of Bandura (1997), Chemers et al. (2011), and Kardash (2000). Researchers used the science self-efficacy scale to assess students' confidence in their abilities to complete particular scientific tasks. Students indicated the "extent to which 
you are confident you can successfully complete the following tasks" for ten research related activities including "use scientific language and terminology" and "create explanations for the results of a study." Students responded on a 5-point scale that ranged from 1 (not at all confident) to 5 (absolutely confident). Researchers tested their model using a series of path analyses using maximum likelihood estimation. Results from these analyses indicated a strong and positive relationship between participation in research experiences and student's self-efficacy suggesting that these hands-on research experiences may support the development in URM STEM students' increased confidence in their abilities to be successful in scientific disciplines.

Russell and colleagues (2007), conducted a study by surveying 4,500 undergraduate students about their research experience in structured research training programs. Using descriptive statistics, researchers found that the research experience within the program was significantly correlated with self-efficacy for students. This study also found that the duration of research experience played a role in this relationship such that students in more extended research placements reported higher levels of selfefficacy. This suggests that the self-efficacy of undergraduate researchers is built through ongoing, incremental, and iterative experiences where they can conduct, propose, and present research to an increasingly broad and professional audience over time.

The results from these studies elevate the importance of hands-on research experience in the development of motivational resources, specifically in supporting 
students' development of self-efficacy. However, more research could provide insight into how these experiences shape a sense of belonging for students.

\section{Professional Development Workshop Participation}

Nearly all undergraduate research training programs offer regular opportunities to participate in workshops designed to support students' personal and professional development. These workshops are a chance for students to connect with peers, prepare for various academic milestones, and get assistance to prepare for the graduate school admissions process. Although this program component is central to many program models designed to support and train URM students, studies to date have not isolated this experience to consider the impact of workshop participation as a unique component of program participation. However, as previous research on undergraduate research training programs has indicated, the opportunities for students to connect with other URM STEM students, gain access to important information regarding success in higher education STEM disciplines, and build positive relationships with faculty is a likely contributor to the positive impacts that may be associated with participating in these programs.

\section{Motivational Resources as Mediators}

As previously discussed, research has demonstrated that self-efficacy and a sense of belonging have positive relationships with academic achievement and persistence in higher education. These relationships have been considered in the context of undergraduate research training programs in past studies. The current study considered the role these motivational resources play for URM students in STEM and how they may 
mediate relationships between program participation and achievement. Next, research on the mediational role of a sense of belonging and self-efficacy in programs for URM STEM students will be reviewed.

\section{A Sense of Belonging as a Mediator}

A sense of belonging may be a central motivational resource for URM students in STEM, but past research has not examined this phenomenon as a mediator within undergraduate research training programs. In fact, Strayhorn, in his review of studies considering a sense of belonging for URM STEM students concluded that more information about how a sense of belonging works "is sorely needed, as it may provide clues to strategies that, if properly mounted, hold promise for effectively increasing the number of minorities in our nation's most critical areas." (2012, p. 68). The literature has demonstrated that not only is a sense of belonging a basic psychological need for humans, it is even more salient for URM STEM students due to the challenges they face at college. Given the importance of this self-appraisal, it is important to understand if it has a role in the relationship between program participation and academic success for these students. This could elevate the importance of building programs that support this self-appraisal in URM STEM students and contribute significantly to supporting URM students in research training programs. 


\section{Self-efficacy as a Mediator}

Recent research has suggested that self-efficacy may serve as a mediating factor between undergraduate research experiences and desired program outcomes. Four studies, all conducted in the last decade, have examined the role of self-efficacy in explaining how undergraduate research educational experiences may be influencing student outcomes such as persistence and achievement.

In a recent study, Ballen and colleagues (2017) were interested in how active learning in STEM classrooms may have more salience for URM student success than for non-URM students. In particular, researchers wanted to understand the possible role of scientific self-efficacy in the relationship between active learning in the classroom and academic performance for URM STEM students. Researchers were also interested in the role self-efficacy might play in explaining the relationship between several covariates of interest (gender, pre-course preparation, and semester in school) and academic performance. To measure students' self-efficacy, researchers modified survey questions from an existing instrument (Robnett et al., 2015) in which students rated their confidence in their ability to complete STEM course-relevant tasks. Preparation was measured using a composite of SAT scores and math scores. Academic performance was measured with course grade and GPA. Researchers used structural equation modeling and ran mediational path analyses to test the role of self-efficacy mediating the relationship between these covariates and academic success. Results showed that selfefficacy had a unique relationship with the performance of URM students in that self- 
efficacy entirely mediated the relationship between previous academic preparation and academic performance as well as semester in school and academic performance. Additionally, self-efficacy mediated the positive effect of active-learning in the classroom on both metrics of student performance.

The next two studies come from the work of Chemers, a well-known scientific self-efficacy researcher, who was interested in better understanding how self-efficacy may relate to a variety of predictors and outcomes that are key for college student success. In the first study, Chemers and colleagues (2001) were curious about the role of cognitive, motivational, and affective processes in the success of college students in their first year. Using previous literature on self-efficacy, researchers posited that academic self-efficacy would have a significant and profound impact on the academic performance of first-year college students, adjustment to the demands and challenges of college life, and the overall health of students. They expected to find direct effects of self-efficacy on performance, health, and adjustment and also hypothesized that self-efficacy would mediate the relationships between pre-college GPA and optimism and the outcomes of interest. Stress and academic expectations were also included in the hypothesized model as researchers believed these things could play a role in these relationships. The sample included 373 first-year students who were surveyed once at the beginning of winter term and again at the end of spring term. Pre-college GPA was measured using final high school GPA and optimism was measured using the life orientations test (Scheier \& Carver, 1985) which included 11 items designed to measure general optimism about life. 
Self-efficacy was measured using an eight-item measure which was developed for the study in which participants rated their agreement with statements reflecting their confidence in their ability to succeed academically on a 7-point Likert scale. Adjustment was measured with Pascarella and Terenzini's (1980) college social support scale which included subscales measuring satisfaction with academic progress and intention to persist at the university. College academic performance was measured using narrative course evaluations that faculty provided for each student which were converted to a quantitative score by researchers. To test their hypothesized model, researchers used structural equation modeling. Results indicated that not only did self-efficacy have a direct effect on academic performance and adjustment to college, it also had significant mediated effects between both antecedents, high school GPA and optimism, and both outcomes, performance and adjustment. These results demonstrate that self-efficacy likely plays a significant role in the relationships between previous academic performance and outlook on life and important outcomes during the first year of college suggesting that students' confidence in their ability to perform well academically is a key ingredient for their successful transition to college.

In a second study by Chemers and colleagues (2011), using a national sample, researchers were interested in the experience of URM students in structured research training programs and the role that self-efficacy may play between their participation and intent to pursue a science related career. More specifically, researchers wanted to examine how psychological processes, like scientific self-efficacy, might explain the 
relationships between support components that exist in undergraduate research training programs and a student's commitment to a science career. The psychological process of interest included scientific self-efficacy, leadership self-efficacy, and identity as a scientist. Support components included instrumental mentoring, research experiences, community involvement and socioemotional mentoring. Based on Chemers' earlier studies about self-efficacy, researchers used a mediation model to predict that the psychological variables of science self-efficacy, leadership self-efficacy, and identity as a scientist would mediate the effects of science support experiences on students' commitment to a science career. The sample included 327 URM STEM undergraduate students from universities across the United States. Surveys were administered electronically. To isolate the effects of program participation, students reported how active they were in program activities using a 5-point scale ranging from 1 (not at all) to 5 (a lot). Self-efficacy was measured using students' responses to questions that asked them to rate the "extent to which you are confident you can successfully complete the following tasks." This included a 10-item scale including "use scientific language and terminology" and "create explanations for the results of a study." The outcome variable, intent to pursue a career in science, was measured by a scale of seven items, rated on a 5point Likert scale ranging from 1 (strongly disagree) to 5 (strongly agree). An example item was "I intend to work in a field of scientific research." The conceptual model was tested through a series of path analyses using maximum likelihood estimation. After initially running the model to look at direct effects, researchers dropped all nonsignificant 
paths. In the final, trimmed model, results concluded that scientific self-efficacy fully mediated the effects between two program components (instrumental mentoring and research experiences) and their commitment to pursue becoming a scientist.

A fourth and final study was conducted by Adedokun and colleagues (2013) and was designed to address gaps in understanding about the "logical relationship among outcomes, the processes through which they are achieved, and the contextual and participant factors at play" when it came to URM student participation in structured research training experiences. To better understand these relationships, researchers tested a hypothesized model of the mediating effect of participant research self-efficacy on the relationship between their research skills and personal desire to persist in STEM. Data for this study came from 156 students that participated in a research training program at a Research I University in the Midwest. For this study, research-self efficacy was a latent variable and items were modified from a scale created by Kardash (2000) in which students responded to five questions using 4-point Likert Scale. These items included "I have the ability to have a successful career as a researcher" and "I possess the motivation and persistence required for a career in a research-oriented field." Researchers used Structural Equation Modeling, with Maximum Likelihood Estimation, to test their model. Results indicated that both research skills and research self-efficacy predicted students' intent to pursue a career in scientific research and the effects of research skills on this intent was partially mediated through the self-efficacy beliefs of students. 
The results of these four studies, when considered together, suggest that selfefficacy may play a significant role for URM STEM students who engage in STEM research training programs. Within these programs, participation may shape students' beliefs about their abilities and this may catalyze better academic performance and other desirable outcomes such as graduate school entrance.

\section{BUILD EXITO: A Multi-level Model to Support URM STEM Students}

The purpose of this study is to consider how two motivational resources, a sense of belonging and self-efficacy, relate to program participation and academic achievement for URM students in STEM. A significant contribution of the study is the consideration of these relationships examining five distinct program components within an undergraduate research training program. The study looked at students participating in an undergraduate research training program, BUILD EXITO, which takes place at a large urban university.

As part of the NIH BUILD initiative to diversify the scientific workforce, the EXITO project seeks to provide extensive support and training for undergraduates from traditionally underrepresented student populations who are pursuing health-related research careers. Portland State University, which is a major public urban university, and Oregon Health \& Science University, a research-intensive academic health center, lead the EXITO network. The network links eleven higher education institutions across the 
Northwest Pacific region including 2-year colleges and 4-year universities which are located in Oregon, Washington, Alaska, Hawaii, the Northern Mariana Islands, Guam, and American Samoa.

The EXITO project focuses on training diverse scholars from indigenous and underserved communities affected by adverse health disparities. EXITO is a three-year program that supports students on their pathway to pursue biomedical research careers by focusing on four critical elements: a supportive environment, integrated curriculum, developmental mentoring, and research experience. All institutions in the EXITO network share these foundational components of the EXITO model but precise implementation differs based on the needs of the particular institution and their unique student population.

The program model is complex and involves a series of supportive mechanisms that are scaffolded together for students over the course of their engagement in the program. Some components are consistent throughout the duration of the program while others occur in a particular program year. A detailed illustration of the program components that constitute the EXITO Scholar Pathway and how they are implemented over the course of the three-year model can be found in Figure 3.1.

EXITO provides students with a supportive environment by offering tailored academic advising, a student lounge and computer lab dedicated for EXITO student use, and 
connections to campus opportunities and services. The integrated curriculum of BUILD EXITO includes a required Gateway course that students take their first year in the program. This course is designed to teach students about research methods and the responsible conduct of research. Additionally, Scholars engage in regular enrichment workshops and training seminars designed to socialize Scholars into science careers.

The EXITO model uses a three-tiered approach to mentoring. At the beginning of their time in the EXITO program, students are matched with a faculty career mentor. This faculty member advises students on academic and career planning, helps them set goals, and provides additional support as they navigate the many demands of their coursework and discipline. At this time, EXITO students also get matched with a peer mentor who is an advanced undergraduate student. Peer mentors help students with academic and personal issues and assist them in gaining access to campus resources. After being placed in their Research Learning Community, which takes place at the beginning of the second year in EXITO, students get a research mentor who provides training for their research placement, guides them as they get acclimated to their role and responsibilities, and provides ongoing oversight as they learn the fundamentals of working on an established research project.

A cornerstone of the BUILD EXITO program is the hands-on research experience which is an 18-month placement in a Research Learning Community (RLC). Students engage in meaningful research activities on an externally-funded research team and often have the opportunity to contribute to scientific posters, presentations, and publications. 
During the summer before their second year in EXITO, they participate in a 4-week Summer Induction which includes professional development workshops twice each week and time getting acclimated in their lab. Then, they spend 10 hours each week throughout the school year working in their RLC. The following summer, which is their final summer in EXITO, students participate in a 10-week long Summer Immersion, which includes weekly journal club, ongoing professional development sessions, and approximately 16 hours each week working on research in their lab. At the end of this summer, students present their research at a Summer Research Symposium for the broader EXITO community. During their final program year, students continue on at 10 hours a week in their lab.

Based on availability of data, the current study focused on five of these components including the dosage and quality of career mentoring relationships, the dosage of research experience and quality of research mentoring, and participation in the enrichment workshops. 


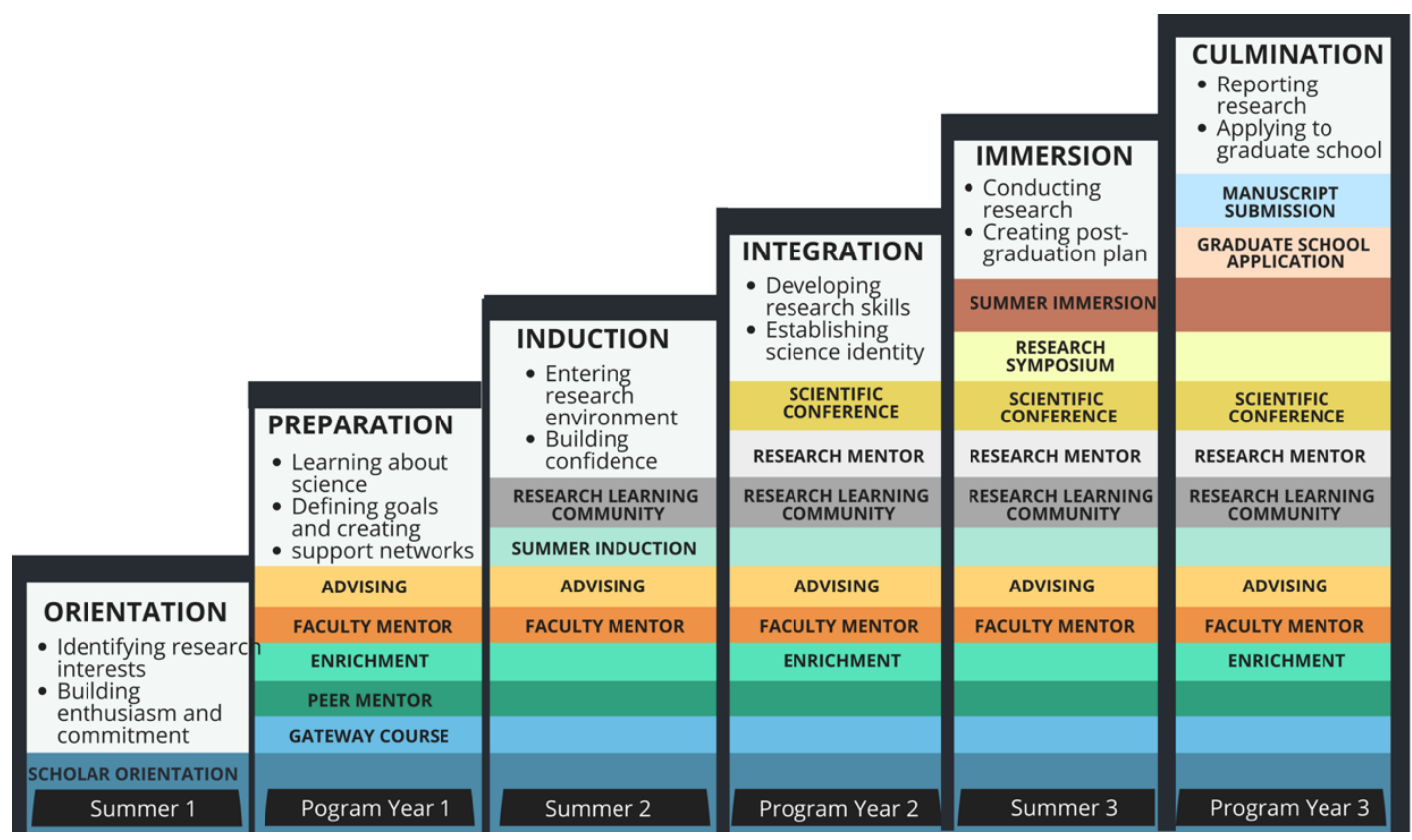

Figure 3.1. The BUILD EXITO Scholar Pathway.

\section{Research Questions}

Research broadly considering the effectiveness of undergraduate research training programs for URM students in STEM has found that program participation may be linked to positive student outcomes. However, detailed and thorough evaluation plans are often not embedded within these programs and as a result, very few studies have considered the role of these training programs in shaping the motivational resources of students. Thus, there is limited information about the ways in which program participation may be supporting students' motivational resources on their pathways to biomedical careers and little is known about what programmatic components are most important for the development of students' sense of belonging or self-efficacy. This study set out to fill this gap in the literature by considering whether program participation as a whole supports a 
sense of belonging and self-efficacy for URM STEM students and whether specific program components are more likely to nurture these students' sense of belonging and self-efficacy at college.

Although undergraduate research training programs are focused on enhancing student performance, only a limited number of studies have looked at the impact of program participation on the academic achievement of URM students within STEM disciplines. This study added to the literature on the effectiveness of undergraduate research training programs by examining the link between program participation and student achievement.

Research in higher education for URM STEM students points to a host of positive outcomes that may result from mentoring relationships but lacks adequate information about how mentoring roles, dosage, and quality may play a role in the effectiveness of these relationships. The current study addressed these gaps in two ways. First, the study considered two different mentoring roles that are common in research training programs. The first mentor is a supportive faculty member who meets with students outside of structured research experience to serve as a supportive guide through their undergraduate experiences. The second mentoring relationship will be within a hands-on research environment where students are supported and supervised by mentors as they complete a variety of science-related tasks. The study also paid close attention to whether these mentoring roles differentially shape motivational resources or academic achievement for URM STEM students. Second, the current study considered student reports of the quality 
and dosage of meetings with mentors to understand what role the amount and perceived quality of contact between mentors and mentees have might play in their subsequent development of motivational resources and academic success.

Research to date suggests that two motivational resources, a sense of belonging and self-efficacy, may play valuable roles in the success of URM students in STEM. Although both have emerged as potentially important components of success on the pathway to degree attainment for URM STEM students, the link between these motivational resources and academic performance has not been widely studied. This study added to the body of work regarding URM STEM student academic achievement by examining how motivational resources might contribute to the academic performance of URM STEM undergraduates.

To date, studies that have considered the motivational resources of URM STEM students often isolate a sense of belonging or self-efficacy and consider the individual role of each one in student success. However, when considered together, results from these studies suggest that URM STEM students likely need both of these self-appraisals to persist to degree completion. By examining a sense of belonging and self-efficacy, the current study provided additional information about the centrality of both of these motivational resources for URM STEM student success and encourage programmatic efforts to holistically support students as they navigate the challenging educational environment in STEM disciplines. 
The motivational resources that students draw on to persist in challenging college environments, a sense of belonging and self-efficacy, may help explain the relationship between participating in an undergraduate research training program and academic outcomes. For instance, the mediational role of self-efficacy was examined in past studies and results indicated that it significantly explained the relationship between participation in several undergraduate research training program activities and positive student outcomes such as scientific identity and intent to pursue graduate school. The current study added to the self-efficacy literature by providing additional evidence of the mediational effects of self-efficacy on the relationship between research training program experiences and achievement and examine if this relationship is similar for the other key motivational resource, a sense of belonging.

The current theoretical model, Figure 3.2, proposes that a sense of belonging and self-efficacy mediate the relationship between program participation, broadly, and academic performance. Program participation is conceptualized and examined both broadly, and along five discrete program components; quality of career mentor, dosage of career mentoring, quality of research mentorship within hands-on research placement, dosage of hands-on research experience, and participation in professional development workshops. This study addresses the following research questions, which are divided into two categories. The first set of questions focuses on the effects of program participation on both motivational resources and academic achievement. The second set explores the effects of motivational resources on academic achievement and considers the 
possible mediational effects of a sense of belonging and self-efficacy on the relationship between program participation and academic achievement.

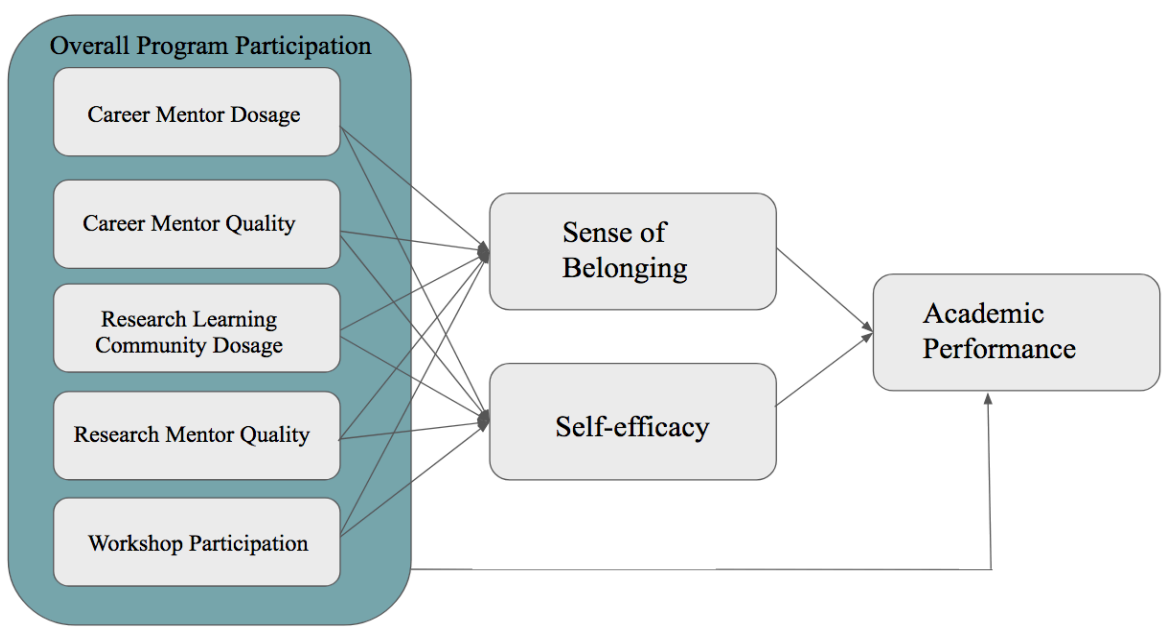

Figure 3.2. The Conceptual Model.

\section{Research Questions and Hypotheses}

\section{Effects of Levels of Program Participation}

Research Question 1: Do students' levels of participation in an undergraduate research training program predict their levels of motivational resources, such that students with higher levels of program participation have higher motivational resources whereas students with lower program participation have lower motivational resources?

R1a: Do students' levels of participation predict their sense of belonging?

R1b: Do students' levels of participation predict their self-efficacy?

R1c: Does each particular program components play a significant role in predicting these motivational resources? 
Hypothesis 1. Participation in an undergraduate research training program will positively relate to students' sense of belonging and self-efficacy.

Research Question 2: Do students' levels of participation in an undergraduate research training program predict their academic performance, such that students with higher quality and/or dosage of program participation have higher performance whereas students with lower quality and/or dosage of program participation have lower performance?

R2a: Does overall program participation play a play a significant role in predicting students' academic performance?

R2b: Does each particular program components play a significant role in predicting students' academic performance?

Hypothesis 2. Program participation will predict academic achievement for students such that students with higher levels of program participation will have higher academic performance whereas students with lower levels of motivational resources will have lower academic performance.

\section{Role of Motivational Resources}

Research Question 3: Do student motivational resources (i.e., sense of belonging and self-efficacy) predict their levels of academic performance, such that students with higher motivational resources have higher academic performance whereas students with lower levels of motivational resources have lower academic performance?

R3a: Does student sense of belonging predict academic performance? 
R3b: Does student self-efficacy predict academic performance?

Hypothesis 3. A sense of belonging and self-efficacy will predict academic achievement for students such that students with greater motivational resources will have higher academic performance whereas students with lower motivational resources have lower academic performance.

Research Question 4: Do students' motivational resources explain the effect of their levels of program participation on academic performance?

R4a: Do students' levels of participation shape academic performance through its effects on a sense of belonging?

R4b: Do students' levels of participation shape academic performance through its effects on self-efficacy?

R4c: Does the mediating effect of motivational resources on the effect of program participation on academic performance differ depending on the specific program component?

Hypothesis 4. A sense of belonging and self-efficacy will play a role in explaining the relationship between program participation and academic achievement for students. 


\section{Chapter 4 : RESEARCH DESIGN AND METHODS}

The current study used data collected from BUILD EXITO program participants. This study examined the student experience of URM students with declared STEM majors participating in a three-year undergraduate research training program at a large urban university in Oregon and partner campuses throughout the Pacific Northwest and Pacific Rim. As part of their participation in the program, students were asked to complete regular surveys about their engagement in program-related activities, their experiences in hands-on research settings and mentoring relationships, and their perceptions of their own abilities and fit in science.

\section{Participants}

Participants were a sample of 137 undergraduate students who were engaged in the BUILD EXITO program. All participants had completed at least one full year of coursework and had declared a major in a biomedical field. This sample includes students from two separate cohorts: Cohort 1, who began in the Fall of 2015; and Cohort 2, who began in fall of 2016. Students indicated a wide range of declared biomedical majors with a majority of students being from Biology or Biological Sciences (30\%) and others indicating declared majors including Social Work, Chemistry, and Psychology. Students self-reported their racial and ethnic identity using the National Institutes of Health categories of race and ethnicity. This includes six categories for race: American Indian or Alaska Native, Asian, Black or African American, Native Hawaiian or Other Pacific Islander, White, and Other (see Appendix A for detailed descriptions of each 
racial group). Students could also select "More than one race," without any detail about their particular racial identities. Additionally, students reported their ethnicity using three categories; Hispanic or Latino, not Hispanic or Latino, or other. Students were given three gender options to select from; male, female, and non-binary/other. $57.7 \%$ of student indicated that they were from a "Disadvantaged background" which includes a variety of different hardships students may have faced. Additionally, $62.8 \%$ of the students indicated they were the first student in their family to attend college. Students were predominantly female $(71.5 \%$ of the sample), non-Hispanic/Latino $(84 \%)$, white $(35 \%)$ or more than one race (19.7\%), economically disadvantaged (57.7\%), and first-generation college students (62.8\%). Detailed demographic information can be found in Table 4.1 and demographic information broken down by racial categories can be found in Table 4.2 . 
Table 4.1

Demographic Characteristics of Participants

\begin{tabular}{|c|c|c|c|c|c|}
\hline Characteristic & $\mathbf{N}$ & $\%$ & Characteristic & $\mathbf{N}$ & $\%$ \\
\hline Gender & & & Major & & \\
\hline Female & 98 & $71.5 \%$ & Biological Sciences & 6 & $4.4 \%$ \\
\hline Male & 37 & $27.0 \%$ & Biology & 35 & $25.5 \%$ \\
\hline \multirow[t]{2}{*}{ Other/non-binary } & 2 & $1.5 \%$ & Chemistry & 14 & $10.2 \%$ \\
\hline & & & Health Studies & 27 & $19.7 \%$ \\
\hline Cohort & & & Psychology & 13 & $9.5 \%$ \\
\hline One & 61 & $44.5 \%$ & Social Work & 6 & $4.4 \%$ \\
\hline \multirow[t]{3}{*}{ Two } & 76 & $55.5 \%$ & Hard Science: Other & 21 & $15.3 \%$ \\
\hline & & & Social Science: Other & 13 & $9.5 \%$ \\
\hline & & & N/A & 2 & $1.5 \%$ \\
\hline Race & & & Ethnicity & & \\
\hline \multirow{2}{*}{$\begin{array}{l}\text { American Indian or } \\
\text { Alaska Native }\end{array}$} & 4 & $2.9 \%$ & Hispanic/Latino & 31 & $22.6 \%$ \\
\hline & & & $\begin{array}{l}\text { Non- } \\
\text { Hispanic/Latino }\end{array}$ & 84 & $61.3 \%$ \\
\hline $\begin{array}{l}\text { Asian or Asian } \\
\text { American }\end{array}$ & 20 & $14.6 \%$ & Other & 22 & $16.1 \%$ \\
\hline \multirow{2}{*}{$\begin{array}{c}\text { Black or African } \\
\text { American }\end{array}$} & 11 & $8.0 \%$ & & & \\
\hline & & & Disadvantaged & & \\
\hline \multirow{2}{*}{$\begin{array}{l}\text { Native Hawaiian or } \\
\text { other Pacific Islander }\end{array}$} & 8 & $5.8 \%$ & Yes & 79 & $57.7 \%$ \\
\hline & & & No & 58 & $42.3 \%$ \\
\hline White & 48 & $35.0 \%$ & & & \\
\hline More than one race & 27 & $19.7 \%$ & First Generation & & \\
\hline \multirow[t]{2}{*}{ Other } & 19 & $13.9 \%$ & Yes & 86 & $62.8 \%$ \\
\hline & & & No & 51 & $37.3 \%$ \\
\hline
\end{tabular}




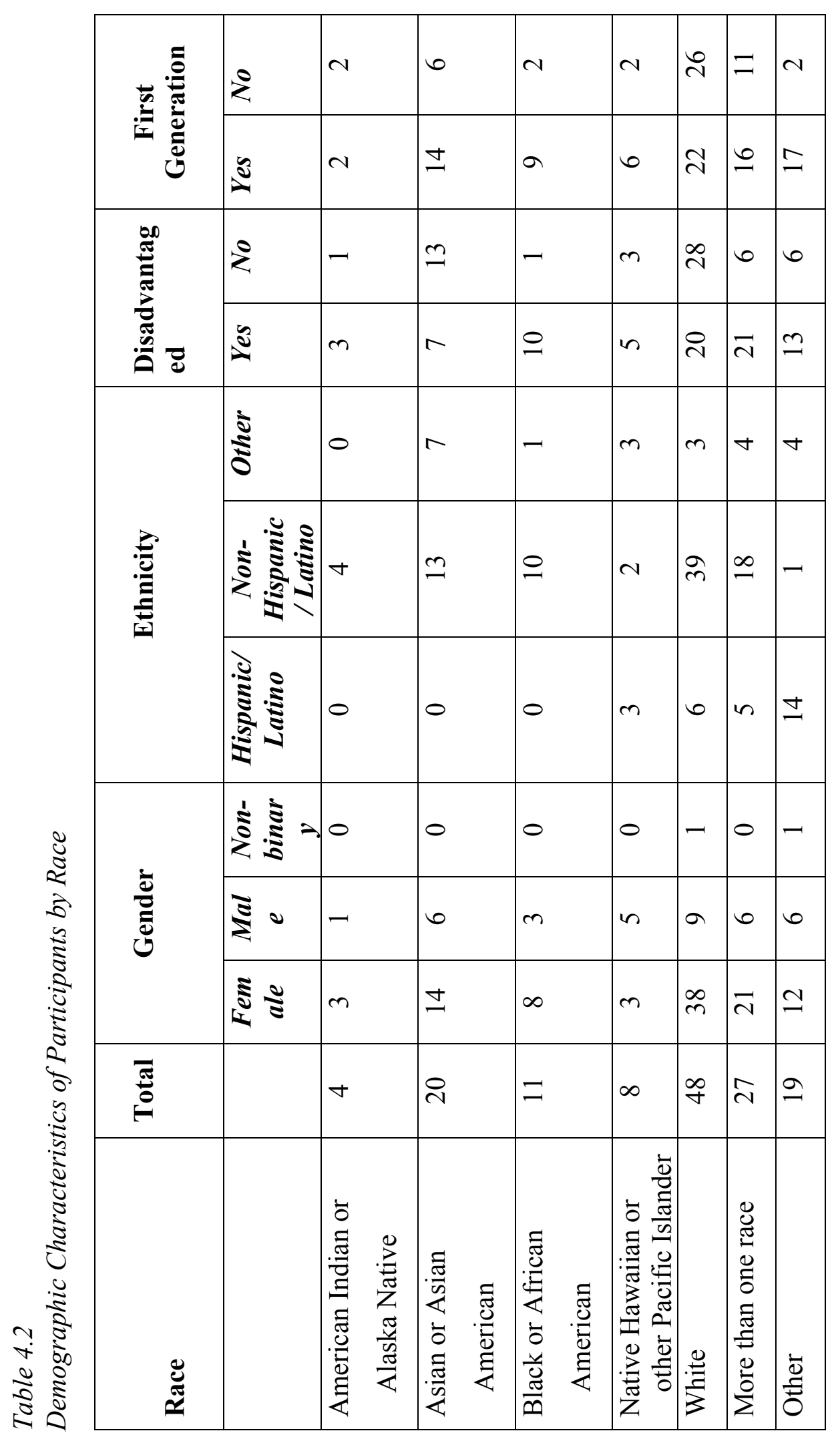




\section{Design}

The student report data were collected using a cohort sequential design. Data about dosage, quality, and duration of program activities were collected monthly using Electronic Mentoring Support Network (EMSN) logs. Data on student perceptions about their training experience, research skills, and fit were collected in a survey administered each fall called the Yearly Academic Scholar Survey (YASS). For the present study, data collected during program year two of the monthly EMSN logs was used along with data from the survey that was administered during the fall or winter term of BUILD EXITO students' second program year. Additionally, the present study utilized demographic data collected from students and academic information available through institutional records.

Figure 4.1 depicts the timeline of data collection for EXITO Scholars relevant to the current study.

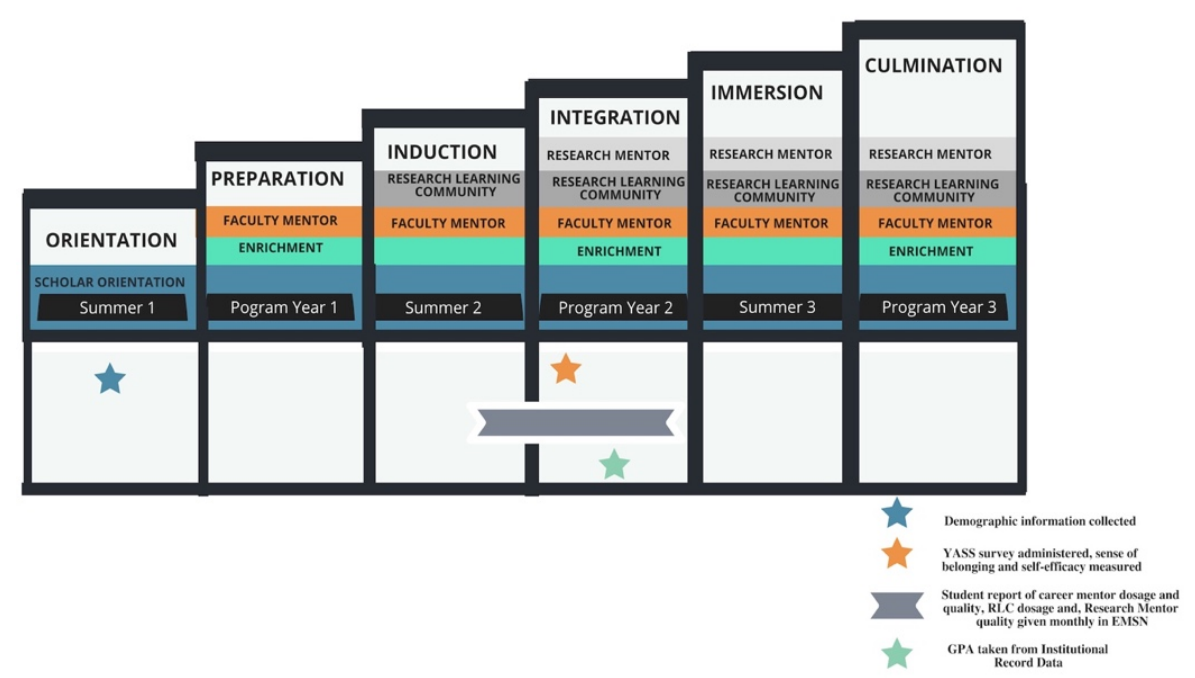

Figure 4.1. BUILD EXITO Student Pathway and Data Collection Timeline. 


\section{Procedure}

Students consented to participate in the study at a new scholar orientation which occurred before they started their first program year in BUILD EXITO. All students were asked to fill out monthly logs through an electronic platform called the Electronic Mentoring Support Network (EMSN). Students responded to a variety of questions about their mentoring relationships and research placement. One reminder e-mail was sent for each monthly EMSN log. Students also completed the Yearly Academic Scholar Survey (YASS) during the middle of each academic year as a BUILD EXITO Scholar. In this survey, students answered questions about their experiences as a STEM college student and self-perceptions about their fit and abilities within their disciplines. Three reminder emails were sent asking students to complete the YASS survey. No incentives for participation in data collection were offered as EXITO program participation has tangible financial benefits for students. Institutional record data was accessed for student GPA.

\section{Measures}

Student report measures included items from the YASS survey and monthly EMSN logs pertaining to a variety of background factors, self-perceptions about abilities and fit, duration of research activities, and details about mentoring relationships. Students also reported demographic information such as their major and racial/ethnic identity. All negatively worded items were reverse coded so that higher numbers indicate more of the constructs, and for particular constructs, items were averaged to create a 
composite scale score. Scales were also standardized for analyses and centered at their mean for interpretation.

\section{Motivational resources.}

A sense of belonging in science. Students' sense of belonging in science was assessed using items drawn from a 5-item pool. Students were asked "To what extent are the following statements true of you?" on the following five items: "I have a strong sense of belonging to a community of scientists"; "I derive great personal satisfaction from working on a team that is doing important research"; "I feel like I belong in the field of science"; "I see myself as part of the campus community;" and "I see myself as a scientist." Students responded on a five-point Likert Scale (1=Strongly agree, $2=$ Agree somewhat, $3=$ Neutral, $4=$ Disagree somewhat, $5=$ Strongly disagree). These items were reverse coded so that a higher score indicates a greater sense of belonging. The item "I see myself as part of the campus community" was removed because when deleted, internal consistency reliability for the construct was improved. The remaining 4-item pool had a Cronbach's Alpha of .797. Responses were averaged to create one sense of belonging score for each student.

Science self-efficacy. Students' self-efficacy was assessed using items drawn from a 10-item pool. Participants rated their confidence in their ability to complete ten common research tasks using a five-point Likert Scale (1=Not at all, 2=Somewhat, 3=Moderately, 4=Very, 5=Absolutely). Items included "Use technical science skills (use of tools, instruments, and/or techniques)"; "generate a research question"; "determine 
how to collect appropriate data"; "explain the results of a study"; "use scientific literature to guide research"; "integrate results from multiple studies"; "ask relevant questions"; "identify what is known and not know about a problem"; "understand scientific concepts"; and "see connection between different areas of science and math." The item pool was analyzed for internal consistency reliability and had a Cronbach's alpha of .894. For no items did removal improve the internal consistency of the scale, so all ten items were retained. Responses were averaged to create one self-efficacy score for each student.

Program participation. Program participation was considered by measuring five distinct components of engagement in key program activities.

Faculty mentoring dosage. Each month, students reported the amount of time they spent with their faculty mentors each month. They were asked on their EMSN logs, "Approximately how many hours did you spend with your career mentors this month?" They responded with time increments rounding to the nearest half hour (i.e., $0,1,2,1.5$, etc.). The responses from each month that a student filled out the log, which ranged from 1 to 9 months, were combined and a monthly average score was created.

Faculty mentoring quality. Students also reported information regarding the quality of their contact with their faculty mentors throughout that month. Students were asked, "Overall, how would you rate your contact(s) with this EXITO Mentor this past month?" They responded using a five-point Likert scale (1=very poor, $2=$ poor, $3=$ Fair, 4=good, $5=$ Very good or NA=Not applicable we have not met this month). Responses 
from all completed logs were combined and averaged providing a summary quality score for the career mentoring relationship during the students' second year in the program. Months marked "NA" were considered missing and not included.

Research experience dosage. Each month, students reported the amount of time they spent working in their Research Learning Community (RLC) placement. They were asked on their EMSN logs, "Approximately how many hours did you spend in your research placement this month?" They responded with hour time increments rounding to the nearest half hour (i.e., $0,1,2,1.5,3$, etc.). Again, responses from all logs completed over the 9-month duration of the study were combined and a monthly average was calculated. Because a few students indicated spending large amounts of time with their career mentors, likely as the result of expanded opportunities to engage in activities with these mentors, high outliers valued were replaced with the top value in the expected range of career mentor dosage.

Research mentoring quality. Students also reported information regarding the quality of their contact with their research mentors. Students were asked, "Overall, how would you rate your contact(s) with this EXITO Mentor this past month?" They responded on a five-point Likert scale ( $1=$ very poor, $2=$ poor, $3=$ Fair, $4=$ good, $5=$ Very good or NA=Not applicable we have not met this month). Responses of all completed logs over these nine months were combined and averaged providing a summary quality score for the research mentoring relationship over the duration of the student's second year in the program. Months marked "NA" were considered missing and not included. 
Enrichment workshop attendance. Weekly enrichment workshops were offered to students and included professional development curriculum and an opportunity to connect with peers and supportive faculty. The enrichment attendance measure was calculated using program attendance records by calculating the percentage of workshops that students attended out of the total sessions. Percentages were used because students form different cohorts had different numbers of workshops available.

Overall program participation. This variable was calculated as the summary of these five program dosage, quality, or participation components. Each individual component score was standardized and then the five items were averaged together to provide one score that indicated overall program participation for each student. Overall participation scores were transformed to a 0 to 5 scale for interpretability.

Academic performance. Academic performance was measured using Institutional Record Data of student's cumulative grade point average (GPA) for each student during the winter quarter of their second year in the program, close to the time of completion for the YASS survey. For students attending institutions on the semester system, spring GPA was used. 


\section{Chapter 5 : RESULTS}

The goal of this study was to examine the relationships between participation in an undergraduate research training program, motivational resources (i.e., a sense of belonging and self-efficacy), and academic achievement for URM STEM students. An initial discussion of missing data, preliminary data cleaning steps, and an examination of measurement properties will be described in detail in the following section followed by analyses and results addressing each of the research questions.

\section{Missing Data}

Due to the nature of this study, which seeks to understand the effects of program participation, it was especially important to try to gauge meaningful missingness within the dataset. Missingness was examined by considering data availability for each participant from eight distinct data sources, including workshop attendance, reports of self-efficacy, reports of a sense of belonging, research mentor dosage, research mentor quality, career mentor dosage, career mentor quality, and GPA. Considering missingness based on these categories provided a broader sense of patterns in missingness for both individual cases and the sample as a whole.

Missing data were examined using SPSS version 23. To determine whether the data were considered missing at random (MAR), missing completely at random (MCAR), or not missing at random (NMAR), missing values were evaluated using both variablewise and case-wise analyses. These analyses suggested that data were NMAR, with a significant result for Little's MCAR test $(X 2=129.581(65), p=.001)$ suggesting possible 
meaningful patterns of missingness and structural differences within the sample. Specifically, 17 students in the sample had only demographic information and 14 additional students had only demographic information and GPA. These 31 individuals were removed from the sample. Although removing participants can increase the risk of biasing results, given that these students were lacking any information about program participation or motivational resources, any attempt to estimate their missing data would have been constructing their experience and self-appraisals without any indicators to support these estimations.

The remaining 137 participants were retained in the sample. Of this group, every participant had GPA and at least some data on motivational resources or program participation. Of this group, 79 individuals had complete data, 39 were missing data from only one data source, (i.e., 11 were missing only career mentor quality, 13 only workshop attendance, 8 only motivational resources, 7 were missing one dosage or quality composite and workshop participation), and the other 21 were missing data from two or more sources. The missing data were estimated with the maximum likelihood (ML) estimation algorithm (Cohen, Cohen, West, \& Aiken, 2003) using the Missing Values module for SPSS 23. Single imputation was utilized instead of case-wise or list-wise deletion to maximize power. All analyses described in following sections were completed using the imputed dataset. 


\section{Measurement Properties and Descriptive Statistics}

Analyses were conducted using SPSS Version 24. Initial descriptive statistics

were evaluated for each variable included in the study. The means, standard deviations, and internal consistencies for each subscale are presented in Table 5.1.

Table 5.1

Summary of Descriptive and Psychometric Statistics for Each Construct

\begin{tabular}{lcccccc}
\hline & & & & & & \\
\cline { 5 - 6 } Measure & of Items & $M$ & $S D$ & $\alpha$ & min & max \\
\cline { 5 - 7 } Participation in EXITO & & & & & & \\
Overall Participation & 5 & 2.5 & .29 & - & & \\
Career Mentor Dosage & 9 & 1.58 & 2.64 & - & 0 & 17.57 \\
Career Mentor Quality & 9 & 4.49 & .612 & - & 1 & 5 \\
Research Experience Dosage & 9 & 31.8 & 14.14 & - & 0 & 76 \\
Research Mentor Quality & 9 & 4.57 & .583 & - & 2 & 5 \\
Workshop Participation (\%) & 30 & 83.06 & 14.92 & - & 24.67 & 100 \\
Motivational Resources & & & & & & \\
Sense of Belonging & 4 & 3.94 & .787 & .797 & 1.5 & 5 \\
Self-efficacy & 10 & 3.20 & .633 & .894 & 1.2 & 5 \\
GPA & 1 & 3.33 & .469 & - & 2.08 & 3.99 \\
\hline
\end{tabular}

Note. Dosage is measured in number of hours. Rating scales for Quality range from 1 (very negative) to 5 (very positive); for Sense of Belonging from 1 (strongly agree) to 5 (strongly disagree); and for Self-efficacy from 1(not at all) to 5 (absolutely).

The mean levels of all constructs were examined to better understand the overall functioning of the sample. With regards to motivational resources which had a top rating of 5, mean levels indicated that students experience a higher sense of belonging $(M=3.94)$ compared to self-efficacy ( $M=3.20)$, which fell just above the mid-point (i.e., 3.0) of the 
scale. Mean levels of quality ratings were very high, almost reaching the ceiling of the scale (5.0), and student's ratings were similar for both the career $(\mathrm{M}=4.49)$ and research mentors $(\mathrm{M}=4.57)$ indicating that students tended to rate the quality of interactions as high for both mentors. In terms of dosage, students spent about 31.8 hours each month in their research learning communities, whereas they spent about 1.58 hours per month with their career mentors. As expected, the average monthly time spent in research learning communities was much higher than monthly career mentor dosage which is representative of the EXITO program model wherein students are asked to spend 10 hours per week in their research placement and only meet with career mentors on one occasion each month. Students appeared to be mostly adhering to program requirements regarding time spent with career mentors with an average monthly meeting time of 1.58 hours. Student's average GPA was 3.33 indicating roughly a B average for participants. Examination of the range statistics for each scale revealed that for three scales including the research mentor quality rating, a sense of belonging, and self-efficacy, no students endorsed the average lowest score of 1.0. The motivational resource and mentor quality scales had moderate standard deviations, ranging from .583 to .787 which suggests there may be low variability in responses between students and this could potentially limit the power to detect significant effects. Ceiling effects were found for both the career mentor quality and research mentor quality scales as the maximum scale scores for these variables fell within one standard deviation of the scale means. As a result, regression results that indicate significant relationships between these variables and others may be 
attenuated and underestimate the true magnitude of the relationship between the variables of interest, representing the low bound estimate of these connections.

\section{Univariate Outliers and Non-Normality}

The data were also examined for non-normality, outliers, and nonlinear relationships among the variables of interest. In order to assess potential distributional non-normality, skewness and kurtosis statistics were assessed for each of the nine variables and can be seen in Table 5.2. Overall program participation, research mentoring quality, career mentoring quality, and workshop participation were all was significantly negatively skewed, suggesting that students were more likely to report higher levels of these constructs and had higher summary scores of level, quality, and dosage of participation. The GPA and sense of belonging scales were moderately negatively skewed indicating that students were more likely to have slightly higher GPAs and indicate higher levels of belongingness. Career mentor dosage, on the other hand, was significantly positively skewed revealing that students were more likely to report less time spent with their career mentors.

All variables had acceptable kurtosis accept for career mentor quality and career mentor dosage which were leptokurtic suggesting that students' ratings of dosage and quality of career mentors fell close to the median. Boxplots were examined to check for possible outliers for all variables. A sense of belonging contained two outliers at the lower end of the scale and self-efficacy also had two outliers, one at the high and one at the low end of the scale. Several of the program participation components also had 
outliers which is likely due to the wide variation of student participation in programrelated activities and mentoring relationships. For instance, workshop attendance had 5 outliers on the low side which may be the result of students who did not or could not attend the weekly workshop sessions. Career mentoring quality had 5 low outliers, most ratings were clustered at the high end of this scale and these outliers represent the students who did not rate their mentoring relationships quality very highly. Career mentoring dosage had the largest number of outliers, 18 in total, all of which were on the high end of the scale. This may be the result of students who expanded their reports of dosage in these mentoring relationships beyond a monthly meeting to include participation in additional activities or outreach with their career mentor.

Given its significant positive skew of 3.639 and leptokurtic nature, a transformation was needed for the career dosage variable to be useful in regression analyses. The career dosage variable was winsorized which involves a statistical transformation that limits extreme values in the data to reduce the effect of possibly spurious outliers by replacing outlier values with the highest value that falls within the expected distribution (Tukey, 1962). This transformation provided new fit statistics for the career dosage variable with a skew of 1.055 and a kurtosis of $\quad-.142$. Overall participation was recalculated with this new career dosage value and had a resulting skew of -1.153 and kurtosis of 2.208. Other outliers in the data were not transformed or removed because they had the potential to provide valuable information about the URM STEM student experience. 
Table 5.2

Skew and Kurtosis Statistics for Each Construct

\begin{tabular}{lcc}
\hline Scale & Skew & Kurtosis \\
\hline Participation in EXITO & & \\
Overall Participation & -.865 & 2.34 \\
Career Mentor Dosage & 3.639 & 15.95 \\
Career Mentor Quality & -2.16 & 7.64 \\
Research Experience Dosage & -.373 & .520 \\
Research Experience Quality & -1.607 & 2.837 \\
Workshop Participation & -1.30 & 2.047 \\
Motivational Resources & & \\
Sense of Belonging & -.794 & .355 \\
Self-efficacy & .143 & .347 \\
GPA & -.739 & -.232 \\
\hline
\end{tabular}

\section{Intra-Construct Correlations}

The correlations among the variables from the subcomponents of participation are presented in Table 5.3. Correlations among subcomponents of the motivational resource constructs are presented in Table 5.4. Although most correlations were significant, levels were not so high that problems with multicollinearity were anticipated. Notably, career and research mentor quality were positively and significantly correlated, indicating that students who reported high quality interactions with one mentor also reported experiencing high quality interactions with the other mentor. Research experience dosage and research mentor quality were also significantly related indicating that students 
who spent more time in their research placements, reported higher quality for their research mentor experiences.

Surprisingly, workshop participation was negatively correlated with all the other components of program participation, and these negative correlations reached significance for two components: career mentor dosage and research mentor quality. One possibility is that students who spend less time with career mentors or who report lower satisfaction with research mentor encounters are motivated to attend a greater number of weekly workshops to connect with others in the program. Alternatively, students who spend more time with their career mentors or who have more satisfying mentoring relationships may be less motivated to attend workshops due to the personal and professional development they receive in their mentoring encounters.

Table 5.3

Intra-Correlations among Program Participation Components

\begin{tabular}{lccccc}
\hline & $\begin{array}{c}\text { Career } \\
\text { Mentor } \\
\text { Quality }\end{array}$ & $\begin{array}{c}\text { Career } \\
\text { Mentor } \\
\text { Dosage }\end{array}$ & $\begin{array}{c}\text { Research } \\
\text { Mentor } \\
\text { Quality }\end{array}$ & $\begin{array}{c}\text { Research } \\
\text { Experience } \\
\text { Dosage }\end{array}$ & $\begin{array}{c}\text { Workshop } \\
\text { Participati } \\
\text { on }\end{array}$ \\
\hline $\begin{array}{l}\text { Career Mentor } \\
\text { Quality }\end{array}$ & - & & & & \\
$\begin{array}{l}\text { Career Mentor } \\
\text { Dosage }\end{array}$ & .063 & - & & \\
$\begin{array}{l}\text { Research Mentor } \\
\text { Quality }\end{array}$ & $.456^{* *}$ & .014 & - & \\
$\begin{array}{l}\text { Research } \\
\text { Experience } \\
\text { Dosage }\end{array}$ & .167 & -.051 & $.296^{* *}$ & - & \\
$\begin{array}{l}\text { Workshop } \\
\text { Participation }\end{array}$ & & & & & \\
\hline
\end{tabular}


Table 5.4

Intra-Correlations among Motivational Resource Components

\begin{tabular}{lcc}
\hline & Sense of Belonging & Self-efficacy \\
\hline Sense of Belonging & - & - \\
Self-efficacy & $.323^{* *}$ & - \\
\hline Note. ${ }^{*} p<.05 * * p<.01 * * * p<.001$. &
\end{tabular}

\section{Results for Research Questions}

\section{Research Question 1}

Does participation in an undergraduate research training program predict students' motivational resources, such that students with higher quality and/or dosage of program participation have higher motivational resources whereas students with lower quality and/or dosage of program participation have lower motivational resources?

The first set of research questions focuses on the effects of program participation on motivational resources and were answered through simple and multiple linear regression analyses using Ordinary Least Squares (OLS). Each regression equation is provided below the corresponding research question. Overall student participation, the five participation components, and the two motivational resources, were mean centered for all analyses. To assist with the interpretation of these data, all beta weights were 
standardized. Inter-correlations among variables are presented in tables 5.5 and 5.7 and regression results are presented in tables 5.6 and 5.8 .

R1a: Do students' levels of participation predict their sense of belonging in science?

$$
\mathrm{Y}_{(\text {sense of belonging })}=\beta_{\mathrm{o}}+\beta_{1(\text { program participation })}+\mathrm{e}
$$

Students' overall participation in an undergraduate research training program explained $4.6 \%$ of the variance in a sense of belonging in science. As expected, students who reported higher levels of overall program participation also reported higher levels of a sense of belonging. This finding is consistent with the notion that participating in an undergraduate research training program may play a role in students' sense of belonging in science.

R1b: Do students' levels of participation predict their scientific self-efficacy?

$$
Y_{(\text {self-efficacy })}=\beta_{\mathrm{o}}+\beta_{1(\text { program participation })}+\mathrm{e}
$$

Students' overall participation in an undergraduate research training program explained $10.7 \%$ of the variance in self-efficacy. Students who reported higher levels of overall program participation also reported higher levels of self-efficacy. This suggests that participating in an undergraduate research training program may also play a role shaping students' scientific self-efficacy.

Hypothesis 1 was supported because regression coefficients linking overall program participation to each of the two motivational resources were positive and significant. 
Table 5.5

Inter-Correlations Among Overall Program Participation and Motivational Resources

Sense of

Self-efficacy

belonging

Overall Program $\quad .214^{*}$

$.327 * * *$

Participation

Note. ${ }^{*} p<.05 * * p<.01 * * * p<.001$.

Table 5.6

Effects of Overall Program Participation on Sense of Belonging and Self-efficacy

\begin{tabular}{lccccccc}
\hline & \multicolumn{3}{c}{ Sense of belonging } & \multicolumn{3}{c}{ Self-efficacy } \\
\hline Predictor & $\mathrm{B}$ & $\mathrm{SE}$ & $\beta$ & $\mathrm{B}$ & $\mathrm{SE}$ & $\beta$ \\
\hline $\begin{array}{l}\text { Overall Program } \\
\text { Participation }\end{array}$ & .072 & .028 & $.214^{*}$ & .089 & .022 & $.327^{* * *}$ \\
$\mathrm{R}^{2}$ & & & & & & \\
\hline
\end{tabular}

Note. ${ }^{*} p<.05 * * p<.01{ }^{* * *} p<.001$.

R1c: Do particular program components play a significant role in predicting students' motivational resources?

$Y_{(\text {sense of belonging) }}=\beta_{\mathrm{o}}+\beta_{1 \text { (Career Mentor Quality) }}+\beta_{2 \text { (Career Mentor Dosage) }}+\beta_{3 \text { (Research Mentor Quality) }}+$ $\beta_{4(\text { Research Experience Dosage })}+\beta_{5 \text { (Workshop Participation) }}+\mathrm{e}$

$Y_{(\text {self-efficacy })}=\beta_{\mathrm{o}}+\beta_{1(\text { Career Mentor Quality })}+\beta_{2 \text { (Career Mentor Dosage })}+\beta_{3 \text { (Research Mentor Quality) }}+$ $\beta_{4(\text { Research Experience Dosage })}+\beta_{5 \text { (Workshop Participation) }}+\mathrm{e}$

This question was answered in two steps. First, the correlations between each of the five program components and the two motivational resources were calculated. They 
are presented in Table 5.7. As can be seen in the inter-correlations, both motivational resources were significantly and positively correlated with both of the program components focused on research experience: dosage and research mentor quality, indicating that students who spent more time in their research learning communities and who experienced a higher quality relationship with their research mentors also reported a greater sense of belonging and higher levels of self-efficacy. In contrast, the two program components focusing on career mentors (dosage and quality) showed positive and significant associations only with self-efficacy. Surprisingly, workshop attendance again showed a negative association with self-efficacy. One possibility is that students with higher levels of self-efficacy were less likely to attend workshops because of their confidence in their scientific abilities. Alternatively, students who attended more workshops could have gained a more realistic picture of what it takes to "do science," and so be more critical of own their abilities to carry out these tasks.

In a second step, the five distinct program participation components were used to predict a sense of belonging in science and science self-efficacy in a simultaneous multiple linear regression analysis. Regression results can be seen in Tables 5.8 and Figures 5.1-5.2 which follow. For a sense of belonging in science, results of the multiple regression indicated that the five program participation components explained $10.5 \%$ of the variance in this outcome. Only research experience dosage had a significant and positive unique effect, indicating that students with higher levels of dosage in their 
research experiences had higher levels of a sense of belonging in science, after controlling for the other variables in the model. Although it showed a significant and

Table 5.7

Inter-Correlations among Program Participation Components and Motivational Resources

Program Participation Component Sense of Belonging Self-efficacy

Career Mentor Quality

Career Mentor Dosage

Research Mentor Quality

Research Experience Dosage

Workshop Participation

Note. ${ }^{*} p<.05 * * p<.01{ }^{* * *} p<.001$.
.140

.031

$.171 *$

$.359 * *$

$.305^{* *}$

$.317 * *$

$-.087$

positive zero-order correlation with sense of belonging, research mentor quality had no significant effect over and above the effects of research experience dosage and did not contribute uniquely to the regression model.

For students' scientific self-efficacy, the results of the multiple regression model indicated that the five program participation components explained $27.6 \%$ of the variance in this outcome. Three program components showed unique effects: Research experience 
dosage, research mentor quality, and career mentor dosage all had significant and positive unique effects, indicating students with higher levels of these constructs had higher levels of scientific self-efficacy, after controlling for the other variables in the model. Although career mentoring quality had a significant and positive zero-order correlation with selfefficacy, it did not did not contribute uniquely to the multiple regression model over and above the effects of the other components. Consistent with the zero-order correlations, workshop attendance had a significant negative weight, indicating that after accounting for the other program components, those students with higher workshop attendance reported lower scientific self-efficacy.

Table 5.8

Effects of Program Participation Components on Sense of Belonging and Self-efficacy

\begin{tabular}{lccccccc}
\hline & \multicolumn{3}{c}{ Sense of Belonging } & \multicolumn{3}{c}{ Self-efficacy } \\
\cline { 2 - 8 } Predictors & $\mathrm{B}$ & $\mathrm{SE}$ & $\beta$ & $\mathrm{B}$ & $\mathrm{SE}$ & $\beta$ \\
\hline Career Mentor Quality & .085 & .120 & .066 & -.022 & .087 & -.022 \\
Career Mentor Dosage & -.017 & .060 & -.024 & .123 & .043 & $.213^{* *}$ \\
Research Mentor Quality & .076 & .130 & .056 & .286 & .094 & $.263^{* *}$ \\
Research Ex. Dosage & .015 & .005 & $.272 * *$ & .010 & .004 & $.219^{* *}$ \\
Workshop Participation & -.001 & .005 & -.024 & -.009 & .003 & $-.201^{*}$ \\
$\mathrm{R}^{2}$ & .105 & & & .276 & & \\
\hline
\end{tabular}

Note. ${ }^{*} p<.05 * * p<.01 * * * p<.001$. 


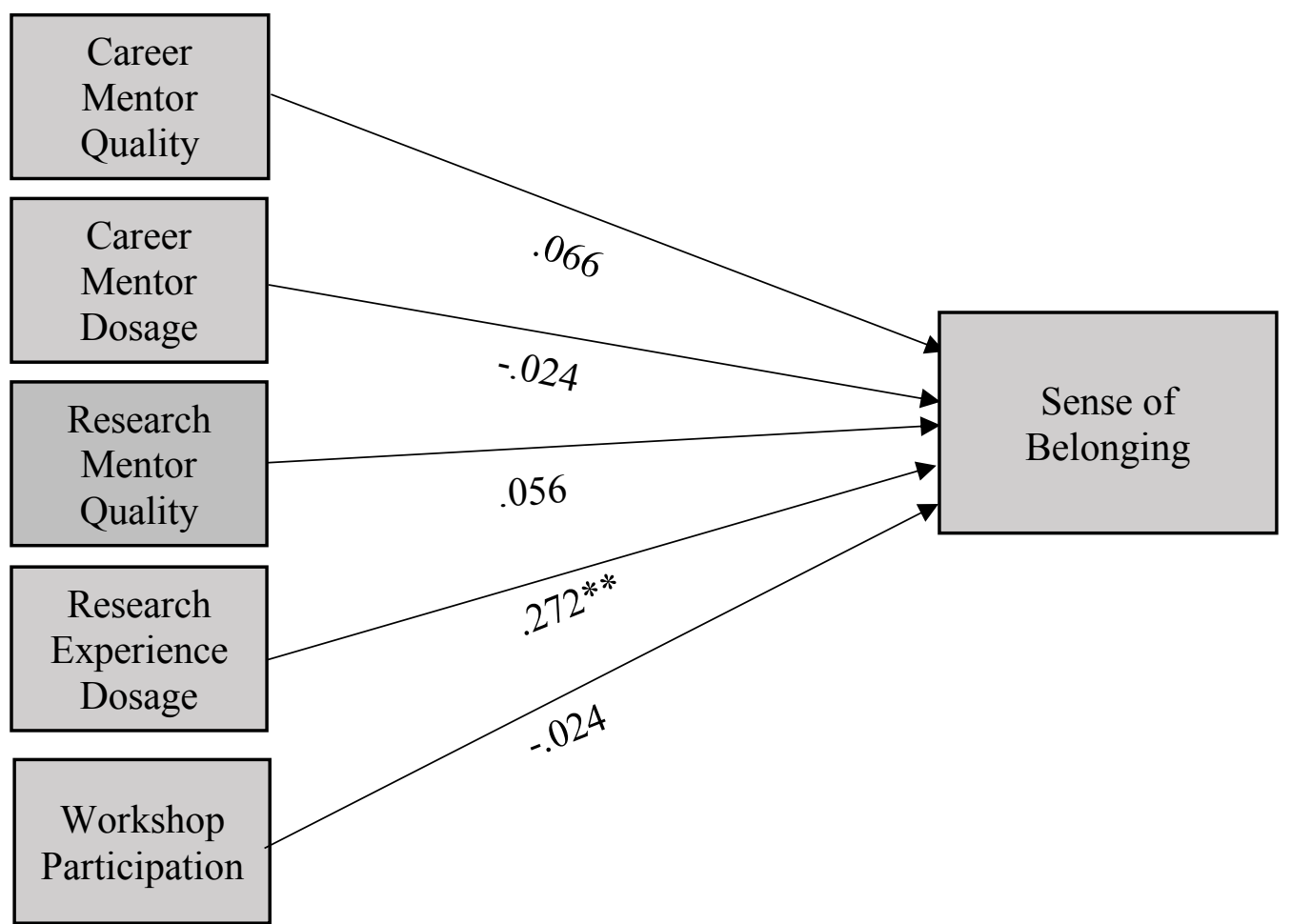

Figure 5.1. Effects of Program Participation Components on Sense of Belonging. 


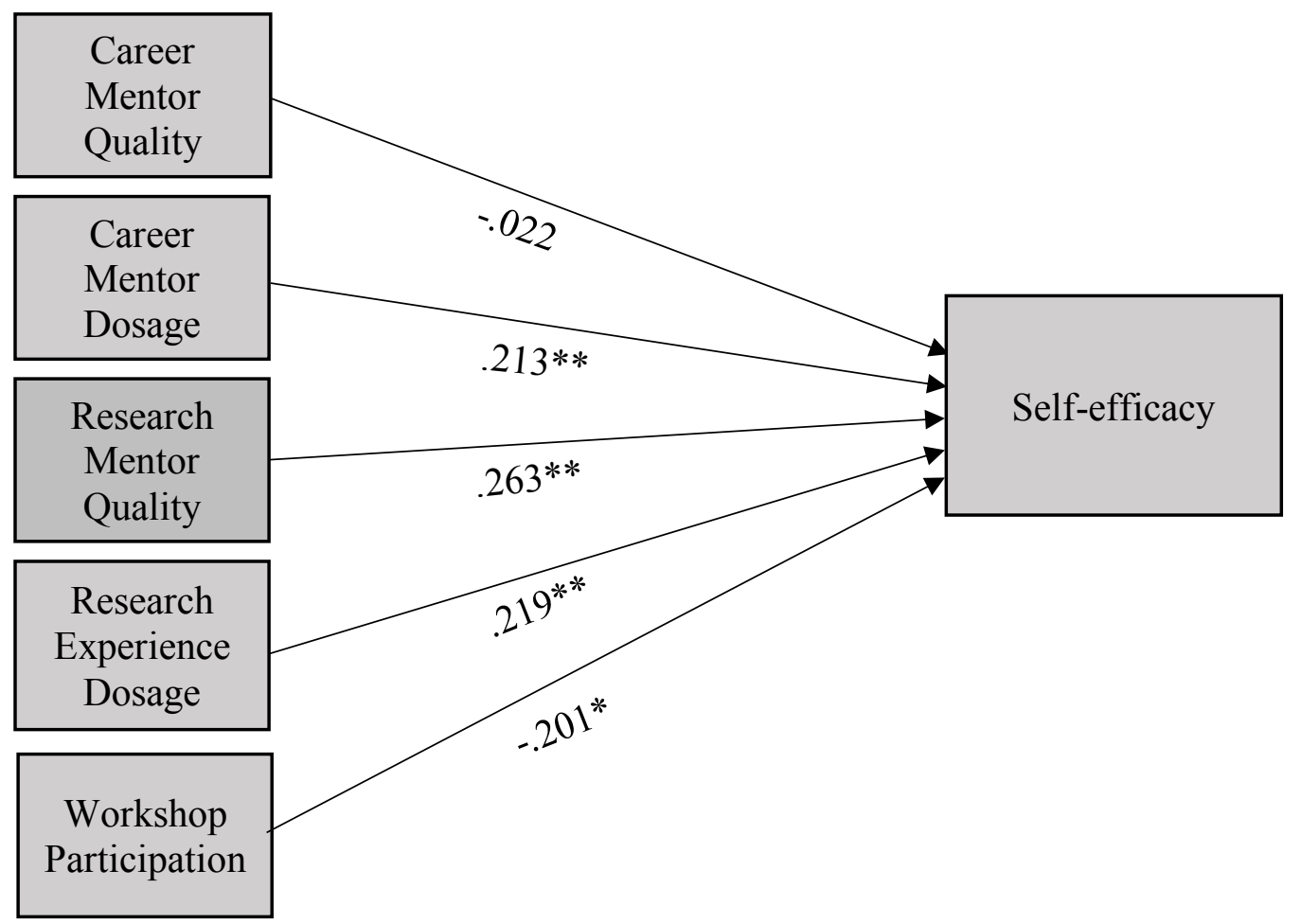

Figure 5.2. Effects of Program Participation Components on Self-efficacy.

\section{Research Question 2}

Do students' levels of participation in an undergraduate research training program predict their academic performance, such that students with higher program participation have higher performance whereas students with lower program participation have lower performance?

The second set of research questions, which focus on the relationship between participation in an undergraduate research training program and academic performance, were answered through simple and multiple linear regression analyses using Ordinary Least Squares (OLS). Each regression equation is provided below the corresponding research question. Overall participation, the five participation components, and the two 
motivational resources were again mean centered for all analyses. To assist with the interpretation of these data, all beta weights were standardized. Inter-correlations between these constructs are presented in table 5.9. Zero-order correlations revealed no significant relationships between overall program participation and academic performance or between any of the five program participation components and academic performance. These results suggest that participation does not seem to have an impact on graded performance and students with a high levels of academic performance do not participate more in the program.

Table 5.9

Inter-Correlations between Program Participation, Participation Components and Academic Performance

\begin{tabular}{lc}
\hline & Academic Performance \\
\hline Overall Program Participation & .088 \\
Career Mentor Quality & .026 \\
Career Mentor Dosage & -.079 \\
Research Mentor Quality & -.057 \\
Research Experience Dosage & .155 \\
Workshop Participation & .104 \\
\hline
\end{tabular}

R2a: Does overall program participation play a play a significant role in predicting 
students' academic performance?

$$
\mathrm{Y}_{(\text {Academic Performance })}=\beta_{\mathrm{o}}+\beta_{1(\text { Program Participation })}+\mathrm{e}
$$

Students' overall participation in an undergraduate research training program explained $1 \%$ of the variance in student's academic performance suggesting that overall program participation did not significantly predict academic achievement for this sample of students. Regression results are presented in Table 5.10.

Table 5.10 Effects of Overall Program Participation on Academic Performance

\begin{tabular}{lccc}
\hline & \multicolumn{3}{c}{ Academic Performance } \\
Predictor & $\mathrm{B}$ & $\mathrm{SE}$ & $\beta$ \\
\hline Overall Program Participation & .018 & .017 & .088 \\
\multicolumn{1}{c}{$\mathrm{R}^{2}$} & .088 & & \\
\hline Note. ${ }^{*} p<.05 * * p<.01 * * * p<.001$. & &
\end{tabular}

R2b: Do particular program components have a role in predicting students' academic performance?

$\mathrm{Y}_{\text {(academic performance) }}=\beta_{\mathrm{o}}+\beta_{1 \text { (Career Mentor Quality) }}+\beta_{2 \text { (Career Mentor Dosage) }}+\beta_{3 \text { (Research Mentor Quality) }}$ $+\beta_{4(\text { Research Experience Dosage })}+\beta_{5 \text { (Workshop Participation })}+\mathrm{e}$

The five distinct program participation components were used to predict academic performance in a simultaneous multiple linear regression analysis. Regression results can be seen in Tables 5.11 and Figures 5.3 which follow. Results of the multiple regression indicated that the five program participation components explained 5.3\% of the variance in this outcome. Only research experience dosage had a significant and positive unique 
effect, indicating that students with higher levels of dosage in their research experiences had higher academic performance after controlling for the other variables in the model. Consistent with zero-order correlations, the other four program participation components had no significant effect over and above the effects of research experience dosage and did not contribute uniquely to the regression model.

Table 5.11

Effects of Program Participation Components on Academic Performance

\begin{tabular}{lccc}
\hline & \multicolumn{4}{c}{ Academic Performance } \\
\cline { 2 - 4 } Predictor & $\mathrm{B}$ & $\mathrm{SE}$ & $\beta$ \\
\hline Career Mentor Quality & .052 & .074 & .068 \\
Career Mentor Dosage & .003 & .037 & .008 \\
$\begin{array}{l}\text { Research Mentor } \\
\text { Quality }\end{array}$ & -.100 & .080 & -.125 \\
$\begin{array}{l}\text { Research Experience } \\
\text { Dosage }\end{array}$ & .007 & .003 & $.202 *$ \\
Workshop Participation & .004 & .003 & .126 \\
$\mathrm{R}^{2}$ & .053 & & \\
\hline Note. & & & \\
\hline
\end{tabular}

Note. ${ }^{*} p<.05 * * p<.01 * * * p<.001$. 


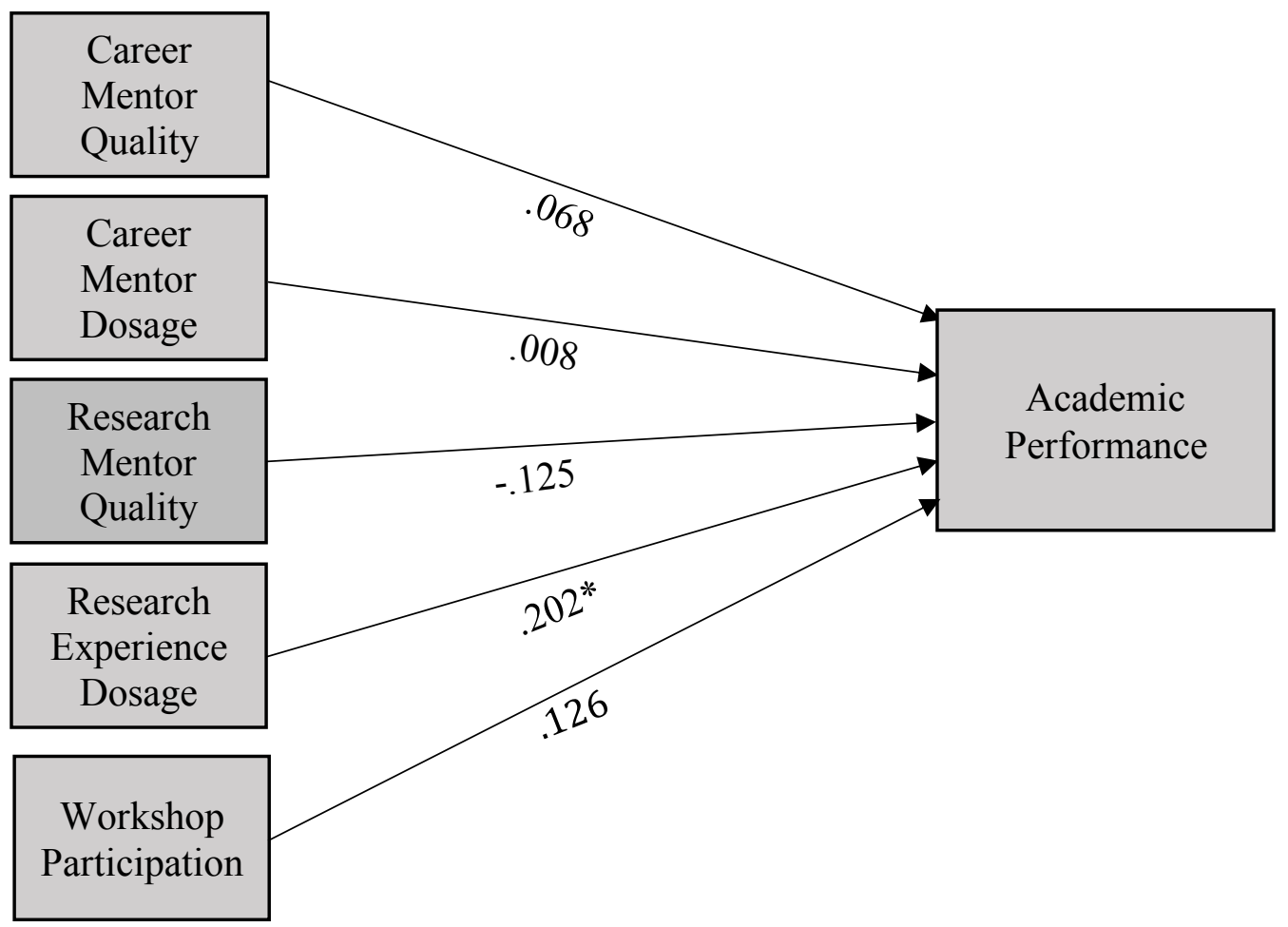

Figure 5.3. Effects of Program Participation Components on Academic Performance. 


\section{Research Question 3}

\section{Do students' levels of motivational resources (i.e., sense of belonging and self-} efficacy) predict their levels of academic performance, such that students with higher motivational resources have higher academic performance whereas students with lower levels of motivational resources have lower academic performance?

The third set of research questions focused on the effects of motivational resources on student's academic performance and were answered through simple linear regression analyses using Ordinary Least Squares (OLS). Each regression equation is provided below the corresponding research question. To assist with the interpretation of these data, the two motivational resources and academic performance were mean centered for all analyses and all beta weights were standardized. Inter-correlations among variables are presented in table 5.12. No significant zero-order correlations were found although correlations were not in the expected direction, but were negative indicating students with higher grades had lower levels of motivational resources. Regression results are presented in table 5.13.

R3a: Do students' sense of belonging predict their academic performance?

$$
\mathrm{Y}_{(\text {Academic Performance) }}=\beta_{\mathrm{o}}+\beta_{1 \text { (Sense of Belonging) }}+\mathrm{e}
$$

Regression results indicated that student's sense of belonging in science explained $1.3 \%$ of the variance in student's academic performance suggesting that a sense of belonging did not shape student's academic performance. 
R3b: Do students' self-efficacy predict their academic performance?

$$
\mathrm{Y}_{(\text {Academic Performance) }}=\beta_{\mathrm{o}}+\beta_{1 \text { (Self-efficacy) }}+\mathrm{e}
$$

Regression results indicated that student's scientific self-efficacy explained less than $1 \%$ of the variance in student's academic performance suggesting that a sense of belonging did not shape student performance.

Hypothesis 3 was not supported because regression coefficients linking a sense of belonging and self-efficacy to academic achievement were not positive or significant.

Table 5.12.

Inter-Correlations Between Motivational Resources and Academic Performance

\begin{tabular}{lcc}
\hline & Sense of Belonging & Self-efficacy \\
\hline Academic Performance & -.013 & -.008 \\
\hline
\end{tabular}

Table 5.13

Effects of Sense of Belonging on Academic Performance

Academic Performance

\begin{tabular}{lclc}
\cline { 2 - 4 } Predictor & $\mathrm{B}$ & $\mathrm{SE}$ & $\beta$ \\
\hline Sense of Belonging & -.008 & .051 & -.013 \\
$\mathrm{R}^{2}$ & .013 & & \\
Self-efficacy & -.006 & .064 & -.008 \\
$\mathrm{R}^{2}$ & .008 & & \\
\hline Note. ${ }^{*} p<.05^{* *} p<.01^{* * *} p<.001$. & &
\end{tabular}




\section{Research Question 4}

\section{Do students' motivational resources explain the relationship between their levels of program participation and their academic performance?}

To explore the possible mediational role of motivational resources (i.e., a sense of belonging and self-efficacy), a mediation analysis was used (Baron \& Kenny, 1986) which assessed if either motivational resource mediated the relationship between program participation and academic performance. Four steps are involved in the Baron and Kenny approach to establishing a mediation and three regressions were needed in this process.

In step 1 of the mediation model, the regression of overall program participation on academic performance (performed for research question 2), ignoring the mediator, was not significant, $b=.088, p>.05$. However, when a multiple regression analysis was used to look at the five distinct program components individually, mentoring experience dosage was significantly related to academic performance for students $(b=.202 *, \mathrm{p}<.05)$ providing justification to proceed to the second step of the mediational analyses.

Step 2, which examined the relationship between the causal variable of program participation and the mediational variables of a sense of belonging and self-efficacy was answered in research question 1. A regression analysis showed a significant effect of overall program participation on a sense of belonging in science $(b=.214, \mathrm{p}<.05)$. A multiple regression, examining the effect of the five program components on a sense of belonging found that only research experience dosage had a significant effect on a sense of belonging $(b=.272, \mathbf{p}<.01)$. In looking at the second motivational resource, scientific self-efficacy, a regression analysis showed that the effect of overall program participation 
on a self-efficacy was also significant $(b=.327, \mathrm{p}<.001)$. A multiple regression, looking at all five components showed significant effects of four components including career mentor dosage $(b=.213, \mathrm{p}<.01)$, research experience dosage $(b=.219, \mathrm{p}<.01)$, research mentor quality $(b=.263, \mathrm{p}<.01)$, and workshop participation $(b=-.201, \mathrm{p}<.05)$. These results indicated that the second step of Baron and Kenny's approach, which confirms a significant relationship between the causal variables and mediational variables of interest, was met and that the third step in this approach was appropriate.

Step 3 of the mediation process examined the relationships between the two possible mediators, a sense of belonging and self-efficacy, and academic performance. In the regression analysis examining the relationship between a sense of belonging and academic performance, a sense of belonging had no significant effect on academic performance $(b=-.013, p>.05)$. Similarly, a regression indicated no significant effect of self-efficacy on academic performance $(b=-.008, p>.05)$. As a result, step four of Baron and Kenny's mediational analysis could not be completed as all steps were not met. 


\section{Chapter 6 : DISCUSSION}

This study aimed to surface the experience of URM STEM college students by exploring how participation in an undergraduate research training program may be shaping students' motivational resources and their academic performance and thus contributing to their successful completion of undergraduate biomedical degrees. The study provided a deeper understanding of how two key motivational resources, a sense of belonging and self-efficacy, relate to URM student participation in these programs and their academic success. To do so, it examined the relationships between program participation, these motivational resources, and academic achievement; dissected overall program participation into five components; and explored whether a sense of belonging or self-efficacy played a mediational role between program participation and academic success for URM STEM students. In doing this, the study made four primary contributions to research on college success for URM STEM students.

First, it considered how program participation may be influencing student selfperceptions of belongingness and self-efficacy along with their academic achievement. Program participation was looked at overall and as five distinct components that capture core program activities including career mentor dosage, career mentor quality, hands-on research experience dosage, research mentor quality, and workshop participation. As a result, the study was able to glean additional information about specific mechanisms within programs that may be particularly salient for URM STEM student success and may serve as a lever for programs designed to support the success and retention of these students. 
Second, the study looked at the motivational resources of students by examining two aspects of student perceptions: their sense of belonging and their convictions about their abilities to complete important scientific tasks. Given the potential salience of these self-perceptions for URM STEM students uncovered in previous research, these motivational resources were considered both as outcomes of program participation and as predictors of academic achievement, providing a more robust view of the sources and outcomes of the development of these motivational resources within this student population.

Third, the theoretical framework of this study considered the process of motivational resource development through the lenses of the student experience and the role of institutions. Thus, the study viewed the development of motivational resources as a complex process that involves both how student participation in various program activities may shape their sense of belonging and self-efficacy and what institutions can provide to support student's motivation as they pursue biomedical degrees. This focus on institutional context yields implications for colleges as it has the potential to highlight whether research program offerings are playing a role in increasing students' motivational resources.

Fourth and finally, this study considered the importance of motivational resources in the success of URM STEM college students by examining whether a sense of belonging and self-efficacy played a role in explaining how participation in these programs shaped academic success. Although the meditational role of these constructs 
could not be tested in this study, theoretical considerations of the mediational role of these motivational resources elevate that these self-perceptions may be an important pathway for students. Next, an overview of study results and a summary of key findings will be provided followed by a discussion of the strengths, limitations, and implications of this study.

\section{Summary of Findings}

In the next section, the results of this study are summarized for each program component and motivational resource. An overall summary of the research findings can be seen in Table 6.1 .

Overall program participation in an undergraduate research training program was hypothesized to be a key predictor of students' motivational resources and their academic performance. The zero-order correlations among these three constructs indicated that the two motivational resources were significantly interconnected, and both were significantly related to overall program participation. Counter to expectations, no connection was found between overall program participation and academic performance.

Analyses examining the five program components separately revealed that measures of quality for research and career mentors were linked as were the two indicators for research, namely, research experience dosage and research mentor quality. Surprisingly, workshop participation had a significant and negative relationship with both research experience dosage and research mentor quality suggesting that students who spend more time with their career mentors and rate their interactions with research 
mentors more highly, attend fewer workshops. When looking at links between each program component and the motivational resources, the only program participation components to show correlations with sense a belonging were research experience dosage and research mentor quality. These two program components, along with career mentor dosage and quality, were positively and significantly related to self-efficacy. Workshop participation, however, showed a significant, negative link with self-efficacy. When considering the links between each program component and academic performance, only research experience dosage was significantly correlated with students' academic performance. Finally, when examining zero-order correlations between the two motivational resources and academic performance, neither a sense nor belonging or self-efficacy had a significant link to academic performance. 
Table 6.1

Summary of Results

\begin{tabular}{|c|c|c|c|c|}
\hline \multirow[t]{2}{*}{ Predictor } & & \multicolumn{2}{|c|}{ Motivational Resource } & \multirow{2}{*}{$\begin{array}{c}\text { Academic } \\
\text { Performance }\end{array}$} \\
\hline & & $\begin{array}{c}\text { Sense of } \\
\text { Belonging }\end{array}$ & Self-efficacy & \\
\hline \multirow{2}{*}{$\begin{array}{l}\text { Overall Program } \\
\text { Participation }\end{array}$} & Zero-order & positive & positive & $n s$ \\
\hline & $\begin{array}{l}\text { Unique } \\
\text { effect }\end{array}$ & positive & positive & $n s$ \\
\hline \multirow[t]{2}{*}{ Career Mentor Dosage } & Zero-order & $n s$ & positive & $n s$ \\
\hline & $\begin{array}{l}\text { Unique } \\
\text { effect }\end{array}$ & $n s$ & positive & $n s$ \\
\hline \multirow[t]{2}{*}{ Career Mentor Quality } & Zero-order & $n s$ & positive & $n s$ \\
\hline & $\begin{array}{l}\text { Unique } \\
\text { effect }\end{array}$ & $n s$ & $n s$ & $n s$ \\
\hline \multirow{2}{*}{$\begin{array}{l}\text { Research Experience } \\
\text { Dosage }\end{array}$} & Zero-order & positive & positive & $n s$ \\
\hline & $\begin{array}{l}\text { Unique } \\
\text { effect }\end{array}$ & positive & positive & positive \\
\hline \multirow[t]{2}{*}{ Research Mentor Quality } & Zero-order & positive & positive & $n s$ \\
\hline & $\begin{array}{l}\text { Unique } \\
\text { effect }\end{array}$ & $n s$ & positive & $n s$ \\
\hline \multirow[t]{2}{*}{ Workshop Participation } & Zero-order & $n s$ & negative & $n s$ \\
\hline & $\begin{array}{l}\text { Unique } \\
\text { effect }\end{array}$ & $n s$ & negative & $n s$ \\
\hline \multirow[t]{2}{*}{ Sense of Belonging } & Zero-order & - & positive & $n s$ \\
\hline & $\begin{array}{l}\text { Unique } \\
\text { effect }\end{array}$ & - & - & $n s$ \\
\hline \multirow[t]{2}{*}{ Self-efficacy } & Zero-order & positive & - & $n s$ \\
\hline & $\begin{array}{l}\text { Unique } \\
\text { effect }\end{array}$ & - & - & $n s$ \\
\hline
\end{tabular}

Note: Zero-order means zero-order correlation, positive indicates significant and positive relationship, negative indicates significant and negative relationship, $n s$ indicates relationship did not reach significance.

When looking at the potential unique effect of each of the five program

components, particular components emerged as shaping these motivational resources.

For a sense of belonging, research experience dosage was the only program component 
that significantly predicted student's sense of belonging suggesting that students who spend more hours working in their research labs had higher levels of belongingness. When considering the effect of these components on the other motivational resource, self-efficacy, career mentor dosage, research experience dosage, and research mentor quality all emerged as significantly and positively related to self-efficacy suggesting that students who spend more time with career mentors and in research labs and who have high-quality ratings of their research mentoring interactions indicate higher levels of selfefficacy when considering their abilities to complete research related tasks. Conversely, workshop participation had a significant, negative relationship with self-efficacy. Although unexpected, the potential implications of this finding do not necessarily suggest that workshop participation is having a negative impact on student's self-efficacy but may speak to a more complex relationship. For instance, students with high levels of selfefficacy may be prioritizing more time in hands-on research experiences, where they feel competent to complete their assigned tasks, over attending workshops on a weekly basis. Additionally, students with higher levels of self-efficacy may have a higher involvement in research and academic-related activities or better ratings of mentoring relationships, which is consistent with the negative correlations found between workshop participation and career mentor dosage and workshop participation and research mentor quality, which may lead them to prioritize these things over workshop attendance.

Research questions $2 \mathrm{a}$ and $2 \mathrm{~b}$ considered the relationship between program participation and academic performance. Although overall program participation did not 
significantly predict academic performance for URM STEM students, the picture that emerges from analyses examining the role of program participation broken down by component suggests that research experience dosage shows a positive connection, consistent with the notion that it plays a role in shaping student's academic performance. Results indicated that students with more reported hours in research experiences also had higher levels of academic performance as measured by GPA.

Research questions $3 \mathrm{a}$ and $3 \mathrm{~b}$ considered the relationship between motivational resources and academic performance and found that neither a sense of belonging nor selfefficacy significantly predicted academic performance, suggesting that for the participants in this study, having higher levels of motivational resources did not coincide with higher levels of academic performance. Although this finding was unexpected, as these two motivational resources were hypothesized to positively influence student's ability to perform well in courses, there are several potential explanations which will be explored more in the implication section of the study. Research question 4 sought to examine the mediational role that motivational resources may play in explaining how overall program participation and relevant components shape academic success. However, due to the lack of significance in the relationships between motivational resources and performance for students, these relationships could not be tested.

\section{Strengths and Limitations}

Although this study has the potential to offer higher education administers and practitioners insight into how to best support URM STEM students as well provide 
grounds for future studies that may be of interest to higher education researchers, it has several limitations. The following section will detail both the strengths and limitations of the study's design, measurement, and generalizability. This will be followed by suggestions for future directions for research on this topic and implications for higher education practitioners and administrators.

Design. A strength of this study is that it provided an in-depth exploration into the experience of URM STEM students in biomedical disciplines who are embedded in a multiyear program designed to support their progress to careers in biomedical research. The complexity of the program design and three-year model of student participation provided an ideal context in which to examine the important, yet under-researched, motivational resources that may play a significant role in URM STEM student success.

A notable limitation of this study, however, is that it is cross-sectional. Although the conceptual framework posited program participation as an antecedent and academic performance as an outcome, this cross-sectional information provided no information about causal precedence and could not rule out potential alternative explanations. As a result, no information about the direction or reciprocal nature of these relationships was uncovered in this study.

The motivational resource variables and student GPA were taken at only one-time point and so these measures provide just one snapshot of the student experience and may not be an accurate representation of students' true self-perceptions or academic performance, especially if these processes fluctuate or develop over time. Furthermore, 
the motivational resource measures were collected just a few months after students were placed in their research learning communities. Given that this study was interested in how program participation may be shaping motivational resources for these students, asking students about their sense of belonging and self-efficacy closer to the end of the program, after more than a year in their research placement, may have provided more information about this connection.

A longitudinal study, which carefully considers the best time to collect information about program participation and student self-perceptions, could provide crucial information about how the student experience unfolds over the course of several years. Short-term longitudinal data could come closer to causal influence by using antecedents to predict changes in student achievement over time. Studies could gain more information about the strength and directionality of these relationships by measuring all constructs at several time points for students while in the program, thus providing a fuller picture of how participation and students' motivational resources may relate to ongoing academic achievement or changes in achievement.

A second limitation of this study design is study participants came from two EXITO cohorts but potential differences in students' experiences based on cohortspecific program implementation were not examined in this study. As EXITO continues to serve students, it likely adapts workshop content, mentor matching processes, mentor training materials, and more based on learning from previous cohorts. These changes could significantly shape the student experience and subsequent outcomes. Future 
studies, in addition to examining cohort effects within a longitudinal design, should consider using students from only one cohort or only conducting analyses after the program has been fully implemented.

A third limitation of this study is the lack of a comparison group. As a result, the study is not able to attribute students' motivational resources or academic achievement to program participation. This leaves a gap in understanding of if and how URM STEM students who participate in structured training programs benefit compared to similar students who are not in these programs. Future work may consider a randomized control trial in which students from similar backgrounds are randomly assigned to treatment and control groups.

Sample size is a fourth and final design limitation worth noting in the current study. The small sample of participants available for this study may have reduced power and impacted the potential for finding significant patterns in relationships between the variables of interest. Future studies should examine these relationships in a larger sample of students.

Measurement. One significant strength of this study's measurement is that the five distinct program participation components are measured as a composite of monthly reports over the course an academic year. As such, students were not required to retrospectively reconstruct their mentoring relationship when reporting quality or dosage. However, a limitation is that by combining months into a composite score, fluctuations or changes in dosage or quality of mentoring interactions could not be examined. 
Additionally, students with more monthly ratings represented in their composite score may have given a more robust indicator of their relationship dosage and quality.

A sense of belonging and self-efficacy were also measured by creating a composite score of the items in each scale which removed the opportunity to examine differences in responses across items. For instance, students could have rated their belonging to the "field of science" extremely low due to not feeling a connection with the larger scientific community while rating their sense of belonging to their group of researchers very high because of their connections in their hands-on research community. For self-efficacy, potential differences in student self-perceptions of their abilities to complete activities such as "generate a research question" and "explain the results of a study" may surface important information about how to support students in these placements. Future work may want to isolate student ratings of belongingness and selfefficacy for each domain and task to better understand these student perceptions.

A strength of the study is that academic performance was measured with institutional record data and did not rely on student reports of grades. However, a third measurement limitation is that program participation measures were provided via a platform that tracks students' mentoring relationships within the EXITO program which may have influenced students' willingness to be candid about perceptions of mentoring relationship quality or honest about time spent in these environments. Although students were assured that their responses are confidential, they were also aware that program staff regularly review these monthly reports. Should a student report low-quality scores about 
their interactions with a mentor, they might fear that mentors would discover their responses and retaliate. Additionally, reports of dosage scores could be impacted by a student's need to meet certain participation thresholds to remain in good standing in the program. Having completely unbiased scores for dosage and quality is important because it allows researchers to truly understand how the quantity and quality of these program components may serve students on their pathways. Future work may avoid this limitation by giving students a separate, anonymous survey that asks about program participation and mentoring relationships used only for evaluation purposes.

A fourth limitation is that this study did not consider the wide range of assets students bring to the college environment both as they transition into college and develop along their pathways. URM students transition into college with a host of positive experiences and relationships, along with many other attributes that may support them in their academic pursuits. Future research might consider examining the assets these students bring into their disciplines and how these assets shape their experience.

Finally, although a previously noted strength of this study is that program participation is broken down into five distinct program components, these components were chosen because data were available on them and yet they do not represent the program model in its entirety. As a result, key information on peer mentoring relationships or details about scientific conference presentations were missing from these analyses. This could lead to inaccurate information regarding student outcomes or leave out some of the key mechanisms that could be utilized to support students in these 
programs. Future work should find a valid way to measure all core activities within a research training program so that the details necessary for the replication of various components are available to practitioners.

Generalizability. One notable strength of this study is a very racially and ethnically diverse group of students in the sample. The participants included students who identified as Black/African American, Asian, Pacific Islander, White, Alaska Native or American Indian, Mixed Race, and Other. As a result, the perspectives from numerous underrepresented and marginalized groups are included in this study. However, a notable limitation is that these racial and ethnic categories placed students into just one racial group which may not accurately capture how they identify. In addition, for some of these racial/ethnic groups, the number of students was quite small which limits the opportunity to consider the unique perspectives and experiences of each group. Future work may consider examining motivational resources and program participation for larger subsets of the URM student population to surface unique and varied experiences for students in these unique minority populations.

Students in BUILD EXITO are selected because of their passion for science, previous academic success, and ability to articulate a meaningful interest in research. This presents a second limitation which is that selection bias in the sample may limit the generalizability of results because the students who were invited to participate in this program may not represent the broader URM STEM student population. Future work 
might consider reducing program criteria and allowing any interested URM STEM student to participate, increasing the likelihood of a more representative sample.

A third generalizability limitation is that all students in the sample are participating in a research training program that was designed specifically to serve students at particular campuses. Because of this, generalizing these findings to URM STEM students who are participating in other programs may not be appropriate. Future research might consider finding programs at a variety of institutions that share common program components and looking at the experiences of students across these programs.

\section{Implications for Research}

This study has important implications for higher education institutions and for future researchers interested in underrepresented minority (URM) student success in science fields (STEM). The following section will address implications that may shape researchers' perspectives on the URM STEM student experience and influence future study directions by discussing each of the main components included in this study: academic performance, motivational resources, and facets of student participation in a program designed to support URM undergraduates majoring in STEM disciplines.

\section{Academic Performance for URM STEM Students in Research Training Programs}

Study results indicated that although research dosage showed a significant and positive relationship with academic performance for URM STEM students, the two motivational resources and the remaining four program participation components were not significantly related to GPA. These results must be understood in the larger context 
of the measurement and conceptualization of student performance in this study. Specific and important considerations include the measurement of academic performance via GPA, whether GPA is a robust indicator of student learning, the contextual factors that may shape students' performance, and possible explanations for the link between GPA and research dosage.

Measurement of academic performance. Academic performance in this study was measured using students' cumulative GPA up to the final term of their second year in the program. This operationalization likely impacted the study's ability to examine the relationships of interest because academic performance included students' GPA over their entire undergraduate education, not just their GPA while in the program. EXITO Scholars enter the EXITO program with a wide variety of undergraduate histories. Some students have only one year of credits whereas others have several years of undergraduate experience. This measure of cumulative GPA includes academic performance for the time before students were participating in the program and grades in courses that may be unrelated to their current discipline. Future researchers should consider measuring GPA only while students are actively participating in program activities and may want to isolate classes that only fall within the major requirements for each student to best understand the link between program participation and concurrent performance.

GPA as a marker of student learning and academic performance. Although GPA provides an indicator of a student's academic achievement within classes, it may not be a satisfactory measure of student learning or success for two key reasons. First, 
GPA may be insufficient as a marker of student performance because it provides only one indicator of how effectively students are learning by considering only final course grades. Given the complex and multi-dimensional process of learning for students, course grades may not adequately capture how much a student is learning because they do not factor in how much a student knew about a particular topic when they started the course. Future research should consider assessing student performance by measuring student's content knowledge before and after taking the course to understand the amount of content that students are learning during the course. $\backslash$

Second, GPA as a proxy for student learning leaves out important learning experiences that happen outside of the classroom. College students engage in the learning process in a variety of contexts. For instance, students in research training programs are attending workshops and participating in hands-on research experiences, spaces they are engaged in the learning process and demonstrating their understanding of scientific concepts. Future research should consider student learning in contexts outside of the classroom when examining the effects of motivational resources or program participation on student performance.

Contextual factors impacting GPA. Grades given for student performance do not represent an objective or universally recognized set of standards for students' academic achievement. GPA captures course grades given by professors grading with different metrics, providing varying levels of academic support, and working within a unique discipline. Two important considerations regarding contextual factors beyond 
student effort that may shape GPA include differences in grading norms between classes and how being a URM student has shaped college preparation opportunities and oncampus interactions for students.

Students in BUILD EXITO represent over twenty STEM-related majors, each with different coursework and academic task requirements. These potential differences and lack of standardized grading practices, make drawing conclusions about URM STEM student academic performance from the findings of this study particularly challenging. Two notable ways that differences in GPA might manifest for these students are through varying course difficulty and differences in modes of testing across courses. For the first, a student who completed an extremely rigorous organic chemistry class may have a lower course grade when compared to a student who took an elective in the sociology department based on grading norms in these departments. For the second, different disciplines and courses may test student learning with various modalities resulting in different grades. For instance, a student who takes a biology class may receive a grade that is the average of several scantron tests while a student in a psychology course may get a final grade based on several written assignments on which they were given feedback from their instructor. In future studies, researchers may consider standardizing grades within each major to account for differences in grades between disciplines. Alternatively, future research, using much larger samples, could consider potential differences in grades that may result from differences in course difficulty and testing modes by examining 
connections among GPA, motivational resources, and program participation separately for students from different majors.

In order to examine whether the relationships between students' program participation and GPA was moderated by the larger disciplinary focus of their major, the current study also conducted a small exploratory analysis examining the relationship between program participation, motivational resources, and academic performance for students divided into two groups based on their major. The first was made up of students with more traditional "natural science" majors such as biology and chemistry while the second group included all students who were from the "social science" majors such as psychology and social work. These analyses revealed no differences in the links between program participation, motivational resources, and academic performance as a function of disciplinary major. Although this would suggest that major did not play a role in these relationships for students, it is still highly likely that discipline and course-related factors are impacting student's GPA. Future studies may be able to more closely examine these factors if a measure of GPA was used that focused on courses only from the students' major.

A second potential set of contextual factors shaping student academic achievement stems from student's membership in a minority group. As discussed in this study's literature review, URM students often have reduced access to academically rigorous science courses and other opportunities designed to help prepare students for difficult STEM majors in college. Additionally, it is well documented that once these 
students arrive on campus, they typically face bias and discrimination in their courses which may play a role in how students are graded. Furthermore, URM students may struggle in classes where they do not feel welcome and have higher academic performance in classes where professors prioritize creating an inclusive classroom climate. Until these barriers are removed for minority students, we should remain highly skeptical of grades as markers of student learning or success.

Research training program target outcomes. The lack of correlation between program participation and GPA may also be explained, in part, by the focus and intent of research training programs which often dedicate significant effort to outcomes that go beyond student's course grades. For instance, although BUILD EXITO naturally encourages students to perform well in classes as a part of their efforts towards future goal attainment, the program also focuses on cultivating students' ability to overcome "imposter syndrome," supporting them to persist in the face of ongoing microaggressions, and fostering a strong identity as a person who can contribute significantly to their lab and the broader scientific research field. Given the significant link between program participation and the motivational resources that emerged in this study, it is likely that students are reaping significant benefits related to their success from participating in EXITO. Future work may conduct in-depth interviews inquiring about student's perceptions of what they are gaining and take a more holistic view of student performance by including other markers of success such as persistence and commitment to a science career. 


\section{Research experience dosage and academic performance for URM STEM}

students. Although most of the program components did not emerge as significant in shaping URM STEM student academic performance, regression results indicated that research experience dosage was significantly and positively related to academic performance for the students in this study. There are several possible explanations for this connection.

First, hands-on research experiences may help students develop a particular selfperception that helps them perform better in their classes. Students in research placements have the opportunity to engage in research team meetings, give input on study design, assist with the interpretation of results, and present their research. These activities could help students develop a greater scientific identity which could allow students to more confidently approach their academic work and increase achievement in their courses. Another possible mediating factor in this relationship could be an increase in students' perceptions of the relevance of content being taught in courses. For instance, a student who is placed in a psychology lab completing data collection with structured qualitative interviews may have an increased interest in mastering these concepts in their research design course and thus perform better in the class. These are only a few of many possible mechanisms that may explain why students who spend more time in their research labs also perform better in their courses and future studies may want to consider testing constructs that may play a mediational role in this relationship. 
Second, the correlational nature of these analyses may present a feedforward effect in which students who perform better in classes are more likely to spend more time in their research learning environments. This could be the result of certain characteristics or qualities about the student, such as better time management skills, that allow them to be high performing in all academic settings. Longitudinal studies would be able to uncover this feedforward effect.

Summary. In sum, study results related to students' academic performance must be understood in the context of limitations of the measurement of GPA and the conceptualization of student performance in this study. These include that GPA was cumulative and measured only once, that GPA may not be a robust measure of academic performance, that there is a lack of standardized grading across courses, that additional contextual factors beyond the scope of this study may be influencing students' GPA, and that target program outcomes extend beyond focusing solely on student academic performance. First, researchers could develop a better way to measure student learning and consider this process for students both inside and outside the classroom. Second, researchers could work to capture research dosage and GPA at multiple time points to separate the feedforward and feedback effects in this relationship and examine the directionality and strength of this connection. Third, future studies could consider other mediators in this process such as self-confidence and science identity to understand how program participation may be shaping student performance.

\section{Motivational Resources of URM STEM Students in Research Training Programs}


Results from this study raise several important considerations about the motivational resources of URM STEM students for researchers to consider in future studies, including the measurement of motivational resources, the conceptualization of motivational resources, the role of academic performance in motivational resource development, how program participation may be linked to higher levels of belongingness and self-efficacy, and possible additional motivational resources of URM STEM students to consider.

\section{Measurement of motivational resources.}

Sense of belonging in science. In this study, a sense of belonging was measured by selecting from a 5-item pool which included survey questions that asked students about their belonging in various scientific domains. After removing items that reduced the internal consistency, four items were selected for the final scale. Study results have the potential to provide important insight into the role of belongingness for URM STEM students. However, an important consideration around the measurement of a sense of belonging is the potentially multi-dimensional nature of this measure.

Although the small number of items available to measure belongingness could have produced poor reliability, the internal reliability consistency of the scale was strong, with a Cronbach's alpha of .797, providing an indication that these items measured a core construct for students. At the same time, these four items included questions that looked at belongingness in several, broad domains which may have represented different contexts to different students. If this construct was, in fact, multi-dimensional, four items 
would not provide sufficient information to detect these distinct dimensions. Future research may consider better defining domains for student belongingness and adding more items for each domain, allowing for belongingness scales that are more clearly and precisely focused on targeted contexts. In particular, the belongingness scale from Strayhorn's (2015) Student Success Questionnaire (SSQ) may be particularly useful as it is multi-dimensional and has been validated with URM college students in past studies.

Scientific self-efficacy. The self-efficacy items in this study, which were been previously tested and proved to be reliable (Chemers et al., 2011; Robnett et al., 2015), included 10 items asking students about their confidence in their ability to complete basic science and research related tasks. These items demonstrated good internal reliability consistency with a Cronbach's alpha of .894 . However, the 10 items that compose this self-efficacy scale may not adequately capture the core, essential research tasks for all the biomedical disciplines represented in BUILD EXITO.

Given the array of majors that EXITO students represent, the tasks listed in the selfefficacy items in this scale may not necessarily capture students' self-efficacy to complete important scientific tasks equally well for all students. Items such as "use technical science skills (use of tools, instruments, and/or techniques)" and "ask relevant questions" likely have higher prevalence or importance in particular labs. Additionally, in some cases, low scores could represent a lack of exposure or knowledge about particular tasks based on their proximal research environment. Future research should consider discipline 
and lab-specific tasks and avoid tasks that may only apply to particular types of research settings.

\section{Conceptualization of motivational resources.}

Sense of belonging in science. In this study, a sense of belonging was conceptualized as a student self-perception that would be developed and shaped by participation in an undergraduate research training program and lead to higher academic performance for students. Several implications of this conceptualization are worth discussing including the lack of consideration of the multi-dimensional nature of belongingness and the importance of examining differential experiences of belongingness across groups.

First, this study's literature review surfaced the multi-dimensionality of the belongingness of minority students yet the conceptualization of a sense of belonging in this study may not sufficiently capture the breadth and depth of student experiences. The items in this study may have neglected important considerations of belongingness such as with peers on campus. Additionally, a sense of belonging for students likely differs across contexts or may shift within a context. For instance, a student may have a high sense of belonging in their lab when working with peers but feel very isolated in research team meetings. Attempting to assess students' perceptions of their belongingness in science with just a few items likely provides only a small glimpse of students' beliefs 
about belongingness and leaves out important information that might help explain how a sense of belonging shapes the URM STEM student experience. Future studies interested in belongingness for students should consider adding items that would better capture the breadth and depth of this student perception by assessing different experiences within scientific contexts and adding items to assess belongingness in additional, related contexts.

A second important implication is that this study did not account for how belongingness may differ across minority groups. Students likely think about what it means to belong in a variety of ways and cultural identity, such as being from a collectivist or individualistic cultural background, may play a role in how students think about their belongingness in scientific settings. On one hand, it may be that minority students in scientific environments would describe their belonging in similar ways. On the other hand, particular student groups may have unique ways of understanding and expressing their sense of belonging in these settings. Future work should consider adding a qualitative component that provides an open-ended way for students to provide their perspective on how they define and experience a sense of belonging.

Self-efficacy. In this study, the conceptualization of student's scientific selfefficacy was guided by Ballen and colleagues (2017) who operationally defined this concept as a student's self-reported confidence in their ability to do science. However, this conceptualization requires exploration of the role of non-research related tasks along 
with how belonging to different URM student groups may be shaping student's selfefficacy.

First, this study did not look at student's confidence in their abilities to perform tasks that may be necessary to be successful but were not directly tied to research work. For instance, the tasks did not include any assessment of a student's ability to raise their hand for clarification in a course, to ask for academic assistance when struggling, or to network at a conference. Future studies should consider self-efficacy related to tasks outside of students' research placements and may also consider measuring similar constructs such as students' perceived competence and self-confidence.

Second, this study's literature review discussed numerous challenges including bias, discrimination, and stereotype threat that URM STEM students regularly face. These experiences may differ across URM groups and differentially shape student selfperceptions. For instance, some students may belong to groups that are more regularly socialized to believe that they are unfit for a career in science yet this study did not consider how belonging to these groups may be impacting student's perceptions of their abilities to complete lab work. Future research should consider the influence of racial and ethnic identity on students' self-efficacy.

Student performance and motivational resource development.

Sense of belonging in science and student academic performance. This study surfaced no significant relationship between students' sense of belonging and their academic 
achievement. However, given the limitations in conceptualization and measurement of both a sense of belonging and student performance that were previously discussed, it is still plausible that the level to which students feel they belong may influence their achievement in academic work. There are several considerations for future research that may help provide a deeper understanding of this possible connection.

First, the items from this study did not ask students about belongingness in their courses or disciplines. It is theoretically justifiable that student levels of belongingness in a particular course would be linked to how they perform in that course. Research to date on the URM STEM student experience in the classroom has suggested that students face bias and discrimination within their STEM courses which may negatively impact their academic performance. Future work may consider asking students about their sense of belonging in their courses to understand how academic performance is shaped by students' sense of their belongingness within that class.

Second, there may be other processes that explain the relationship between the self-perception of belongingness and the desired student outcome of academic performance that were not explored in this study such as student engagement or levels of self-confidence. Students also may be performing well in their courses and see this as incongruent with stereotypes about their minority group, leading them to feel less like they belong. Future research could look more closely at these processes by asking more questions about how a sense of belonging influences students' perceptions and behaviors in their academic work. 
Scientific self-efficacy and academic performance. The hypothesized relationship between self-efficacy and student academic performance did not emerge in these analyses. Although previously discussed issues with the measurement may have contributed to this, there are two additional and important considerations on this topic.

First, the self-efficacy task focus of this study was within the research lab and tasks related to academic performance in courses were not considered. It is plausible that if students had been asked about their confidence in abilities to complete academic tasks required for their classes, this link may have surfaced. For example, a student may feel confident in their abilities to complete a task in their lab but they may feel nervous about their ability to do well on a general chemistry test. Future research may consider this link by asking students to rate their confidence to complete the tasks required for success in their courses and majors.

Second, this study's measurement of academic performance may not have adequately captured students learning or success because it was cumulative GPA for student's entire undergraduate career and did not target their performance while in the program. If the student performance measure in this study had targeted GPA for the term in which self-efficacy was assessed, students with higher self-efficacy may have performed better in their classes. Future research should address student performance measurements to better understand this connection.

The feedforward effect of academic performance on motivational resources. It is possible to think about the lack of correlational connections between these constructs 
as revealing something about a feedforward effect of academic performance on motivational resources. If BUILD EXITO succeeds in its goal to give students tools to successfully navigate their pathway to a career in biomedical research by increasing their science identity, confidence, and more, it is plausible that students would increasingly see themselves as worthy to contribute to the scientific research field. More specifically, they may begin to understand that this contribution goes beyond their academic performance in classes. For instance, students may feel an increased sense of belonging in science as a result of the program and become less focused on perfect academic performance because of the value in their work outside of courses. This suggests that BUILD EXITO may be building a program that supports students at varying levels of performance and successfully helping them develop their sense of belonging and selfefficacy. Future research should consider asking students how program participation may be shaping their understanding of their contributions and identify additional indicators of success that students are recognizing on their pathways.

\section{Program participation and motivational resources.}

Sense of belonging. Study results suggested that students with higher levels of dosage and quality ratings in various program components also indicated higher levels of belongingness. When breaking down participation into distinct components, only research experience dosage had a unique effect, showing a positive connection with a sense of belonging. This link has a couple of possible explanations. 
First, this link may be explained by relationships formed with researchers within the lab environment. Students in these labs spend time working alongside these individuals, attend team meetings, and travel to conferences with their lab mates. These relationships may serve as an important catalyst to increase student belongingness because they meet the basic needs of relatedness and connection for students in these scientific environments, thus developing and reinforcing students' sense of place in science. Future research should consider asking students about the role of these relationships in shaping their sense of belonging in science.

Second, the connection between time spent in the research lab and students' sense of belonging may be explained by a feedback effect where students who have higher levels of belongingness are more likely to spend more time in their lab. Students who feel more like they belong in science generally may actively seek out ways to spend more time in these environments. Future studies could separate out this feedback effect by measuring a sense of belonging at multiple time points and also considering how baseline levels of belongingness may shape research experience dosage for students.

Self-efficacy. In addition to overall program participation being connected to higher levels of self-efficacy for students, zero-order correlations from this study surfaced that all distinct program components had a significant link to self-efficacy. Regression results indicated unique effects in positive links between self-efficacy and career mentor dosage, research mentor quality, and research experience dosage and a surprising, negative link between workshop participation and self-efficacy. The resulting 
implications for future research on URM STEM student success will be discussed in the following section.

Students who spent more time with their career mentors demonstrated higher levels of self-efficacy suggesting that these mentoring relationships may have positively shaped students' confidence in their abilities. These mentoring relationships, which are designed to focus on meeting particular student needs, may serve as confidence boosters for students and may also buffer students against the negative effect of discrimination and bias on campus. This relationship is not tied to academic performance or lab work and as a result, students may be forming stronger and more personal bonds with these faculty which in turn may bolster their self-efficacy. Take a student, for instance, who brings a concern about their ability to succeed in the lab to their career mentor who responds with affirmation and encouragement about their abilities. Numerous interactions of this nature over time with this mentor could have a significant impact on how students think about their own abilities. Future studies should capture more information about mentor qualities and conversation topics to understand the particular mechanisms in these relationships that may increase self-efficacy for students.

Second, students who rated the quality of their interactions with their research mentor higher were more likely to have higher levels of self-efficacy. Students in these lab environments may be intimidated by working with researchers and encounters with these research mentors may significantly shape their perceptions of their abilities in the lab. It is not surprising, then, that students who feel better about their encounters with 
these mentors are also more confident about their abilities. Consider, for instance, a research mentor who listens openly and patiently to a student's concerns about their ability to complete assigned tasks. This mentor may provide additional support and training including specific strategies for students that allow them to be more effective in completing tasks, which may, in turn, increase their self-efficacy. Future research may want to better capture the processes in these interactions to understand practically how research mentors can support students and increase their confidence in lab work.

Third, students who spend more time in their research lab also felt more confident that they could complete research tasks. One on hand, it could be that students who had more time in their lab had a chance to practice research tasks more often and were, therefore, more confident in their abilities. On the other hand, it could also be that students who have higher levels of self-efficacy were more likely to spend more time in their research labs. Future studies should capture dosage and self-efficacy at multiple time points to understand the directionality of these relationships and potential reciprocal effects.

A final significant relationship that surfaced between program components and self-efficacy was a negative link between workshop participation and self-efficacy. It could be that students with higher levels of self-efficacy were less likely to attend workshops because they saw less importance in gaining particular skills they believed workshops were designed to highlight. These students may, instead, be prioritizing spending more time in their research experiences or participating in other academic 
activities. Future studies could better understand this negative link by capturing student perceptions of workshops to better understand how students see the importance of this component compared to other activities.

\section{Additional motivational resources and assets of URM STEM students.}

Future studies should look beyond a sense of belonging and self-efficacy to consider other assets students bring with them, including additional motivational resources. For instance, student's self-confidence, academic engagement, peer relationships, or involvement on campus may all serve as significant mediational pathways in these relationships. Moreover, URM STEM students bring a host of assets into their college environments including supportive family relationships, the ability to persevere, strong peer networks, and much more. Future work should consider examining how students' assets may influence their participation in undergraduate research programs, their motivational resources, and their academic performance.

\section{URM STEM Student Undergraduate Research Training Program Participation}

Results from this study raise several important considerations regarding the study of URM STEM student participation in undergraduate research training program including the ways in which program participation and its various components may differentially shape URM STEM student success and the importance of creating a more comprehensive conceptualization of program experiences.

Differential effects of different components of program participation. When program participation was broken down into five components, several significant 
connections emerged between various components, a sense of belonging, self-efficacy, and academic performance. These results provide important implications for future research on some of the key activities within many research training programs including research experience, research mentoring, career mentoring, and workshop participation which will be discussed in the following sections.

\section{Research experience dosage, motivational resources, and academic}

performance. Research experience dosage was the only program component with positive and significant relationships to both motivational resources and academic performance. Potential explanations for these connections were explored in previous sections but two additional implications are worth noting: the need for significant amounts of time in placements to reap benefits from these types of experiences and the impact of the exposure that hands-on research experiences provide for students.

A first potential explanation for these connections is that students who spend more time in their research experiences have the opportunity to master particular tasks and make greater contributions to the work leading to numerous positive outcomes for these students. It seems likely that the opportunity to achieve mastery of research related tasks has the most likely connection with self-efficacy, but it is also plausible that this dedicated time spent in the lab working on particular research projects also serves to deepen students' connections in the lab resulting in a higher sense of belonging and may even lead to better academic performance. Future researchers may want to compare 
student groups based on how much time they spend in their research placement and attempt to identify a threshold for participation that optimizes student outcomes.

A second possible explanation could be that increased exposure to dynamic and diverse scientific environments broadens students' perspectives and enhances their overall self-perceptions and performance. For instance, a student may travel to an international conference and get the chance to speak with a researcher at the top of their field. This may result in feeling a greater connection to their place within the broader research community, higher levels of confidence in their ability, and even increased engagement in their discipline courses. Future studies could more closely examine the impact of this exposure by capturing engagement in these activities throughout their participation in their research training program.

Research mentor quality and self-efficacy. Zero-order correlations were found between research mentor quality and both motivational resources and regression analyses surfaced a significant and positive relationship between research mentor quality and selfefficacy. Given the importance of high-quality interactions in these mentoring relationships, there is a need for a deeper understating of the nature of these interactions along with a better grasp on how these high-quality interactions may shape students' motivational resources.

First, monthly logs asked students to provide an overall rating score for the quality of their research mentoring interactions but did not gather any information about what led them to this rating. Examining the precise mechanisms within these 
relationships that may be responsible for students' ratings in future research is important because it may allow researchers to uncover information that could be used to create training modules for these mentors. Future research should look for ways to examine research mentor characteristics and content of mentor/mentee interactions.

Second, although quality interactions for research mentoring relationships appear important, how these quality interactions are shaping motivational resources remains a question. It could be that higher quality research mentor ratings shaped student levels of belongingness because students perceived these mentors to be warm and approachable in lab environments. Regarding student self-efficacy, it could be that higher quality ratings were the result of instrumental lab training that research mentors. Most likely, these interactions and the motivational resource development of these students are the result of ongoing proximal processes in these relationships. Future studies may consider asking students what precisely about these interactions results in important forms of support for them.

Career mentoring dosage, quality, and self-efficacy. Study results revealed that both career mentor dosage and quality had positive and significant zero-order correlations with self-efficacy. Career mentor dosage had a unique effect on self-efficacy in subsequent regression analyses. Potential explanations for this effect were discussed in the previous section. These results highlight the importance of the career mentor role in the EXITO program and provide justification for a more careful examination of these types of mentoring relationships. 
For EXITO, career mentors are faculty members who offer encouraging guidance to scholars on a range of academic and career development topics and this relationship is designed to be customized to each student based on their unique needs. Given that this study did not examine the nature of these relationships or interactions, there is limited information about why the quality and dosage in these relationships may have shaped self-efficacy for students. It could be that the open-ended nature of these relationships in which students' get to customize their interactions based on their needs, serves to bolster their confidence. Future work may want to dive into the particular characteristics of career mentors, the nature of conversations between career mentors and students, and students' perceptions of the support and assistance provided in these mentoring relationships.

The role of mentoring quality and dosage. Results from this study indicated that both dosage and quality of mentoring relationships within an undergraduate research training program may play a role in shaping students' motivational resources. However, the study did not consider whether the quality of these mentoring interactions plays a role in the effect of career mentor dosage and research experience dosage on a sense of belonging or self-efficacy. Future research may consider examining the potential interaction of quality and dosage to better understand the salience of quality within these mentoring relationships and whether higher quality relationships differentially shape a sense of belonging and self-efficacy for URM STEM students when they spend more time in these environments. 
Workshop participation and self-efficacy. As previously discussed, a surprising negative link was found between workshop participation and self-efficacy. This does not, however, mean that participating in workshops has a negative effect on students but has alternate explanations including that students may have a greater drive to attend workshops when they have low levels of motivational resources. It is possible that students are more likely to attend workshops when they have lower levels of a sense of belonging and self -efficacy as a way to bolster their self-perceptions and prepare themselves for the work ahead. Future research interested in the role of workshops in URM STEM student success should capture information about motivations for attending these workshops.

\section{Implications for Program Development and Implementation}

Results from this study raise several important implications for practitioners working to design and implement research training programs for URM STEM students and administrators in higher education working on efforts to support diverse students on their campuses. The following sections include a discussion on key takeaways for those in program development, the importance of continuing to build a broad framework for conceptualizing URM student success, and considerations for those evaluating program effectiveness.

Developing undergraduate research training programs. In this study, overall program participation was linked to the motivational resources for URM STEM students and research experience dosage was positively related to student achievement. 
Practitioners developing programs should consider a few key takeaways from these findings.

First, this study advanced what is known about how to support URM STEM students by providing evidence regarding the potential role of hands-on research in supporting the development of students' motivational resources and promoting their academic achievement. From this study, it appears that this experience is valuable for student success both in developing positive self-appraisals and performing well in courses. As program models are developed and adapted, practitioners should pay careful attention to student opportunities for hands-on research and ensure that students have adequate access to these opportunities.

Second, those who develop and implement programs must think intentionally about what each component provides for students and how these experiences could best be scaffolded and sequenced to support students. It is not sufficient for practitioners to design complex and multi-faceted programs without carefully considering what each component adds to the student experience and how to intentionally scaffold experiences to optimize potential program impact. In sum, practitioners must place a high priority on considerations of how, why, and when program components will be most effective in supporting URM STEM students.

\section{A theoretical framework for URM STEM student participation. An} important take-home message from this study is that a broader and more comprehensive 
theoretical framework is needed to capture the most critical elements for URM STEM student success and the mechanisms that play significant roles in these relationships.

First, this study suggests blocks of constructs that are necessary for examining the URM STEM student experience. The first block included institutional level phenomena and captured opportunities and affordances on college campuses available to URM STEM students. Next, the study looked at individual level motivational factors by considering students' motivational resources. Finally, the study looked at student outcomes by examining students' academic performance. Higher education administrators can contribute to the ongoing conversation about the central and important elements of this theoretical model by recognizing the role of institutional and individual factors in shaping student outcomes and the ways in which these relationships are dynamic and reciprocal.

Second, this study highlighted the need for a more intentional focus on the mechanisms and processes within the student experience at college. Although the study worked to identify participation levers and important self-perceptions for students, practitioners can expand what is known about how to support students by thinking carefully about the many contextual factors and processes within these student experiences and work to build programs with this complex and multi-faceted web of relationships in mind.

Evaluation of undergraduate research training programs. Higher education administrators and practitioners could benefit greatly from more empirical evidence 
regarding whether these programs are effective. Evaluation teams who are tasked with considering the efficacy of these programs should design studies that can uncover the nature and directionality of relationships between participation and desired outcomes and look carefully at mechanisms within each program component.

First, given that many past studies considering undergraduate research training program effectiveness have been correlational in nature, evaluation teams should create study designs that can capture the directionality and changes in these relationships over time. This study's theoretical model suggested that participation in a research training program might lead to higher levels of belongingness and self-efficacy. However, the opposite direction of effects is equally plausible. A sense of belonging could be the driving force that propels students to engage in program activities. It could also be that high levels of self-efficacy are enabling students to engage in more deeply in the program. Additionally, a sense of belonging and self-efficacy levels likely change over time and these trajectories of students' motivational resources provide insight into important self-perceptions with demonstrated connections to student success. Evaluators should design studies that measure students' attitudes, participation, and desired outcomes at multiple time points and use these longitudinal data to test the directionality and strength of these relationships.

Second, it is not sufficient to only consider if these programs are supporting students, much more information is needed about how program components function. Understanding these experiences more deeply may provide crucial information about 
how programs can best support students and are needed for any attempts at program replication. Evaluation teams play a crucial role in uncovering this information based on their areas of focus and the types of information they gather from students. Work to understand the student experience within each program component must be prioritized along with efforts to collect program information about elements such as workshop content and mentoring relationships. Before program implementation, evaluators should put significant time and effort into creating an evaluation plan that prioritizes data collection that can illuminate the most salient mechanisms within each program component in the program model.

Summary. The findings from this study contribute to future research on this topic by highlighting links between program participation, a sense of belonging and selfefficacy, and academic achievement. By looking from individual student attitudes all the way up to the institutional level and using program participation as an antecedent, this study shifted the focus from the individual attitudes or behaviors of URM STEM students, to opportunities at the institutional level to support these students, thus placing responsibility on institutions to move beyond a deficit-based approach to student success to instead work to create environments where all students can thrive. Ultimately, it is the responsibility of institutions to provide students with opportunities that allow them to develop a sense of belonging and self-efficacy at college. Higher education administrators and those working on student success efforts can continue to deepen their 
commitment to this responsibility through the creation and implementation of effective undergraduate research training programs. 


\section{References}

Adedokun, O. A., Bessenbacher, A. B., Parker, L. C., Kirkham, L. L., \& Burgess, W. D. (2013). Research skills and STEM undergraduate research students' aspirations for research careers: Mediating effects of research self-efficacy: RESEARCH SKILLS AND STEM UNDERGRADUATE RESEARCH. Journal of Research in Science Teaching, 50(8), 940-951. https://doi.org/10.1002/tea.21102

Ali, S. R., McWhirter, E. H., \& Chronister, K. M. (2005). Self-Efficacy and Vocational Outcome Expectations for Adolescents of Lower Socioeconomic Status: A Pilot Study. Journal of Career Assessment, 13(1), 40-58.

Allen, D. (1999). Desire to finish college: An empirical link between motivation and persistence. Research in Higher Education, 40(4), 461-485.

Allen, W. (1992). The Color of Success: African-American College Student Outcomes at Predominantly White and Historically Black Public Colleges and Universities. Harvard Educational Review, 62(1), 26-45. https://doi.org/10.17763/haer.62.1.wv5627665007v701

Allen, W. R., Bonous-Hammarth, M., \& Suh, S. A. (2003). Who goes to college? High school context, academic preparation, the college choice process, and college attendance. Readings on Equal Education, 20, 71-113.

Allen-Ramdial, S.-A. A., \& Campbell, A. G. (2014). Reimagining the pipeline: advancing STEM diversity, persistence, and success. BioScience, 64(7), 612-618.

Anant, S. S. (1966). Need to belong. Canadas Mental Health, 14(2), 21-27. 
Anderson-Butcher, D., \& Conroy, D. E. (2002). Factorial and Criterion Validity of Scores of a Measure of Belonging in Youth Development Programs. Educational and Psychological Measurement, 62(5), 857-876.

https://doi.org/10.1177/001316402236882

Astin, A. W. (1984). Student involvement: A developmental theory for higher education. Journal of College Student Personnel, 25(4), 297-308.

Ballen, C. J., Wieman, C., Salehi, S., Searle, J. B., \& Zamudio, K. R. (2017). Enhancing Diversity in Undergraduate Science: Self-Efficacy Drives Performance Gains with Active Learning. Cell Biology Education, 16(4), ar56. https://doi.org/10.1187/cbe.16-12-0344

Bandura, A. (1993). Perceived Self-Efficacy in Cognitive Development and Functioning. Educational Psychologist, 28(2), 117-148.

Bandura, A. (1997). The exercise of control. New York: Freeman.

Bandura, A., \& Wessels, S. (1994). Self-efficacy. Encyclopedia of Human Behavior, 4, $71-81$.

Barlow, A. E. L., \& Villarejo, M. (2004). Making a difference for minorities: Evaluation of an educational enrichment program. Journal of Research in Science Teaching, 41(9), 861-881. https://doi.org/10.1002/tea.20029

Baron, R. M., \& Kenny, D. A. (1986). The moderator-mediator variable distinction in social psychological research: Conceptual, strategic, and statistical considerations. Journal of Personality and Social Psychology., 51(6), 1173-1182. 
Bean, J., \& Eaton, S. B. (2001). The psychology underlying successful retention practices. Journal of College Student Retention: Research, Theory \& Practice, 3(1), 73-89.

Betz, N. E., \& Gwilliam, L. R. (2002). The Utility of Measures of Self-Efficacy for the Holland Themes in African American and European American College Students. Journal of Career Assessment, 10(3), 283-300.

Betz, N. E., \& Hackett, G. (1997). Applications of self-efficacy theory to the career assessment of women. Journal of Career Assessment, 5(4), 383-402.

Bong, M. (2004). Academic Motivation in Self-Efficacy, Task Value, Achievement Goal Orientations, and Attributional Beliefs. The Journal of Educational Research, 97(6), 287-298. https://doi.org/10.3200/JOER.97.6.287-298

Brennen, A. (2006). Enhancing Students Motivation. Retrieved March 9, 2018, from http://www.soencouragement.org/enhancing-students-motivation.htm

Britner, S. L., \& Pajares, F. (2006). Sources of science self-efficacy beliefs of middle school students. Journal of Research in Science Teaching, 43(5), 485-499. https://doi.org/10.1002/tea.20131

Brown, S. D., Lent, R. W., \& Larkin, K. C. (1989). Self-efficacy as a moderator of scholastic aptitude-academic performance relationships. Journal of Vocational Behavior, 35(1), 64-75.

Byars-Winston, A., Rogers, J., Branchaw, J., Pribbenow, C., Hanke, R., \& Pfund, C. (2016). New Measures Assessing Predictors of Academic Persistence for 
Historically Underrepresented Racial/Ethnic Undergraduates in Science. Cell Biology Education, 15(3), ar32-ar32. https://doi.org/10.1187/cbe.16-01-0030

Campbell, T. A., \& Campbell, D. E. (1997). Faculty/student mentor program: Effects on academic performance and retention. Research in Higher Education, 38(6), $727-$ 742.

Carpi, A., Ronan, D. M., Falconer, H. M., \& Lents, N. H. (2017). Cultivating minority scientists: Undergraduate research increases self-efficacy and career ambitions for underrepresented students in STEM: MENTORED UNDERGRADUATE RESEARCH AT A MSI. Journal of Research in Science Teaching, 54(2), 169194. https://doi.org/10.1002/tea.21341

Chang, M. J., Eagan, M. K., Lin, M. H., \& Hurtado, S. (2011). Considering the impact of racial stigmas and science identity: Persistence among biomedical and behavioral science aspirants. The Journal of Higher Education, 82(5), 564-596.

Chang, M. J., Sharkness, J., Hurtado, S., \& Newman, C. B. (2014). What matters in college for retaining aspiring scientists and engineers from underrepresented racial groups: RETAINING ASPIRING SCIENTISTS. Journal of Research in Science Teaching, 51(5), 555-580. https://doi.org/10.1002/tea.21146

Chemers, M. M., Hu, L., \& Garcia, B. F. (2001). Academic self-efficacy and first year college student performance and adjustment. Journal of Educational Psychology, 93(1), 55-64. https://doi.org/10.1037//0022-0663.93.1.55 
Chemers, M. M., Zurbriggen, E. L., Syed, M., Goza, B. K., \& Bearman, S. (2011). The role of efficacy and identity in science career commitment among underrepresented minority students. Journal of Social Issues, 67(3), 469-491.

Chen, X. (2009). Students Who Study Science, Technology, Engineering, and Mathematics (STEM) in Postsecondary Education. Stats in Brief. NCES 2009161. National Center for Education Statistics.

Cohen, J., Cohen, P., West, S. G., \& Aiken, L. S. (2003). Applied multiple regression/correlation analysis for the behavioral sciences, 3rd ed. Mahwah, NJ, US: Lawrence Erlbaum Associates Publishers.

Cole, D., \& Espinoza, A. (2008). Examining the Academic Success of Latino Students in Science Technology Engineering and Mathematics (STEM) Majors. Journal of College Student Development, 49(4), 285-300. https://doi.org/10.1353/csd.0.0018

Connell, J., \& Wellborn, J. (1991). COMPETENCE, AUTONOMY, AND RELATEDNESS - A MOTIVATIONAL ANALYSIS OF SELF-SYSTEM PROCESSES. Minnesota Symposia On Child Psychology, 23, 43-77.

Cooper, C. R. (1999). Multiple Selves, Multiple Worlds: Cultural Perspectives on. Cultural Processes in Child Development: The Minnesota Symposia on Child Psychology, 29, 25. Psychology Press.

Corwin, L. A., Graham, M. J., \& Dolan, E. L. (2015). Modeling Course-Based Undergraduate Research Experiences: An Agenda for Future Research and 
Evaluation. Cell Biology Education, 14(1), es1-es1.

https://doi.org/10.1187/cbe.14-10-0167

Cramer, M. (2017). Understanding Sense of Belonging among Undergraduate Latino Men at Indiana University Bloomington. Journal of the Student Personnel Association at Indiana University, 98-111.

Crisp, G., \& Cruz, I. (2009). Mentoring College Students: A Critical Review of the Literature Between 1990 and 2007. Research in Higher Education, 50(6), 525545. https://doi.org/10.1007/s11162-009-9130-2

Deci, E. L. (1985). Intrinsic motivation and self-determination in human behavior. New York: Plenum.

Demetriou, C., \& Schmitz-Sciborski, A. (2011). Integration, motivation, strengths and optimism: Retention theories past, present and future. Proceedings of the 7th National Symposium on Student Retention, 300-312. Retrieved from https://pdfs.semanticscholar.org/909d/94498abfe9d8606994c319509f43ac6b06fa. pdf

DiBenedetto, M. K., \& Bembenutty, H. (2013). Within the pipeline: Self-regulated learning, self-efficacy, and socialization among college students in science courses. Learning and Individual Differences, 23, 218-224.

https://doi.org/10.1016/j.lindif.2012.09.015 
Dyer-Barr, R. (2014). Research to practice: Identifying best practices for STEM intervention programs for URMs. Quality Approaches in Higher Education September 2014• Volume 5, No., 19.

Eagan, M. K., Hurtado, S., Chang, M. J., Garcia, G. A., Herrera, F. A., \& Garibay, J. C. (2013). Making a Difference in Science Education: The Impact of Undergraduate Research Programs. American Educational Research Journal, 50(4), 683-713. https://doi.org/10.3102/0002831213482038

Fechheimer, M., Webber, K., \& Kleiber, P. B. (2011). How Well Do Undergraduate Research Programs Promote Engagement and Success of Students? Cell Biology Education, 10(2), 156-163. https://doi.org/10.1187/cbe.10-10-0130

Freeman, T. M., Anderman, L. H., \& Jensen, J. M. (2007). Sense of belonging in college freshmen at the classroom and campus levels. The Journal of Experimental Education, 75(3), 203-220.

Fuchs, J., Kouyate, A., Kroboth, L., \& McFarland, W. (2016). Growing the Pipeline of Diverse HIV Investigators: The Impact of Mentored Research Experiences to Engage Underrepresented Minority Students. AIDS and Behavior, 20(S2), 249257. https://doi.org/10.1007/s10461-016-1392-z

Furrer, C., \& Skinner, E. (2003). Sense of relatedness as a factor in children's academic engagement and performance. Journal of Educational Psychology, 95(1), 148162. https://doi.org/10.1037/0022-0663.95.1.148 
Gainor, K. A., \& Lent, R. W. (1998). Social cognitive expectations and racial identity attitudes in predicting the math choice intentions of Black college students. Journal of Counseling Psychology, 45(4), 403.

Gándara, P., \& Maxwell-Jolly, J. (1999). Priming the pump: Strategies for increasing the achievement of underrepresented minority undergraduates.

Garcia, G. A., \& Hurtado, S. (2011). Predicting Latina/o STEM persistence at HSIs and non-HSIs. University of California, Los Angeles.

Gasiewski, J., Tran, M. C., Herrera, F., Garcia, G. A., \& Newman, C. B. (2010). Barricades, bridges, and programmatic adaptation: A multi-campus case study of STEM undergraduate research programs. Association for Institutional Research Annual Meeting, Chicago, IL.

Gershenfeld, S. (2014). A review of undergraduate mentoring programs. Review of Educational Research, 84(3), 365-391.

Goodnow, C. (1993). Classroom Belonging Among Early Adolescent Students: Relationships to Motivation and Achievement. Journal of Early Adolescence. Guiffrida, D. A. (2006). Toward a Cultural Advancement of Tinto's Theory. The Review of Higher Education, 29(4), 451-472. https://doi.org/10.1353/rhe.2006.0031

Guiffrida, D. A., Lynch, M. F., Wall, A. F., \& Abel, D. S. (2013). Do Reasons for Attending College Affect Academic Outcomes?: A Test of a Motivational Model From a Self-Determination Theory Perspective. Journal of College Student Development, 54(2), 121-139. https://doi.org/10.1353/csd.2013.0019 
Gwilliam, L. R., \& Betz, N. E. (2001). Validity of Measures of Math- and ScienceRelated Self-Efficacy for African Americans and European Americans. Journal of Career Assessment, 9(3), 261-281.

Hackett, G., Betz, N. E., Casas, J. M., \& Rocha-Singh, I. A. (1992). Gender, ethnicity, and social cognitive factors predicting the academic achievement of students in engineering. Journal of Counseling Psychology, 39(4), 527.

Haeger, H., \& Fresquez, C. (2016). Mentoring for Inclusion: The Impact of Mentoring on Undergraduate Researchers in the Sciences. Cell Biology Education, 15(3), ar36ar36. https://doi.org/10.1187/cbe.16-01-0016

Hausmann, L. R. M., Schofield, J. W., \& Woods, R. L. (2007). Sense of Belonging as a Predictor of Intentions to Persist Among African American and White First-Year College Students. Research in Higher Education, 48(7), 803-839. https://doi.org/10.1007/s11162-007-9052-9

Hoffman, M., Richmond, J., Morrow, J., \& Salomone, K. (2002). Investigating "sense of belonging" in first-year college students. Journal of College Student Retention: Research, Theory \& Practice, 4(3), 227-256.

Hunter, A.-B., Laursen, S. L., \& Seymour, E. (2007). Becoming a scientist: The role of undergraduate research in students' cognitive, personal, and professional development. Science Education, 91(1), 36-74. https://doi.org/10.1002/sce.20173

Hurtado, S., Cabrera, N. L., Lin, M. H., Arellano, L., \& Espinosa, L. L. (2009). Diversifying Science: Underrepresented Student Experiences in Structured 
Research Programs. Research in Higher Education, 50(2), 189-214. https://doi.org/10.1007/s11162-008-9114-7

Hurtado, S., \& Carter, D. F. (1997). Effects of College Transition and Perceptions of the Campus Racial Climate on Latino College Students' Sense of Belonging. Sociology of Education, 70(4), 324. https://doi.org/10.2307/2673270

Hurtado, S., Clayton-Pedersen, A. R., Allen, W. R., \& Milem, J. F. (1998). Enhancing campus climates for racial/ethnic diversity: Educational policy and practice. The Review of Higher Education, 21(3), 279-302.

Hurtado, S., Eagan, M. K., Tran, M. C., Newman, C. B., Chang, M. J., \& Velasco, P. (2011). "We do science here": Underrepresented students' interactions with faculty in different college contexts. Journal of Social Issues, 67(3), 553-579.

Hurtado, S., Han, J. C., Sáenz, V. B., Espinosa, L. L., Cabrera, N. L., \& Cerna, O. S. (2007). Predicting transition and adjustment to college: biomedical and behavioral science aspirants' and minority students' first year of college. Research in Higher Education, 48(7), 841-887. https://doi.org/10.1007/s11162-007-9051-x

Hurtado, S., \& Ponjuan, L. (2005). Latino Educational Outcomes and the Campus Climate. Journal of Hispanic Higher Education, 4(3), 235-251. https://doi.org/10.1177/1538192705276548

Hurtado, S., \& Ruiz, A. (2012). The climate for underrepresented groups and diversity on campus. American Academy of Political and Social Science, 634(1), 190-206. 
Hurtado, S., \& Ruiz Alvarado, A. (2015). Discriminination and Bias,

Underrepresentation, and Sense of Belonging on Campus.

Jacobi, M. (1991). Mentoring and undergraduate academic success: A literature review. Review of Educational Research, 61(4), 505-532.

James, K. C., \& Carlson, K. (2012). A holistic model for supporting a diverse student body in the STEM fields. Advancing the STEM Agenda: Quality Improvement Supports STEM, 11-28.

Johnson, D. R. (2012). Campus Racial Climate Perceptions and Overall Sense of Belonging Among Racially Diverse Women in STEM Majors. Journal of College Student Development, 53(2), 336-346. https://doi.org/10.1353/csd.2012.0028

Johnson, D. R., Soldner, M., Leonard, J. B., Alvarez, P., Inkelas, K. K., Rowan-Kenyon, H. T., \& Longerbeam, S. D. (2007). Examining Sense of Belonging Among FirstYear Undergraduates From Different Racial/Ethnic Groups. Journal of College Student Development, 48(5), 525-542. https://doi.org/10.1353/csd.2007.0054

Jones, M. T., Barlow, A. E. L., \& Villarejo, M. (2010). Importance of Undergraduate Research for Minority Persistence and Achievement in Biology. The Journal of Higher Education, 81(1), 82-115. https://doi.org/10.1353/jhe.0.0082

Jordan, K. L. (2014). Intervention to Improve Engineering Self-Efficacy and Sense of Belonging of First-Year Engineering Students. The Ohio State University.

Judson, E., Ernzen, J., Chen, Y.-C., Krause, S., Middleton, J., \& Culbertson, R. (2015). What is the effect of establishing programs that address sense of belonging on 
undergraduate engineering retention? 1-8.

https://doi.org/10.1109/FIE.2015.7344202

Kappe, R., \& van der Flier, H. (2012). Predicting academic success in higher education: what's more important than being smart? European Journal of Psychology of Education, 27(4), 605-619. https://doi.org/10.1007/s10212-011-0099-9

Kardash, C. M. (2000). Evaluation of undergraduate research experience: Perceptions of undergraduate interns and their faculty mentors. Journal of Educational Psychology, 92(1), 191.

Kinkead, J. (2003). Learning through inquiry: An overview of undergraduate research. New Directions for Teaching and Learning, 2003(93), 5-18.

Kuh, G. D. (1996). Guiding principles for creating seamless learning environments for undergraduates. Journal of College Student Development, (37(2)), 35-48.

Kuh, G., Kinzie, J., Buckley, J., Bridges, B., \& Hayek. (2006). What Matters to Student Success. National Postsecondary Education Cooperative.

Lane, A. (2001). SELF-EFFICACY AND ACADEMIC PERFORMANCE. Social Behavior and Personality: An International Journal, 29(7), 687-693.

Leggon, C., \& Pearson, W. (2006). Assessing programs to improve minority participation in STEM fields: What we know and what we need to know. Retrieved from http://citeseerx.ist.psu.edu/viewdoc/summary?doi=10.1.1.357.9613 
Lent, R., Brown, S., \& Hackett, G. (1994). Toward a Unifying Social Cognitive Theory of Career and Academic Interest, Choice, and Performance. Journal of Vocational Behavior, 45, 79-122.

Lent, R. W., Brown, S. D., \& Larkin, K. C. (1986). Self-efficacy in the prediction of academic performance and perceived career options. Journal of Counseling Psychology, 33(3), 265-269. https://doi.org/10.1037/0022-0167.33.3.265

Lent, R. W., Brown, S. D., Sheu, H.-B., Schmidt, J., Brenner, B. R., Gloster, C. S., ... Treistman, D. (2005). Social Cognitive Predictors of Academic Interests and Goals in Engineering: Utility for Women and Students at Historically Black Universities. Journal of Counseling Psychology, 52(1), 84-92. https://doi.org/10.1037/0022-0167.52.1.84

Linn, M. C., Palmer, E., Baranger, A., Gerard, E., \& Stone, E. (2015). Undergraduate research experiences: Impacts and opportunities. Science, 347(6222), 12617571261757. https://doi.org/10.1126/science. 1261757

Lopatto, D. (2004). Survey of Undergraduate Research Experiences (SURE): First Findings. Cell Biology Education, 3(4), 270-277. https://doi.org/10.1187/cbe.0407-0045

Lopatto, David. (2007). Undergraduate research experiences support science career decisions and active learning. CBE-Life Sciences Education, 6(4), 297-306.

Lounsbury, J. W., \& DeNeui, D. (1995). Psychological sense of community on campus. College Student Journal, 29(3), 270-277. 
Lundberg, C. A., \& Schreiner, L. A. (2004). Quality and Frequency of Faculty-Student Interaction as Predictors of Learning: An Analysis by Student Race/Ethnicity. Journal of College Student Development, 45(5), 549-565.

https://doi.org/10.1353/csd.2004.0061

Luzzo, D. A., \& McWhirter, E. H. (2001). Sex and ethnic differences in the perception of educational and career-related barriers and levels of coping efficacy. Journal of Counseling \& Development, 79(1), 61-67.

Marra, R. M., Rodgers, K. A., Shen, D., \& Bogue, B. (2009). Women engineering students and self-efficacy: A multi-year, multi-institution study of women engineering student self-efficacy. Journal of Engineering Education, 98(1), 2738.

Maton, K. I., Hrabowski, F. A., \& Schmitt, C. L. (2000). African American college students excelling in the sciences: College and postcollege outcomes in the Meyerhoff Scholars Program. Journal of Research in Science Teaching, 37(7), 629-654.

McGee, E. O., \& Martin, D. B. (2011). "You Would Not Believe What I Have to Go Through to Prove My Intellectual Value!” Stereotype Management Among Academically Successful Black Mathematics and Engineering Students. American Educational Research Journal, 48(6), 1347-1389.

https://doi.org/10.3102/0002831211423972 
McGee Jr, R., Saran, S., \& Krulwich, T. A. (2012). Diversity in the Biomedical Research Workforce: Developing Talent. Mount Sinai Journal of Medicine: A Journal of Translational and Personalized Medicine, 79(3), 397-411. https://doi.org/10.1002/msj.21310

Mitchell, D. A., \& Lassiter, S. L. (2006). Addressing health care disparities and increasing workforce diversity: the next step for the dental, medical, and public health professions. American Journal of Public Health, 96(12), 2093-2097.

Multon, K. D., Brown, S. D., \& Lent, R. W. (1991). Relation of self-efficacy beliefs to academic outcomes: a meta-analytic investigation. Journal of Counseling Psychology, 38(1).

Nagda, B., Gregerman, S., Jonides, J., Hippel, W. von, \& Lerner, J. (1998). Undergraudate Student-Faculty Resaerch Partnerships Affect Student Retention. The Review of Higher Education, 22(1), 55-72.

National Academy of Sciences, National Academy of Engineering, Institute, Institute, \& of Medicine. (2007). Rising Above the Gathering Storm: Energizing and Employing America for a Brighter Economic Future. https://doi.org/10.17226/11463

National Commission on Teaching \& America's Future (U.S.) (Ed.). (1996). What matters most: teaching for America's future: report of the National Commission on Teaching \& America's Future (1st ed). New York, N.Y. : Woodbridge, Va: 
The Commission; Available from National Commission on Teaching \& America's Future.

National Science Board. (2012). Science and Engineering Indicators 2012. Arlington VA: National Science Foundation (NSB 12-01).

National Science Foundation. (2017). Women, Minorities, and Persons with Disabilities in Science and Engineering: 2017. Retrieved from www.nsf.gov/statistics/wmpd/.

Niehaus, K., Rudasill, K. M., \& Adelson, J. L. (2012). Self-Efficacy, Intrinsic Motivation, and Academic Outcomes Among Latino Middle School Students Participating in an After-School Program. Hispanic Journal of Behavioral Sciences, 34(1), 118-136. https://doi.org/10.1177/0739986311424275

Noble, K., Flynn, N. T., Lee, J. D., \& Hilton, D. (2007). Predicting successful college experiences: Evidence from a first year retention program. Journal of College Student Retention: Research, Theory \& Practice, 9(1), 39-60.

Nora, A., \& Cabrera, A. F. (1996). The Role of Perceptions of Prejudice and Discrimination on the Adjustment of Minority Students to College. The Journal of Higher Education, 67(2), 119. https://doi.org/10.2307/2943977

Oakes, J. (1990). Multiplying inequalities: the effects of race, social class, and tracking on opportunities to learn mathematics and science. Santa Monica, CA: Rand Corp.

O'Keeffe, P. (2013). A sense of belonging: Improving student retention. College Student Journal, 47(4), 605-613. 
Osterman, K. F. (2000). Students' need for belonging in the school community. Review of Educational Research, 70(3), 323-367.

Padilla, R. V., Trevino, J., Trevino, J., \& Gonzalez, K. (1997). Developing Local Models of Minority Student Success in College. Journal of College Student Development, $38(2), 125-35$.

Pajares, F. (1996). Self-Efficacy Beliefs in Academic Settings. Review of Educational Research, 66(4), 543-578. https://doi.org/10.3102/00346543066004543

Pajares, F., \& Miller, M. D. (1994). Role of self-efficacy and self-concept beliefs in mathematical problem solving: a path analysis. Journal of Educational Psychology, 86(2).

Pascarella, E. T., \& Terenzini, P. T. (1980). Predicting freshman persistence and voluntary dropout decisions from a theoretical model. The Journal of Higher Education, 51(1), 60-75.

Pascarella, E. T., \& Terenzini, P. T. (1991). How college affects students (First edition). San Francisco: Jossey-Bass Publishers.

Pfund, C., Byars-Winston, A., Branchaw, J., Hurtado, S., \& Eagan, K. (2016). Defining Attributes and Metrics of Effective Research Mentoring Relationships. AIDS and Behavior, 20(S2), 238-248. https://doi.org/10.1007/s10461-016-1384-z

Rainey, K., Dancy, M., Mickelson, R., Stearns, E., \& Moller, S. (2018). Race and gender differences in how sense of belonging influences decisions to major in STEM. 
International Journal of STEM Education, 5(1). https://doi.org/10.1186/s40594018-0115-6

Ramist, L. (1981). College attrition and retention (College Board Rep. No. 81-1). (College Board Rep. No. 81-1). New York: College Entrance Examination Board., (College Board Rep. 81-1).

Rankin, S. R., \& Reason, R. D. (2005). Differing Perceptions: How Students of Color and White Students Perceive Campus Climate for Underrepresented Groups. Journal of College Student Development, 46(1), 43-61. https://doi.org/10.1353/csd.2005.0008

Rittmayer, A. D., \& Beier, M. E. (2008). Overview: Self-efficacy in STEM. SWE-AWE CASEE Overviews.

Robnett, R. D., Chemers, M. M., \& Zurbriggen, E. L. (2015). Longitudinal associations among undergraduates' research experience, self-efficacy, and identity: RESEARCH EXPERIENCE, SELF-EFFICACY, AND IDENTITY. Journal of Research in Science Teaching, 52(6), 847-867. https://doi.org/10.1002/tea.21221

Russell, S. H., Hancock, M. P., \& McCullough, J. (2007). THE PIPELINE: Benefits of Undergraduate Research Experiences. Science, 316(5824), 548-549. https://doi.org/10.1126/science.1140384

Ryan, R. M., \& Deci, E. L. (2000). Self-determination theory and the facilitation of intrinsic motivation, social development, and well-being. American Psychologist, $55(1), 68$. 
Scheier, M. F., \& Carver, C. S. (1985). The Self-Consciousness Scale: A Revised Version for Use with General Populations 1. Journal of Applied Social Psychology, 15(8), 687-699.

Schneider, M., \& Preckel, F. (2017). Variables associated with achievement in higher education: A systematic review of meta-analyses. Psychological Bulletin, 143(6), 565-600. https://doi.org/10.1037/bul0000098

Schunk, D. H. (1982). Progress Self-Monitoring: Effects on Children's Self-Efficacy and Achievement. Journal of Experimental Education, 51(2), 89-93.

Sebastian Cherng, H.-Y. (2017). If they think I can: Teacher bias and youth of color expectations and achievement. Social Science Research, 66, 170-186. https://doi.org/10.1016/j.ssresearch.2017.04.001

Seymour, E., Hunter, A.-B., Laursen, S. L., \& DeAntoni, T. (2004). Establishing the benefits of research experiences for undergraduates in the sciences: First findings from a three-year study. Science Education, 88(4), 493-534.

https://doi.org/10.1002/sce.10131

Shapiro, D., Dundar, A., Huie, F., Wakhungu, P. K., Yuan, X., Nathan, A., \& Hwang, Y. (2017). Signature 13 Tracking Transfer: Measures of Effectiveness in Helping Community College Students to Complete Bachelor's Degrees.

Smedley, B. D., Myers, H. F., \& Harrell, S. P. (1993). Minority-Status Stresses and the College Adjustment of Ethnic Minority Freshmen. The Journal of Higher Education, 64(4), 434. https://doi.org/10.2307/2960051 
Solberg, V. S., O’Brien, K., Villareal, P., Kennel, R., \& Davis, B. (1993). Self-efficacy and Hispanic college students: Validation of the college self-efficacy instrument. Hispanic Journal of Behavioral Sciences, 15(1), 80-95.

Solorzano, D. (n.d.). Critical Race Theory, Racial Microaggressions, and Campus Racial Climate: The Experiences of African American College Students. 15.

Steele, C. M. (1997). A threat in the air: How stereotypes shape intellectual identity and performance. American Psychologist, 52(6), 613.

Strayhorn, Lo, Travers, \& Tillman-Kelly. (2015). Assessing the Relationship Between Well-Being, Sense of Belonging, and Confidence in the Transition to College for Black Male Collegians. Spectrum: A Journal on Black Men, 4(1), 127. https://doi.org/10.2979/spectrum.4.1.07

Strayhorn, T. L. (2009). Fittin' In: Do Diverse Interactions with Peers Affect Sense of Belonging for Black Men at Predominantly White Institutions? Journal of Student Affairs Research and Practice, 45(4). https://doi.org/10.2202/1949-6605.2009

Strayhorn, T. L. (2010a). Bridging the Pipeline: Increasing Underrepresented Students' Preparation for College Through a Summer Bridge Program. American Behavioral Scientist, 55(2), 142-159. https://doi.org/10.1177/0002764210381871

Strayhorn, T. L. (2010b). Work in progress - Social barriers and supports to underrepresented minorities' success in STEM fields. Frontiers in Education Conference (FIE), 2010 IEEE, S1H-1. IEEE. 
Strayhorn, T. L. (2012). College students' sense of belonging: a key to educational success for all students. New York; London: Routledge.

Strayhorn, T. L. (2015). Factors influencing Black males' preparation for college and success in STEM majors: a mixed methods study. The Western Journal of Black Studies, 39(1). Retrieved from http://go.galegroup.com.proxy.lib.pdx.edu/ps/i.do?\&amp;id=GALE|A419267248 \&amp; $=2.1 \& a m p ; u=s 1185784 \& a m p ; i t=r \& a m p ; p=I T O F \& a m p ; s w=w \& a m p ; a u t h$ Count $=1$

Swim, J. K., Hyers, L. L., Cohen, L. L., Fitzgerald, D. C., \& Bylsma, W. H. (2003). African American College Students' Experiences With Everyday Racism: Characteristics of and Responses to These Incidents. Journal of Black Psychology, 29(1), 38-67. https://doi.org/10.1177/0095798402239228

Thiry, H., Laursen, S. L., \& Hunter, A.-B. (2011). What experiences help students become scientists? A comparative study of research and other sources of personal and professional gains for STEM undergraduates. The Journal of Higher Education, 82(4), 357-388.

Thomas, L. (2012). Building student engagement and belonging in Higher Education at a time of change. Paul Hamlyn Foundation, 100.

Tinto, V. (1975). Dropout from higher education: A theoretical synthesis of recent research. Review of Educational Research, 45(1), 89-125. 
Tomasko, D. L., Ridgway, J. S., Waller, R. J., \& Olesik, S. V. (2016). Association of summer bridge program outcomes with STEM retention of targeted demographic groups. Journal of College Science Teaching, 45(4), 90.

Tovar, E., \& Simon, M. A. (2010). Factorial Structure and Invariance Analysis of the Sense of Belonging Scales. Measurement and Evaluation in Counseling and Development, 43(3), 199-217. https://doi.org/10.1177/0748175610384811

Tsui, L. (2007). Effective strategies to increase diversity in STEM fields: A review of the research literature. The Journal of Negro Education, 555-581.

Tukey, J. W. (1962). The Future of Data Analysis. The Annals of Mathematical Statistics, 33(1), 1-67. https://doi.org/10.1214/aoms/1177704711

Vaccaro, A., \& Newman, B. M. (2016). Development of a Sense of Belonging for Privileged and Minoritized Students: An Emergent Model. Journal of College Student Development, 57(8), 925-942. https://doi.org/10.1353/csd.2016.0091

Valantine, H. A., \& Collins, F. S. (2015). National Institutes of Health addresses the science of diversity. Proceedings of the National Academy of Sciences, 112(40), 12240-12242. https://doi.org/10.1073/pnas.1515612112

Walton, G. M., \& Cohen, G. L. (2007). A question of belonging: Race, social fit, and achievement. Journal of Personality and Social Psychology, 92(1), 82-96. https://doi.org/10.1037/0022-3514.92.1.82 
Wang, X. (2013). Why Students Choose STEM Majors: Motivation, High School Learning, and Postsecondary Context of Support. American Educational Research Journal, 50(5), 1081-1121. https://doi.org/10.3102/0002831213488622

Wigfield, A., Eccles, J. S., Schiefele, U., Roeser, R. W., \& Davis-Kean, P. (2006). Development of Achievement Motivation. In Handbook of child psychology: Social, emotional, and personality development, Vol. 3, 6th ed. (pp. 933-1002). Hoboken, NJ, US: John Wiley \& Sons Inc.

Wilson, D., Jones, D., Bocell, F., Crawford, J., Kim, M. J., Veilleux, N., ... Plett, M. (2015). Belonging and Academic Engagement Among Undergraduate STEM Students: A Multi-institutional Study. Research in Higher Education, 56(7), 750776. https://doi.org/10.1007/s11162-015-9367-x

Zajacova, A., Lynch, S. M., \& Espenshade, T. J. (2005). Self-Efficacy, Stress, and Academic Success in College. Research in Higher Education, 46(6), 677-706. https://doi.org/10.1007/s11162-004-4139-z

Zhang, Z., \& RiCharde, R. S. (1998). Prediction and analysis of freshman retention. AIR 1998 Annual Forum Paper, Minneapolis, MN.

Zimmerman, B. J. (2000). Self-Efficacy: An Essential Motive to Learn. Contemporary Educational Psychology, 25(1), 82-91. https://doi.org/10.1006/ceps.1999.1016 


\section{Appendix A: Description of NIH Racial Categories}

The following are descriptions for each racial category included in the racial categorizations

designed and used by the National Institute of Health

American Indian or Alaska Native: A person having origins in any of the original

peoples of

North and South America (including Central America), and who maintains tribal

affiliation or

community attachment.

Asian: A person having origins in any of the original peoples of the Far East, Southeast

Asia, or

the Indian subcontinent including, for example, Cambodia, China, India, Japan, Korea, Malaysia,

Pakistan, the Philippine Islands, Thailand, and Vietnam.

Black or African American: A person having origins in any of the black racial groups

of

Africa. Terms such as Haitian can be used in addition to Black or African

American.

Hispanic or Latino: A person of Cuban, Mexican, Puerto Rican, Cuban, South or Central

American, or other Spanish culture or origin, regardless of race. The term Spanish origin can be used in addition to Hispanic or Latino. 
Native Hawaiian or Other Pacific Islander: A person having origins in any of the original peoples of Hawaii, Guam, Samoa, or other Pacific Islands.

White: A person having origins in any of the original peoples of Europe, the Middle

East, or

North Africa. 